\title{
Oncolytic HSV Vectors and Anti-Tumor Immunity
}

Joseph C. Glorioso ${ }^{1 *}$, Justus B. Cohen ${ }^{1}$, William F. Goins ${ }^{1}$, Bonnie Hall' Joseph W. Jackson ${ }^{1}$, Gary Kohanbash ${ }^{2}$, Nduka Amankulor ${ }^{2}$, Balveen Kaur $^{3}$, Michael A. Caligiuri ${ }^{4}$, E. Antonio Chiocca ${ }^{5}$, Eric C. Holland ${ }^{6}$ and Christophe Quéva ${ }^{7}$

${ }^{1}$ Department of Microbiology and Molecular Genetics, University of Pittsburgh School of Medicine, Pittsburgh, PA, USA

${ }^{2}$ Department of Neurological Surgery, Hillman Cancer Center, University of Pittsburgh School of Medicine, Pittsburgh, PA, USA

${ }^{3}$ Department of Neurosurgery, McGovern Medical School at UTHealth, Houston, TX, USA

${ }^{4}$ City of Hope Medical Center, Duarte, CA, USA

${ }^{5}$ Department of Neurosurgery, Brigham and Women's Hospital, Harvard Medical School, Boston, MA, USA

${ }^{6}$ Fred Hutchinson Cancer Research Center, University of Washington, Seattle, WA, USA

${ }^{7}$ Oncorus Inc., Cambridge, MA, USA

*glorioso@pitt.edu

DOI: https://doi.org/10.21775/cimb.041.381

\section{Abstract}

The therapeutic promise of oncolytic viruses (OVs) rests on their ability to both selectively kill tumor cells and induce anti-tumor immunity. The potential of tumors to be recognized and eliminated by an effective anti-tumor immune 
response has been spurred on by the discovery that immune checkpoint inhibition can overcome tumor-specific cytotoxic T cell (CTL) exhaustion and provide durable responses in multiple tumor indications. OV-mediated tumor destruction is now recognized as a powerful means to assist in the development of anti-tumor immunity for two important reasons: (i) OVs, through the elicitation of an anti-viral response and the production of type I interferon, are potent stimulators of inflammation and can be armed with transgenes to further enhance anti-tumor immune responses; and (ii) lytic activity can promote the release of tumor-associated antigens (TAAs) and tumor neoantigens that function as in situ tumor-specific vaccines to elicit adaptive immunity. Oncolytic herpes simplex viruses (oHSVs) are among the most widely studied OVs for the treatment of solid malignancies, and Amgen's oHSV Imlygic $\circledast$ for the treatment of melanoma is the only OV approved in major markets. Here we describe important biological features of HSV that make it an attractive OV, clinical experience with HSV-based vectors, and strategies to increase applicability to cancer treatment.

\section{A. Introduction}

Recent advances in cancer therapeutics include the use of tumor-specific lytic (oncolytic) viruses that both debulk tumors - reduce their size by eliminating cancer cells - and break down barriers to the induction of anti-tumor immunity. Oncolytic viruses have been derived from a wide variety of both DNA and RNA virus families, each having unique host ranges and replication mechanisms that make them attractive for attacking different tumor types. Oncolytic virusmediated destruction of tumor cells leads to the production of danger signals by infected cells, a process referred to as immunogenic cell death, and to the release and presentation by antigen presenting cells (APCs) of virus and tumor-derived antigens. Tumor antigenic peptides are created by either an accumulation of mutations in cellular proteins, re-emergence of fetal/testis proteins without complete host tolerance, or by misfolded proteins to create novel processed peptides (Coulie et al., 2014; Kamran et al., 2016; Wang and Wang, 2017; Yarchoan et al., 2017). Robust immune responses to viral antigens can attract APCs to the tumor site wherein viral and tumor antigenic 
peptides can participate in cross-priming and the development of both anti-viral and anti-tumor immunity.

Oncolytic herpes simplex viruses (oHSVs) are among the most widely pursued for treatment of solid malignancies and have been validated with the commercial approval of Imlygic $®$ (Talimogene laherparepvec, Amgen, Inc.) for the treatment of metastatic melanoma (Andtbacka et al., 2015; Pol et al., 2016). HSVs have several important features that contribute to their utility as tumor virolytics. These include a broad host cell range, which renders multiple types of tumors permissive for viral growth, and an ability to accommodate large or multiple transgene expression cassettes (referred to as large payload capacity) that enables oHSV-mediated delivery of multiple non-viral immunomodulatory products. Arming oHSVs with combinations of transgenes may increase oncolytic activity, help promote an immune-responsive tumor microenvironment and enhance the induction of innate and adaptive anti-tumor immune responses (Martuza et al., 1991; Andreansky et al., 1998; Chase et al., 1998). Advances in HSV engineering over the past decade and a half have produced oHSVs that have the full complement of viral genes, including virulence functions that resist cellular anti-viral responses and enable aggressive infection and destruction of tumors (Kambara et al., 2005; Gambini et al., 2012; Uchida et al., 2013). Strategies to enable uncompromised viral infection of tumor cells while preserving safety, to increase intratumoral vector spread, and to resist rapid elimination of replicating virus by counteracting antiviral host responses should enhance oHSV potency and utility as anti-cancer agents. In this review, a brief history of the development of oHSVs, clinical outcomes in monotherapy and in combination with checkpoint inhibitors, and prospects for improved vector design are described.

\section{B. oHSV design: curbing neurovirulence}

\section{Relevant biology of HSV}

HSV-1 and HSV-2 are closely related neurotropic viruses that infect humans, their natural hosts. However, the virus can infect a wide variety of species, which has enabled the evaluation of oHSV vector designs in xenogeneic and 
syngeneic rodent tumor models. Some $70 \%$ of the adult human population is seropositive for HSV-1 (Kaufman et al., 2005), the most commonly used oncolytic HSV, and is likely to harbor latent virus in sensory neurons that innervate the site of initial infection. Latent virus reactivation can lead to virus spread to other susceptible individuals by direct contact with a virus-containing lesion. With the exception of herpes keratitis and encephalitis, HSV-1 infections of adults are mostly self-limiting, and latency is held in check largely by local anti-viral immunity (St Leger and Hendricks, 2011; St Leger et al., 2013).

The HSV genome is a double-stranded 152-kb DNA that encodes at least 84 gene products, the majority of which have multiple functions (Roizman, 2001; Roizman and Zhou, 2015). The genome consists of large and small unique segments flanked by repeat elements containing duplicate genes that contribute to virus replication, neurovirulence and latency. The repeat elements are responsible for genome isomerization such that 4 isomers are produced in infected cells. Approximately half of the viral genes encode essential products to complete the replication cycle in permissive cell cultures while the remaining genes contribute to the complex life cycle in the host. The viral genome is surrounded by an icosahedral capsid; a tegument composed of viral proteins involved in processes such as regulation of viral and host gene expression, host immune response, capsid trafficking and viral egress; and a host-derived lipid envelope studded with viral glycoproteins, many of which are involved in host-cell entry and virus spread to neighboring cells.

The basic biology of the virus has been exploited and modified in multiple ways in the design of oHSV. The 14-kb internal repeat region (IRR) can be removed without preventing virus replication since the full array of gene functions remains (Poffenberger et al., 1983; Meignier et al., 1988; Mazzacurati et al., 2015). IRR removal prevents genome isomerization, locking the viral genome into a single species and enhancing recombinant virus stability during production. With IRR removal, the HSV genome can accept $\sim 25-\mathrm{kb}$ of foreign DNA without straining the capsid packaging limits, allowing virus-mediated expression of one or more transgenes that can assist in the induction of anti- 
tumor immunity. In first-generation oHSVs, nonessential genes that overcome innate anti-viral responses, such as type I interferon (IFN) production, were deleted or modified to attenuate the virus in non-tumor cells and limit neurovirulence. More recent modifications have included the addition of microRNA response elements in the 3' UTR of essential genes to restrict replication to tumor cells (Lee et al., 2009; Mazzacurati et al., 2015) and modification of several viral envelope glycoproteins to allow only tumor-specific virus infection (Campadelli-Fiume et al., 2016). Inhibition of neuronal retrograde transport through specific mutation in the R2 domain of the tegument protein UL37 is a recently described alternative to prevent HSV-1 infection of the brain, enabling the design of HSV vaccines (Richards et al., 2017). Because HSV-1 is neurotropic, the initial work in developing oHSV vectors centered on the treatment of brain tumors by direct intratumoral injection (Markert et al., 2000; Rampling et al., 2000; Papanastassiou et al., 2002). Tumor cells of neuronal origin, such as glioma, are generally permissive for HSV mutants that are attenuated for replication in normal brain and do not elicit encephalitis. Although early clinical trials have thus far documented few complete responses using attenuated HSV, recent data from Todo and colleagues have shown promising activity and tolerability for G47 $\triangle$, an unarmed oHSV, in patients with recurrent or residual GBM (Todo, 2019), spurring a renewed interest into the treatment of GBM by oHSV.

\section{2. oHSV vectors and treatment of neuronal tumors}

a. Glioblastoma multiforme (GBM)

GBM (grade IV glioma) is the most common type of primary brain tumor in adults and is almost universally fatal despite aggressive therapies, including combinations of surgery, radiotherapy, and chemotherapy. The incidence of GBM is approximately 3.2 per 100,000 persons in the United States (Tamimi and Juweid, 2017), and GBM patients have a median survival of 12-18 months from initial diagnosis and 6-9 months after recurrence, with only $5 \%$ of patients surviving for 5 years (Wen and Kesari, 2008). The Standard of Care for management of these tumors includes tumor resection, followed by external beam radiotherapy with treatment doses of approximately $60 \mathrm{~Gy}$ (Desjardins et 
al., 2009; Thaker and Pollack, 2009). Partial responses to chemotherapy [e.g., temozolomide (Temodar)] are seen in approximately $30 \%$ of patients (Gilbert et al., 2013; Norden et al., 2013; Blumenthal et al., 2017), but overall survival is only improved by 2.5 months in newly diagnosed GBM in combination with radiotherapy (Stupp et al., 2005; Stupp et al., 2009; Grossman et al., 2010; Delgado-Lopez and Corrales-Garcia, 2016; Feng et al., 2017). Because tumor cells infiltrate the brain, tumor resection is not always complete. Even removal of the entire tumor-containing hemisphere (hemispherectomy) has been found to be non-curative (Chaichana et al., 2014). This is further compounded by the fact that the tumors are genetically and phenotypically heterogeneous, are poorly immunogenic, with scarce CD8+ T-cell infiltration (few $T$ cells in mesenchymal and classical glioblastomas, essentially none in proneural GBM), and do not appear to respond to immune checkpoint inhibitors without induction of an inflammatory tumor microenvironment (Preusser et al., 2015; Reardon et al., 2016; Hodges et al., 2017). Due to the limited benefit of these therapeutic approaches, efforts to develop treatments that improve survival have included various biologic therapies, such as different types of oncolytic viruses, cell-based immunotherapy including chimeric antigen receptor (CAR)T cells (Bagley et al., 2018), CAR-NK cells (Han et al., 2015), and gene therapy (Chiocca et al., 2019). Below is a brief history of the development of oHSVs for treatment of brain tumors.

\section{b. Preclinical development}

The first oncolytic HSV-1 described was dlsptk, a UL23 [thymidine kinase (TK)] deletion mutant that displayed a promising therapeutic potential in the treatment of glioma in animal studies (Martuza et al., 1991). Replication of this mutant HSV-1 virus occurs only in mitotic tumor cells that upregulate their endogenous tk gene. Despite demonstrated tumor-specific replication in mouse models, there were serious concerns about vector safety because this strain of virus is insensitive to the most potent anti-herpetic agents, such as acyclovir, and because high titers of dlsptk caused neurotoxicity in mouse brain tumor models (Martuza et al., 1991). Hence, further development of HSV-1 
vectors involved a search for other genes, the inactivation of which blocked virus replication in normal neurons but not in dividing cells.

One resulting vector was hrR3, an HSV-1 mutant with an in-frame insertion of the lacZ gene into the UL39 (ICP6) gene encoding the large subunit of ribonucleotide reductase (RR), expressed as an ICP6-LacZ fusion protein that retained no RR activity. RR is a key enzyme for viral DNA synthesis in nondividing cells but not in dividing cells where elevated levels of the host-cell RR can provide the deoxynucleotides needed as substrates for viral DNA synthesis. In tumor cells that are defective for $\mathrm{p} 16$ or the retinoblastoma (Rb) gene product, the transcription factor E2F is activated, resulting in increased endogenous RR activity (Hanson et al., 1994; DeGregori et al., 1995) that enables replication of HSV-1 mutants lacking virally encoded RR. Therefore, HSV-1 ICP6 mutants are relatively selective for cells with defects in the p16 tumor suppressor pathway (Aghi et al., 2008). Intratumoral inoculation of hrR3 into rats bearing malignant gliosarcomas improved animal survival (Fulci et al., 2007; Aghi et al., 2008), and this was further improved by ganciclovir (GCV) administration (Boviatsis et al., 1994). Viral TK converts GCV to a toxic product that acts as a chain terminator during DNA synthesis (Fulci and Chiocca, 2007), and the RR-defective phenotype conferred tumor-cell hypersensitivity to GCV (Luo et al., 2007).

Another approach to achieve tumor-restricted vector replication targets viral proteins involved in counteracting the innate immune response to HSV. Incoming HSV is sensed by a variety of pattern recognition receptors (PRRs), including cGAS, melanoma differentiation-associated protein 5 (MDA5), and Toll-like receptors (TLR-2, -3 and -7) (Mossman and Smiley, 2002; Leib et al., 2009; Paludan et al., 2011). These sensors, via multiple signaling pathways, induce the production of type $1 \mathrm{IFNs}$ and the expression of over 2,000 IFNstimulated gene products (ISGs) that mediate viral clearance and increase the expression of MHC class I molecules and the recruitment of innate lymphoid cells. Unsurprisingly, HSV expresses several gene products that counteract the IFN response, including ICP34.5 encoded by the y34.5 gene. ICP34.5 is an 
inhibitor of NF-KB and STING (Pan et al., 2018), key mediators in the IFN pathway needed for induction of the ISGs. One well-characterized ISG, protein kinase $R(P K R)$, shuts off host and viral protein synthesis by phosphorylating the translation initiation factor elF2 $\alpha$. PKR is activated by binding to doublestranded RNA generated during viral infection and subsequent autophosphorylation and dimerization. While protein phosphatase-1a (PP1 $\alpha$ ) can inactivate PKR by dephosphorylation (Cheng et al., 2003), viral ICP34.5 selectively activates PP1 $\alpha$ to mediate elF2 $\alpha$ dephosphorylation, allowing viral protein synthesis to proceed (Li et al., 2011). In addition to these functions, ICP34.5 can directly bind to and inhibit Beclin-1 to block cell death by autophagy (Orvedahl et al., 2007). Another viral protein, encoded by the Us 11 gene, inhibits sensing of viral dsRNA by direct interaction with RIG-I and MDA-5 and works together with ICP34.5 to inhibit host shut-down of viral protein synthesis by the PKR pathway (Poppers et al., 2000; Xing et al., 2012).

While the type I IFN response induced upon virus infection represents an essential first line of defense against incoming virus in normal cells, tumors are often defective for components of the IFN response pathway and this can be exploited in the design of oHSV vectors. Eliminating HSV-1 gene products, such as ICP34.5, compromises virus growth in normal cells with an intact IFN response but allows growth in tumor cells. For example, HSV-1 strains expressing a mutant form of ICP34.5 fail to replicate in normal brain tissue and are non-pathogenic for highly HSV-susceptible primates such as Aotus monkeys following intracranial inoculation (Hunter et al., 1999; Todo et al., 2000; Varghese et al., 2001). Replication of HSV1716, a ү34.5 deleted oHSV, in ependymal cells in BALB/c mice is a notable exception (Kesari et al., 1998). In tumor cells with increased signaling through epidermal growth-factor receptor 1 (EGFR) or 2 (HER2/Neu) or platelet-derived growth-factor receptor (PDGFR), persistent Ras activation inhibits PKR activity. Many glioblastomas express a constitutively active mutant form of EGFR as part of the tumor phenotype that may contribute to effective replication of $\mathrm{Y} 34.5$ mutant HSV-1 vectors. 
HSV-1 vectors deleted for $\mathrm{\gamma} 34.5$ function have thus been highly touted for utility as oncolytic vectors. R3616, a replication competent mutant of HSV-1 strain F, lacks most of the coding regions of the two ү34.5 genes (Kramm et al., 1997) (Figure 1A). R3616 is capable of replicating in glioma xenografts in nude mice, and tumor killing is enhanced by ionizing radiation (Advani et al., 1998; Bradley et al., 1999; Huszthy et al., 2008). R3616 has also been shown to be effective for treatment of chemotherapy-resistant tumors (Chahlavi et al., 1999). HSV1716, a mutant of HSV-1 strain 17, also lacks both ү34.5 genes (Figure 1B) (MacLean et al., 1991; Valyi-Nagy et al., 1994; Kesari et al., 1995) and shows a similar anti-tumor and safety profile (Randazzo et al., 1995; Rampling et al., 2000).

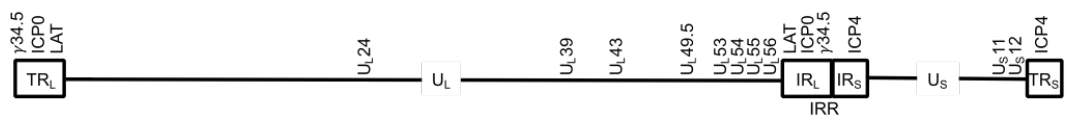

\begin{tabular}{|c|c|c|c|c|c|c|c|c|c|c|c|c|c|}
\hline & Virus & Strain & $\gamma 34.5$ & $\begin{array}{l}\mathrm{U}_{\mathrm{L}} 23 \\
\text { (TK) }\end{array}$ & $\mathrm{U}_{\mathrm{L}} 24$ & $\begin{array}{l}\mathrm{U}_{\mathrm{L}} 39 \\
(\mathrm{ICP} 6)\end{array}$ & $\mathrm{U}_{\mathrm{L}} 43$ & $\begin{array}{l}\mathrm{U}_{\mathrm{L}} 49.5 \\
(\mathrm{gN})\end{array}$ & $\begin{array}{l}U_{L} 55 / \\
U_{L} 56\end{array}$ & IRR & $\mathrm{U}_{\mathrm{s}} 11$ & $\begin{array}{l}\mathrm{U}_{\mathrm{S}} 12 \\
\text { (ICP47) }\end{array}$ & Transgene(s) \\
\hline A & R3616 & $\mathrm{F}$ & $\Delta \gamma 34.5$ & & & & & & & & & & \\
\hline B & HSV1716 & 17 & $\Delta \gamma 34.5$ & & & & & & & & & & \\
\hline C & G207 & $\mathrm{F}$ & $\Delta \gamma 34.5$ & & & $\triangle \mathrm{ICP} 6$ & & & & & & & ICP6p-LacZ [ $[\Delta \mid C P 6]$ \\
\hline D & $\mathrm{G} 47 \Delta$ & $\mathrm{F}$ & $\Delta \gamma 34.5$ & & & $\triangle \mathrm{ICP} 6$ & & & & & $U_{s} 12 p$ & $\triangle \mathrm{ICP} 47$ & ICP6p-LacZ [ $\triangle \mathrm{ICP} 6]$ \\
\hline $\mathrm{E}$ & T-VEC & JS1 & $\Delta \gamma 34.5$ & & & & & & & & $\mathrm{U}_{\mathrm{s}} 12 \mathrm{p}$ & $\triangle \mathrm{ICP} 47$ & CMVp-GMCSF [ $\triangle \gamma 34.5]$ \\
\hline $\mathrm{F}$ & rQNestin34.5 & $\mathrm{F}$ & $\Delta \gamma 34.5$ & & & $\triangle \mathrm{ICP} 6$ & & & & & & & NestinEp- $\gamma 34.5[\Delta \mathrm{ICP} 6]$ \\
\hline G & C134 & $\mathrm{F}$ & $\Delta \gamma 34.5$ & & & & & & & & & & CMVp-CMVIRS1 [U $\left.\mathrm{U}_{L} 3 / 4\right]$ \\
\hline $\mathrm{H}$ & M032 & $\mathrm{F}$ & $\Delta \gamma 34.5$ & & & $\triangle \mathrm{ICP} 6$ & & & & & & & $\begin{array}{l}\text { Egr1p-hIL12 }[\Delta \gamma 34.5] \\
\text { ICP6p-LacZ }[\Delta \mathrm{ICP} 6]\end{array}$ \\
\hline $\mathrm{J}$ & NV1020 ${ }^{1}$ & $\mathrm{~F}$ & & ICP4p-TK & $\Delta \mathrm{U}_{\mathrm{L}} 24$ & & & & $\Delta \mathrm{U}_{\mathrm{L}} 56$ & $\Delta \mathrm{IRR}$ & & & \\
\hline $\mathrm{K}$ & HF10 ${ }^{2}$ & $\mathrm{HF}$ & & & & & $\Delta \mathrm{U}_{\mathrm{L}} 43$ & $\Delta \mathrm{gN}$ & $\Delta \mathrm{U}_{\llcorner} 55 / 56$ & $\Delta$ LAT & & & \\
\hline L & rRp450 & KOS & & & & $\triangle \mathrm{ICP} 6$ & & & & & & & ICP6p-rCYP2B1 [ $\triangle \mathrm{ICP} 6]$ \\
\hline
\end{tabular}

${ }^{1} \mathrm{NV} 1020$ is deleted for a 700-bp region encompassing the thymidine kinase (tk) locus and the promoter of the $\mathrm{U}_{\llcorner} 24$ gene, as well as a region encompassing $U_{\llcorner} 56$ and the internal repeat region (IRR, containing a single copy of ICP0, LAT, $\gamma 34.5$, and ICP4); the $\mathrm{U}_{\mathrm{L}} / \mathrm{U}_{\mathrm{S}}$ junction carries a $3.7-\mathrm{kb}$ duplication of $\mathrm{U}_{\mathrm{L}} 5 / 6$, a $5.2-\mathrm{kb}$ fragment of HSV-2 DNA, and a copy of the tk gene under the ICP4 promoter. ${ }^{2} \mathrm{HF} 10$ naturally overexpresses $\mathrm{U}_{\mathrm{L}} 53(\mathrm{gK})$ and $\mathrm{U}_{\mathrm{L}} 54$ (ICP27).

Figure 1. Oncolytic HSV vectors employed in human clinical trials. Schematic of the wild-type HSV genome (top) with relevant genes indicated above. The unique long $\left(U_{L}\right)$ and unique short $\left(U_{S}\right)$ segments contain single copies of each gene, while the terminal (TRS and $\left.T R_{L}\right)$ and internal repeats $\left(I R_{L}\right.$ and $I R_{S}$, together comprising the IRR) contain duplicate copies of ICP4, ICP0, ү34.5, and LAT. The genome modifications used to attenuate the oHSV vectors described in this review are summarized in the table underneath (descriptions in the text refer to the letters labeling each row). Transgenes expressed from the vectors, their promoters ( $p$ ), and [insertion sites] in the viral genome are listed in the last column. 
HSV1716 was among the first oHSVs to be taken into human clinical trials, along with G207, another $\gamma 34.5$-deleted virus that additionally contains a lacZdisrupted UL39 RR (ICP6) gene (Figure 1C). In preclinical experiments, G207 extended the survival of mice with intracranial GBM tumors, and more recent studies have shown that cisplatin enhanced the effect of G207 without inhibiting viral replication (Chahlavi et al., 1999). Radiation has also been shown to be effective in combination with oncolytic vector therapy (Jorgensen et al., 2001; Blank et al., 2002; Stanziale et al., 2002). Additional viral genome modifications have been considered to improve oncolytic activity of HSV-1. Y34.5 mutants have been combined with deletion of the immediate-early Us12 gene encoding ICP47, a protein that blocks the loading of HSV-1 antigenic peptides onto MHC class I surface molecules (York et al., 1994; Fruh et al., 1995; Goldsmith et al., 1998). In the absence of ICP47, both viral and tumorrelated antigenic peptides can be presented to cytotoxic $T$ cells (CTLs) to eliminate virus-infected and potentially uninfected tumor cells (York et al., 1994; Fruh et al., 1995; Goldsmith et al., 1998). Deletion of the Us12 gene and the $U_{s} 11$ gene promoter in G207-derivative G47 (Figure 1D) (Todo et al., 2001; Zeng et al., 2013) places the Us11 gene, normally a true late gene, under the control of the Us 12 immediate-early gene promoter, resulting in compensation for $\mathrm{y} 34.5$ deletion, increased virus yield and killing of GBM and other tumor lines in culture (Cassady et al., 1998; Mohr et al., 2001; Todo et al., 2001; Liu et al., 2003).

\section{c. Clinical trials}

The tumor-restricted replication and efficacy of y34.5 mutant oHSVs in preclinical experiments led to multiple clinical trials with various HSV-1 strain backgrounds and mutation combinations (Figure 1). In a Phase-I clinical trial of 21 patients with non-histologically proven recurrent GBM, G207 (Figure 1C) was delivered by intra-tumoral injection at three-fold increasing doses from $1 \mathrm{x}$ $10^{6}$ to $3 \times 10^{9} \mathrm{pfu}$ (Markert et al., 2000). Patients only experienced mild adverse events such as fever, malaise and other signs of viral infection that resolved after 3-4 days. This trial showed that inoculation of oHSV was relatively safe in human brain but did not provide an effective treatment. This 
was followed by a Phase-lb trial in 6 patients with recurrent GBM using a dose of $1.15 \times 10^{9} \mathrm{pfu}$, showing radiographic evidence of tumor regression and the presence of an immune infiltrate (Markert et al., 2009). Another trial employing G207 at a dose of $3 \times 10^{9} \mathrm{pfu}$ in combination with 5-Gy radiotherapy is currently recruiting children with recurrent GBM (ClinicalTrials.gov NCT0257845) (Waters et al., 2017; Friedman et al., 2018). In a Phase-I trial of the related G47 virus (Figure 1D) (UMIN000015995), doses of up to $1 \times 10^{9}$ pfu/injection for a total of 6 injections were found to be safe, and efficacy -$92.3 \%$ of recurrent GBM patients remaining alive at 12 months -- was deemed sufficient to prompt the Japanese Ministry of Health, Labor and Welfare to designate G47 $\Delta$ for fast-track approval (Fukuhara et al., 2016; Todo, 2019).

HSV1716, the strain 17 y34.5 mutant (Figure 1B), was well tolerated at doses of up to $10^{5}$ infectious units after stereotactic injection into recurrent malignant gliomas (Papanastassiou et al., 2002; Harrow et al., 2004), a dose much lower than the safe doses observed with G207 (Markert et al., 2000; Markert et al., 2009), which may be due to strain differences and the retention of ICP6 in HSV1716. Analysis of HSV1716-infected tumor explants revealed viral replication at 4-9 days after injection, and the amount of recovered virus exceeded the input dose in at least some patient samples. Radiographic evidence supported a reduction in tumor mass in some patients; yet, long-term survival was not altered, suggesting that more robust oHSV replication may be required.

Strategies employed to maintain vector safety while increasing efficacy include the expression of $\mathrm{\gamma} 34.5$ from a hybrid nestin enhancer-HSP68 minimal promoter in the ICP6-deleted oHSV mutant rQNestin34.5 (Figure 1F), an oHSV that was first shown to be highly active in a GBM model in nude mice (Kambara et al., 2005). A Phase-I trial safety/dose-escalation study using rQNestin34.5 alone or in combination with cyclophosphamide (CPA) for treatment of recurrent GBM patients is underway (NCT03152318). Another strategy is employed in the strain F-based vector C134 that expresses the human cytomegalovirus (CMV) IRS1 gene (Figure 1G) to enhance the 
oncolytic activity of Y34.5 mutant oHSV (Cassady et al., 2017). A Phase-I doseescalation trial (NCT03657576) using $\mathrm{C} 134$ began enrolling patients in November 2018.

A new wave of pre-clinical studies, ultimately leading to further human clinical trials for GBM, now employs these and other oHSV backbones for expression of various transgenes to increase viral spread and penetration within the tumor mass (Dmitrieva et al., 2011; Kim et al., 2014; Jaime-Ramirez et al., 2017; Sette et al., 2019), block neo-vascularization of the tumor (Goodwin et al., 2012; Yoo et al., 2012; Fujii et al., 2013) or modify the immune response in the host tumor microenvironment via the expression of cytokines or chemokines (Liu et al., 2003; Roth et al., 2014; Meisen et al., 2015; Patel et al., 2016; Leoni et al., 2018b). For example, G207 was armed with human IL-12 expressed from the Egr1 promoter (Figure $1 \mathrm{H}$ ). The resulting oHSV, M032, has been shown to be safe in non-human primates and only induce a transient neutrophil and white blood cell host immune response (Roth et al., 2014). It is currently being tested in a Phase-I dose-escalation trial (NCT02062827) in 36 patients with recurrent GBM (Patel et al., 2016). The results of this trial await publication and are likely to influence further human trials for treating GBM with armed oHSV (see section D below for a discussion of arming genes). Together, these Phase-I oHSV trials for GBM demonstrated that the vectors are safe both in HSV-naïve patients and in patients with pre-existing anti-HSV immunity, but they were not designed to examine long-term improvement in overall survival (OS) or progression free survival (PFS).

\section{3. oHSV vectors and treatment of non-neuronal tumors}

Despite the vast preclinical and clinical effort to develop oHSVs to treat GBM, the initial success of using oHSVs to treat patients has come about by treating a tumor of non-neuronal origin. Talimogene laherparepvec (T-VEC; Imlygic ${ }^{\circledR}$ ), an oHSV developed by BioVex (under the name Oncovex ${ }^{\mathrm{GM}-\mathrm{CSF}}$ ) and Amgen, has achieved regulatory approval for the treatment of metastatic melanoma (Pol et al., 2016). T-VEC is an intratumorally injected product; its clinical development for melanoma was facilitated by the accessibility of the malignant 
lesions and the possibility to perform repeated injections. Lesions distant to the sites of injection or visceral metastases, left uninjected, allow for the observation of an abscopal effect, i.e., the induction of anti-tumor activity affecting untreated tumor masses, likely through the generation of a systemic anti-tumor immune response. In addition, melanoma is well-known for its high degree of antigenicity and immunogenicity, a notably 'hot' tumor with expression of several prominent tumor antigens, such as MART-1, gp100, MAGE-1.A1, MAGE-3.A1, Melan-1, Mel-3 and tyrosinase, and a high degree of response to checkpoint inhibitors (Gujar et al., 2018a; Gujar et al., 2018b; Kamran et al., 2018). T-VEC (JS1/Y34.5:HCMVp-GM-CSF/ICP47-; Figure 1E) was derived from an HSV-1 clinical isolate (JS1) and is deleted for both copies of the Y34.5 gene (Liu et al., 2003). The human GM-CSF gene is expressed from both of the deleted $\gamma 34.5$ loci. In addition, the Us12/ICP47 gene is deleted to release interference with transporter associated with antigen presentation (TAP)-dependent MHC class I antigen presentation. As in G47D discussed above, the deletion of ICP47 changes the temporal expression of the late gene $U_{s} 11$ to that of an immediate early gene, at which time the $U_{s} 11$ product can block PKR activation (Cassady et al., 1998; Mohr et al., 2001; Todo et al., 2001; Liu et al., 2003), thereby enhancing viral replication in tumor cells. The TVEC Phase-I study in 30 patients established dose and regimen and showed that the intratumoral injection was well tolerated, with minor treatmentassociated adverse events (AEs), including flu-like symptoms such as fatigue, pyrexia, chills, nausea, and focal cellulitis at the injection site. Notably, these events were more pronounced in previously HSV-seronegative patients, leading to the adoption of an initial dose of $1-4 \times 10^{6} \mathrm{pfu}$ to seroconvert all patients before full therapeutic doses of $1-4 \times 10^{8}$ pfu every 2 weeks (Hu et al., 2006). T-VEC DNA was detected in injected tumors and in some neighboring uninjected lesions, but not in distal lesions, indicating that T-VEC did not spread to distal tumor sites.

The favorable results of this Phase-I trial supported a Phase-II trial with 50 melanoma patients, in which a similar safety profile was observed as in the Phase-I trial, an overall response rate (ORR; i.e., arrested tumor growth) of 
$26 \%$, and a complete response rate (CR; tumor no longer detectable) of $16.9 \%$ (Senzer et al., 2009; Kaufman et al., 2010; Andtbacka et al., 2019). Regression of both injected local tumors as well as more distal tumors was observed, with overall survival (OS) rates of $>50 \%$ at $1-2$ years post-therapy. The immune response was evaluated and showed an increase in MART-1-specific T cells and a corresponding decrease in regulatory $T$ cells (Tregs) and myeloidderived suppressor cells (MDSCs) within the tumor microenvironment (TME) (Senzer et al., 2009; Kaufman et al., 2010). This prompted a large Phase-III OPTiM (Oncovex ${ }^{\mathrm{GM}-\mathrm{CSF}}$ Pivotal Trial in Melanoma) study of 436 patients, in which T-VEC was compared to GM-CSF protein as a standard control therapy for melanoma. T-VEC decreased by $>50 \%$ the size of $64 \%$ of the injected tumors, $34 \%$ of non-visceral tumors, and $15 \%$ of visceral tumors (Andtbacka et al., 2015). The durable response rate (DRR; no evidence of recurrent disease) was $16.3 \%$ for T-VEC, but only $2.1 \%$ for GM-CSF alone, while the ORR for TVEC was $26.4 \%$ versus $5.7 \%$ for GM-CSF alone (Andtbacka et al., 2015; Harrington et al., 2016). These numbers were even better for the earlier-stage subgroup (57.1\% of evaluated patients) with DRRs of $25.2 \%$ versus $1.2 \%$ and ORRs of $40.5 \%$ versus $2.3 \%$ (Andtbacka et al., 2015; Harrington et al., 2016). Together, these results warranted the first FDA approval of an oncolytic virus and gene therapy product in the U.S. for the treatment of a solid tumor, melanoma, in October of 2015.

Currently there are 37 active clinical trials employing T-VEC under its commercial name (Imlygic ${ }^{\circledR}$ ), targeting melanoma, sarcomas, breast cancer, pancreatic cancer, colorectal cancer, head and neck squamous cell carcinoma (HNSCC), lymphoma, liver cancer, pleural and intraperitoneal cancer, and bladder cancer. Since its original success in melanoma treatment, T-VEC has been evaluated in combination with chemo- and radiotherapies. A Phase-1/II trial using T-VEC in HNSCC, in combination with 70 Gy radiotherapy and cisplatin, in 14 patients showed an $82.3 \%$ tumor response and OS of $82.4 \%$ at 2-years post therapy (Harrington et al., 2010). HSV-1 DNA was detected not only within the injected tumor but also in adjacent tumors, and the number of detected genomes was significantly higher than the injected dose, suggesting 
active virus replication in the TME. The fact that T-VEC treatment alone resulted in regression of local tumors but not distal and visceral tumors suggested that the immunosuppressive TME may be inhibiting the cytotoxic $T$ lymphocyte $(C T L)$ response required to effectively eliminate untreated distal and visceral lesions, pointing to a need for combination trials with immune checkpoint-inhibitory antibodies such as anti-CTLA-4 ipilimumab (Yervoy) and anti-PD-1 pembrolizumab (Keytruda). The combination of T-VEC with antiCTLA-4 (Puzanov et al., 2016) showed no added dose-limiting toxicities (DLTs) of T-VEC and raised the ORR from $26 \%$ seen in the Phase-III OPTiM trial to greater than $50 \%$. A greater increase in CD8+ T-cells was detected in patients that were considered to be complete responders $(\mathrm{CR})$ compared to partial responders $(P R)$ or patients with progressive disease. T-VEC combination with pembrolizumab in a Phase-lb/ll trial (Ribas et al., 2017) was found to increase the frequency of complete responses to $62 \%$ compared to $24 \%$ for T-VEC alone, and a dramatic increase in circulating CD3+/CD8+ T-cells was observed. The field is eagerly awaiting the outcome of the large phase III clinical trial Keynote 034 (NCT02263508) combining T-VEC and Keytruda to hopefully confirm the promising phase Ib/ll data. Additional combination studies with T-VEC, checkpoint-inhibitory antibodies and chemo- or radio-therapy are underway. Radiotherapy can increase the levels of tumor antigens and, in combination with T-VEC, may increase the number of tumor-specific targets for activated CTLs.

In addition to T-VEC, other oHSVs have been tested in non-CNS tumor clinical trials. HSV1716 has been evaluated in Phase-I trials for melanoma (MacKie et al., 2001), HNSCC (Mace et al., 2007; Mace et al., 2008) and pediatric nonCNS tumors (Streby et al., 2017). In these trials, doses of $1 \times 10^{5}-2 \times 10^{6} \mathrm{pfu}$ proved safe and led to virus replication in the tumor, yet failed to provide compelling evidence of efficacy. NV1020 (Figure 1J) contains deletions of the Y34.5 genes, the $U_{\llcorner 2} 24$ promoter, the complete internal repeat region, and the $\mathrm{U}_{\llcorner} 56$ gene that encodes a protein likely involved in Golgi vesicular trafficking of virions (Koshizuka et al., 2005). These deletions resulted in a severely attenuated recombinant virus that can still replicate in tumor cells. In-vivo 
analysis with this vector demonstrated tolerability and efficacy in a number of experimental models of bladder carcinoma (Cozzi et al., 2001), HNSCC (Wong et al., 2001), and non-small cell lung cancer (Ebright et al., 2002). These strong efficacy and safety data in mice led to Phase-I trials conducted by hepatic artery infusion of the virus for colorectal cancer (CRC) metastatic to the liver. The results demonstrated safety of NV1020 with only mild to moderate AEs, such as fever and transient lymphopenia, and no patients displayed evidence of virus shedding (Kemeny et al., 2006; Geevarghese et al., 2010; Sze et al., 2012). Antitumor efficacy was limited in this refractory setting, with $50 \%$ of patients showing stable disease. Another oHSV, HF10 (Figure $1 \mathrm{~K}$ ), is a natural HSV-1 variant defective for expression of $U_{\llcorner} 43, U_{\llcorner} 49.5, U_{\llcorner} 55, U_{\llcorner} 56$ and LAT (Ushijima et al., 2007). HF10 replicates to high efficiency in tumor cells while demonstrating substantially reduced toxicity compared to wild-type HSV-1. Takara-sponsored Phase-I trials have been conducted in Japan for solid tumors with superficial lesions (Ferris et al., 2014), breast cancer (Nakao et al., 2004; Kimata et al., 2006; Nakao et al., 2007; Sahin et al., 2012), unresectable pancreatic cancer (Nakao et al., 2011; Kasuya et al., 2014; Hirooka et al., 2018), and resectable HNSCC (Fujimoto et al., 2006). In these Phase-I trials, HF10 was well-tolerated without virus-attributable serious adverse events (SAEs). While viral replication was detected in the tumor mass, no evidence of virus shedding from the injection sites was observed. Some evidence was obtained of moderate tumor cell killing along with $\mathrm{CD} 4+$ and CD8+ T-cell infiltrates within the TME. These results led to a Phase-II combination trial (NCT02272855) of HF10 with ipilimumab in unresectable stage III-IV malignant melanoma that demonstrated an immune-related response criteria (irRC) best overall response rate (BORR) at 24 weeks of $41 \%$ [18\% complete disappearance of all lesions (irCR) and 23\% decrease in tumor burden by $\geq 50 \%$ (irPR)] (Andtbacka et al., 2018). G47 (Figure 1D) has been evaluated in a Phase-I dose-escalation study for the treatment of castrationresistant prostate cancer (UMIN000010463) and in a Phase-I trial (UMIN000011636) for recurrent olfactory neuroblastoma (Fukuhara et al., 2016). Finally, oHSV rRp450, containing a rat cytochrome P450 gene in place of the UL39 RR gene (Figure 1L) (Chase et al., 1998), is under study in a 
Phase-I trial (NCT01071941) for primary liver cancer and liver metastases in 40 patients, comparing single and repeated infusions into the hepatic artery.

\section{Summary}

To date, clinical trials using oHSVs have demonstrated that all of the viral recombinants (i) were well-tolerated; (ii) had limited risk of shedding; (iii) tended to induce some level of T-cell recruitment; (iv) caused sero-conversion of patients who were HSV-seronegative at the time of oHSV administration; and ( $v$ ) displayed evidence of intra-tumoral virus replication. When evaluated as monotherapy, clinical efficacy of most oHSVs was limited for indications other than melanoma. Currently, the data evaluating clinical benefit of oHSVs in combination with chemo-, radio- or immunotherapy is limited by the absence of controlled Phase-III studies. Still, Phase-II clinical data evaluating T-VEC and HF10 in combination with ipilimumab or pembrolizumab appear very promising, with roughly a doubling of the response rate achieved by these checkpoint inhibitors alone. More importantly, in the case of T-VEC combined with pembrolizumab, complete responses were achieved with patients presenting with low intratumoral CD8+ T-cell counts and low expression of PDL1 and IFN-responsive genes, parameters that are indicative of immunologically "cold" tumors that are not expected to respond to immunotherapy (Ribas et al., 2017). These data, on the heels of T-VEC/ Imlygic's approval by the FDA, are fueling the current enthusiasm for oncolytic viruses and the efforts to improve upon the first-generation oHSV vectors.

\section{Advances in oHSV design for increased specificity and efficacy}

\section{Selective HSV attenuation by microRNAs}

As described above, the primary method of attenuating oHSV has been to remove or inactivate genes that contribute to innate immune evasion in order to render the virus susceptible to the innate cellular defenses that are active in normal cells but compromised in tumor cells. However, tumors can vary widely in their loss of type I IFN responses (e.g., (Alain et al., 2010)) and IFN can be produced by myeloid cell types within the TME. Therefore, the maintenance of the complete set of viral defense functions is thought to be beneficial to retain 
full vector replication activity in vivo, thus prompting the development of novel approaches for virus attenuation. The maintenance of normal cellular function by microRNAs (miRNAs) is frequently disrupted in tumors, and this dysregulation of miRNA expression represents a distinct signature of the tumor that has been exploited to attenuate oncolytic vector replication in normal cells. The use of differential miRNA expression to limit oHSV replication to tumor cells was first described in a prostate cancer model using an amplicon vector with recognition sequences for miR-143 and miR-145 engineered into the 3'UTR of the ICP4 gene; both miRNAs are expressed in normal tissues but are significantly down-regulated in prostate cancer cells (Lee et al., 2009). The promise of this strategy was confirmed in models of other tumors, including liver tumors where miR-222 expression is highly reduced compared to hepatocytes (Fu et al., 2012), non-small-cell lung cancer (miR-145) (Li et al., 2013), and urothelial bladder cancer (miR-143 + miR-124) (Zhang et al., 2016). In GBM, tumor cells have low or undetectable expression of miR-124, an miRNA that is highly expressed in normal neurons (Sempere et al., 2004; Gaur et al., 2007; Silber et al., 2008). Incorporation of miR-124 target sites into the 3'UTR of the ICP4 gene blocked virus replication in miR-124 expressing cells in culture and virus replication in normal brain, preventing HSV-induced encephalitis (Mazzacurati et al., 2015). The field is only beginning to harness the power of miRNAs to control off-target oHSV replication, which can be combined with additional safety measures, such as the use of tumor-specific promoters to control the expression of virulence genes (Kambara et al., 2005; Nakashima et al., 2018) and, as described below, retargeting of the virus attachment and entry machinery to tumor-related cell surface receptors (Campadelli-Fiume et al., 2016). These combinatorial approaches will be particularly important in the development of vectors for systemic treatment of metastatic cancer.

\section{Retargeting HSV infection to tumor-cell receptors.}

Vector retargeting is a promising strategy to achieve both oHSV safety and efficacy by restricting virus infection to cells expressing tumor-associated cell surface receptors. By limiting off-target infection, this approach provides 
opportunities for the use of unattenuated oHSVs in cancer therapy. HSV vectors have been retargeted to a number of cell surface receptors, including the epidermal growth factor receptor (EGFR/EGFRvIII) (Uchida et al., 2013), epithelial cell adhesion molecule (EpCAM) (Shibata et al., 2016), and human epidermal growth factor receptor 2 (HER2) (Menotti et al., 2008) (Figure 2), and several of these retargeted viruses have demonstrated considerable efficacy in in-vivo mouse models of solid tumors. Although efficacy following systemic virus administration has yet to be reported, preferential virus homing to tumor sites has been observed (Uchida et al., 2013). Retargeting of HSV is thus emerging as a promising strategy to accomplish unimpaired tumorspecific lytic activity.

\section{a. Virus attachment and entry into host cells}

To accomplish vector retargeting, the virus must be modified to eliminate entry through its cognate receptors. In our current understanding, HSV adsorption and entry involves the coordinated activities of glycoproteins $\mathrm{gB}, \mathrm{gC}, \mathrm{gD}$ and the $\mathrm{gH} / \mathrm{gL}$ heterodimer. Virus attachment is initially mediated by binding of $\mathrm{gC}$ and $\mathrm{gB}$ to cell surface glycosaminoglycans (GAGs), primarily heparan sulfate (HS) (WuDunn and Spear, 1989; Herold et al., 1991; Shieh et al., 1992; Spear et al., 1992; Gruenheid et al., 1993; Herold et al., 1994; Tal-Singer et al., 1995; Trybala et al., 2002). Deletion of $\mathrm{gC}$ and the HS binding domain of gB in a single mutant virus impairs virus adsorption and reduces but does not eliminate entry, and wild-type HSV can infect HS-deficient cells (Gruenheid et al., 1993; Laquerre et al., 1998b). Retargeting of gC to a model receptor (erythropoietin receptor) combined with disruption of the HS-binding elements of $\mathrm{gC}$ and $\mathrm{gB}$ was first reported by Laquerre and colleagues (Laquerre et al., 1998a) and has since been demonstrated by others for additional receptors (Argnani et al., 2004; Grandi et al., 2004; Wang et al., 2005; Kouvatsis et al., 2007; Cao et al., 2010; Grandi et al., 2010). However, while these viruses may preferentially attach to their target cells, their entry specificity is determined by another envelope glycoprotein, gD. In a typical HSV infection, virion attachment to HS is followed by gD-mediated binding to one of several entry receptors: (1) Herpesvirus entry mediator (HVEM/HveA or TNFRSF14), a member of the 
TNFa receptor superfamily (Montgomery et al., 1996); (2) nectin-1 (CD111/ $\mathrm{HveC}$ ), a cell adhesion molecule and a member of the immunoglobulin superfamily (Geraghty et al., 1998; Krummenacher et al., 1998); (3) nectin-2 (CD112/HveB), a receptor for HSV-2 and variant HSV-1 strains that carry a specific amino acid change at position 27 of gD (Q27P or Q27R) (Warner et al., 1998); and (4) 3-O-sulfated HS (3-OS HS), a carbohydrate receptor for HSV-1 (Shukla et al., 1999). Interaction with any of these receptors causes a conformational change in $\mathrm{gD}$ that is currently thought to activate the $\mathrm{gH} / \mathrm{gL}$ heterodimer, which, in turn, activates the fusogenic activity of gB (Atanasiu et al., 2010; Eisenberg et al., 2012). Depending on the cell type, HSV entry takes place either by envelope fusion with the plasma membrane (Fuller and Spear, 1987; Fuller et al., 1989) or by virion endocytosis followed by envelope fusion with the endosomal membrane (Nicola et al., 2003; Nicola and Straus, 2004).

\section{b. HSV retargeting via modification of glycoprotein $D$}

As the receptor-dependent initiator of virus entry, $\mathrm{gD}$ is the key determinant of HSV tropism. Retargeting, therefore, requires both disruption of the ability of gD to interact with its cognate receptors and establishment of entry-initiating interactions with a desired target receptor through incorporation of a cognate ligand into gD. Substantial insight into the structure-function relationship of gD has come from extensive mutagenesis studies, mapping of monoclonal antibody binding sites, and the crystal structures of $\mathrm{gD}$ alone and complexed with HVEM or nectin-1 (Feenstra et al., 1990; Krummenacher et al., 1998; Whitbeck et al., 1999; Carfi et al., 2001; Connolly et al., 2003; Milne et al., 2003; Yoon et al., 2003; Jogger et al., 2004; Manoj et al., 2004; Krummenacher et al., 2005; Di Giovine et al., 2011). Pertinent to the goal of altering the binding specificity of $\mathrm{gD}$ without disrupting its entry-initiating response to receptor binding are the following. First, the membrane-proximal (C-terminal) region of the ectodomain, roughly between residues 260 and 310 and referred to as the profusion domain (Cocchi et al., 2004; Fusco et al., 2005), is required for receptor-dependent signal transduction to $\mathrm{gH} / \mathrm{gL}$ and $\mathrm{gB}$. Second, the $\mathrm{N}$ terminal region contains multiple residues required for binding to HVEM (Connolly et al., 2003) and 3-OS HS (Yoon et al., 2003), and complete 
disruption of this binding can be accomplished by mutations, insertions, and small or large deletions. Third, certain substitutions or deletion of residue 38 abolishes nectin-1 binding. Fourth, the central core of the $\mathrm{gD}$ ectodomain (residues 61-218) that includes much of the immunoglobulin (Ig) fold of the ectodomain [residues 56-184 (Carfi et al., 2001)], is dispensable for gD activity (Zhou and Roizman, 2007). Accordingly, HSV retargeting by the insertion of a novel ligand into gD has thus far relied almost exclusively on disruption of natural receptor binding by mutations and ligand insertion at the amino terminus, or on replacement of the central Ig domain, which also eliminates natural receptor binding. Recent studies have additionally shown that while short insertions ( $\leq 20$ amino acids) C-terminal to the $\mathrm{lg}$ fold are readily tolerated, longer insertions [62 aa or a single-chain antibody (scFv) of nearly the same size as the $\mathrm{gD}$ ectodomain] typically curtail cell surface expression and, consequently, membrane fusion (Fan et al., 2017).

Early attempts at HSV retargeting succeeded in ablating HVEM recognition and facilitating $\mathrm{gD}$ engagement of non-HSV receptors through insertion of cognate foreign ligands, including 247- and 256-amino-acid long scFvs. However, elimination of the interaction of $\mathrm{gD}$ with nectin-1 proved to be more challenging as the nectin-1-binding site was poorly defined and mutations that selectively eliminated nectin-1 binding were elusive (Zhou et al., 2002; Kamiyama et al., 2006; Menotti et al., 2006). The first fully retargeted HSV recombinant, R5141 (Figure 2), was identified in a stepwise process that included a screen of point mutations in a targeted gD construct for loss of virus entry through nectin-1 (Zhou and Roizman, 2006). The ligand in this construct, IL-13, was genetically fused to gD residue 33 to promote gD interaction with the IL-13 receptor a2 (IL-13Ra2), which is specifically overexpressed in malignant brain tumors. The chimeric IL-13-gD protein lacked residues 1-32 of $\mathrm{gD}$, ablating HVEM binding, and used the IL-13 signal peptide instead of the native signal peptide. The screen identified V34S as a substitution that abolished nectin-1 binding while preserving the ability of the virus to use IL-13Ra2 as an entry receptor. The authors were able to grow this fully retargeted virus on HSV receptor-deficient J1.1-2 cells transduced with 
IL-13Ra2 (J-13R), thereby eliminating selective pressure for reversion or complementation of the V34S substitution during propagation, although presumably not during replication in nectin-1-positive tumors. Additionally, R5141 could be grown on IL-13Ra2-transduced Vero cells (Vero-13R), albeit to lower titers than parental wild-type HSV-1, but not on standard Vero cells. Interestingly, while a variety of HSV gene products, including other glycoproteins, were abundantly visible on Western blots of R5141-infected Vero-13R cells, the retargeted gD protein was undetectable, suggesting that very low levels of $\mathrm{gD}$ were sufficient for infection, but also that the protein was improperly processed, undermining robust production of progeny virus.

A number of HSV-1 recombinants, fully retargeted to HER2 using a HER2specific scFv, have since been described (Menotti et al., 2008; Menotti et al., 2009) (Figure 2). In recombinant R-LM113, the anti-HER2 scFv replaced gD residues 6-38, eliminating both HVEM and nectin-1 binding, after attempts to do so by ligand insertion between residues 24 and 25, combined with the V34S mutation, failed (Menotti et al., 2008). Replacement of the entire Ig-like core of the gD ectodomain (residues 61-218) with the anti-HER2 scFv, comprising two Ig domains, also yielded a fully retargeted virus, referred to as R-LM249 (Menotti et al., 2009), in agreement with the evidence that the gD core is dispensable for retargeted HSV entry (Zhou and Roizman, 2007). The authors implied that the deletion of the core ensured resistance to reacquisition of natural receptor binding ability, but no specific evidence supporting this claim was presented.

An orthogonal approach to HSV retargeting involved "bridging" gD with noncognate tumor-specific receptors by using soluble bi-specific adapters (Nakano et al., 2005; Baek et al., 2011). One such adapter, comprising the $\mathrm{N}$-terminal gD-binding Ig domain of nectin-1 and an EGFR-specific ScFv that also recognizes the tumor cell-specific EGFR variant III (EGFRvIII), mediated EGFR-dependent HSV-1 infection (Nakano et al., 2005). Since complete detargeting from cellular nectin-1 proved problematic and since extracellular adapters cannot redirect lateral virus spread, the ScFv was inserted into gD 


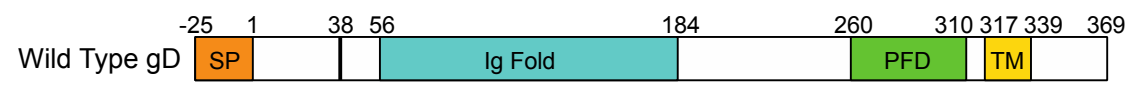

\begin{tabular}{|l|l|l|l|l|l|l|}
\hline Name & Targeting Ligand & $\begin{array}{l}\text { Insertion } \\
\text { Site }\end{array}$ & $\begin{array}{l}\text { Signal } \\
\text { Peptide }\end{array}$ & $\begin{array}{l}\text { Additional gD } \\
\text { Detargeting } \\
\text { Mutations }\end{array}$ & Strain & Reference \\
\hline R5141 & IL13 & gD $\Delta 1-32$ & IL13 & gD V34S & F & $\begin{array}{l}\text { Zhou and Roizman } \\
2006\end{array}$ \\
\hline R-LM113 & scFv HER2 & gD $\Delta 6-38$ & gD & NA & F & Menotti et al, 2008 \\
\hline R-LM249 & scFv HER2 & gD $\Delta 61-$ & gD & NA & F & Menotti et al, 2009 \\
\hline KNE ${ }^{2}$ & scFv EGFR/EGFRvIII & gD $\Delta 2-24$ & gD & gD Y38C & KOS & Uchida et al, 2013 \\
\hline KGNEp ${ }^{2}$ & scFv EpCAM & gD $\Delta 2-24$ & gD & gD Y38C & KOS & Shibata et al, 2016 \\
\hline R-593 & scFv PSMA & gD $\Delta 6-38$ & gD & NA & F & Menotti et al, 2018 \\
\hline R-611 & scFv EGFR & gD $\Delta 6-38$ & gD & NA & F & Menotti et al, 2018 \\
\hline R-613 & scFv EGFRvIII & gD $\Delta 6-38$ & gD & NA & F & Menotti et al, 2018 \\
\hline
\end{tabular}

${ }^{1} \mathrm{R} 5141$ is also retargeted via $\mathrm{gC}$ with IL13 replacing gC residues $1-140$.

2 The viral backbone contains two point mutations in gB, referred to as gB:NT, that enhance virus entry.

Figure 2. oHSV retargeting via modification of gD-receptor interactions. (top) Schematic representation of $\mathrm{gD}$, illustrating the domains described in the text: signal peptide (SP), Ig fold, profusion domain (PFD), transmembrane domain (TM). The amino acid positions defining each domain are indicated above the schematic; mature $\mathrm{gD}$ starts at amino acid 1 . The table underneath describes viruses bearing fully retargeted recombinant $\mathrm{gD}$ molecules.

between residues 24 and 25 , as in the early gD constructs described above. $\mathrm{gD}$ detargeting from HVEM was enforced by deletion of gD residues 7-11, while detargeting from nectin-1 was achieved by changing positions 3 and 38 to cysteines [A3C/Y38C (Connolly et al., 2005)]. Phenotypic complementation assays of a gD-null virus confirmed uniquely EGFR-dependent viral entry that was enhanced by a pair of entry-accelerating mutations in gB (gB:NT) (Uchida et al., 2010). In contrast, replacement of residues 7-39 or 61-218 of gD with the same scFv, similar to the anti-HER2 scFv position in the R-LM113 and RLM249 viruses, respectively, failed to enable entry through EGFR engagement. Indeed, it was recently reported that replacing the 61-218 region of $\mathrm{gD}$ with a different EGFR-specific scFv or with scFvs recognizing EGFRvIll or prostate- 
specific membrane antigen (PSMA), failed to enable virus entry through the respective cognate receptors although all three scFvs were effective when replacing gD residues 6-38 (R-593, R-611, R-613, Figure 2) (Menotti et al., 2018). The authors of this study proposed that the failure of these new scFvs to function within the 61-218 deletion region might be due to the arrangement

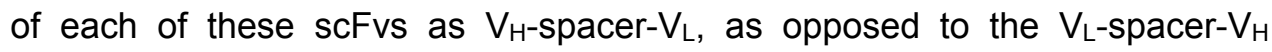
arrangement of the successful HER2-specific scFv. However, the earlier antiEGFR/EGFRvIll scFv had the $V_{L}-$ spacer- $V_{H}$ arrangement (Uchida et al., 2010), suggesting that the relative positioning of the two antibody $V$ domains alone cannot account for the unique ability of the HER2-specific scFv to function from within the 61-218 deletion. More recently, another effective, fully retargeted virus (KNE, Figure 2) was obtained by substitution of $g D$ residues 2-24 with the anti-EGFR/EGFRvIII scFv, in combination with the Y38C mutation (Uchida et al., 2013). This virus could be grown on standard Vero cells without noticeable reversion of the nectin-1-detargeted phenotype (Uchida et al., 2013). Nevertheless, reversion was observed for other retargeted viruses grown on cognate receptor-transduced nectin-1+ cell lines, suggesting that while entry of the EGFR/EGFRvIII-retargeted virus through endogenous (simian) Vero-cell EGFR may be sufficiently efficient to minimize selective pressure for reversion, avoidance of nectin-1+ cell lines for virus production and rigorous detargeting from nectin-1 are critical. It was recently reported that deletion of gD residue 38 from the reversion-sensitive viruses provides reliable resistance to reversion (Uchida et al., 2018).

\section{c. Retargeting virus infection by modification of other glycoproteins}

In recent years, both $\mathrm{gH} / \mathrm{gL}$ and $\mathrm{gB}$ have been found to interact with specific cellular receptors (Parry et al., 2005; Satoh et al., 2008; Arii et al., 2010; Suenaga et al., 2010; Arii et al., 2015), and these interactions may facilitate HSV entry. To clarify the role of $\mathrm{gH} / \mathrm{gL}$ in HSV-1 entry and to explore whether the receptor specificity of this heterodimer affects HSV tropism, the anti-HER2 scFv was inserted into the amino terminus of $\mathrm{gH}$ (gH-HER2) in a wild-type gD virus that could be grown on nectin-1+ cells (Gatta et al., 2015). Remarkably, this virus could both infect and spread on J-HER2 cells that expressed HER2 
but lacked functional gD receptors. In addition, a derivative detargeted from HVEM/nectin-1 by deletion of gD residues 6-38 infected a HER2+/nectin-1+ cancer cell line but not HER2-negative cell lines that were permissive for wildtype HSV-1. Similarly, insertion of the anti-HER2 scFv near the amino terminus of gB (gB-HER2) enabled infection of J-HER2 cells and gD detargeting of this virus did not substantially diminish infection of HER2+ cancer cell lines (Petrovic et al., 2017). While it might be concluded from this result that gBretargeted virus would no longer require $\mathrm{gD}$ and, perhaps, $\mathrm{gH} / \mathrm{gL}$ for entry, neutralizing antibodies to $\mathrm{gD}$ or $\mathrm{gH}$ were found to block HER2-dependent entry of gD-detargeted gB-HER2 virus. This observation suggested that gD performs a required function in entry that is independent of its binding to a receptor. In support of this, fusion of glycoprotein-transfected cells with J-HER2 cells was equally efficient when $\mathrm{gB}-\mathrm{HER} 2$ and $\mathrm{gH} / \mathrm{gL}$ were transfected in the presence of wt $\mathrm{gD}$ or detargeted $\mathrm{gD}$ but was abolished in the absence of $\mathrm{gD}$ (Petrovic et al., 2017). The same results were obtained when gH-HER2 was used with gB and gD (Petrovic et al., 2017). Together, these results not only demonstrated that $\mathrm{HSV}$ can be fully retargeted by insertion of a foreign ligand into $\mathrm{gD}, \mathrm{gH}$ or $\mathrm{gB}$ in viruses that cannot utilize the natural $\mathrm{gD}$ receptors, but also indicated that none of the four essential entry glycoproteins are dispensable, with the implication that these viruses remain susceptible to neutralization by anti-glycoprotein antibodies in HSV-seropositive cancer patients (Cairns et al., 2015).

\section{d. Production of retargeted viruses}

Until recently, retargeted HSV was preferably generated and propagated on gD-receptor-deficient cells transgenic for the target receptor to avoid selective pressure for mutations that could restore $\mathrm{gD}$ binding to one of its natural receptors. To obviate the laborious generation of new cell lines for each new target receptor, a standardized system to produce retargeted viruses without dependence on expression of the target receptor on the producer cells was developed (Leoni et al., 2017). This system is analogous to the peptide tag/ anti-tag pseudoreceptor systems previously used to grow fully retargeted adenoviruses and measles viruses (Douglas et al., 1999; Nakamura et al., 2005). A yeast GCN4 peptide was inserted into the $\mathrm{N}$-terminal region of $\mathrm{gH}$ 
while Vero cells (nectin-1+), which are FDA-approved for clinical-grade virus preparation, were engineered to express a high-affinity scFv to the GCN4 peptide as an artificial GCN4 peptide receptor (GCN4R). This tag/ pseudoreceptor system was shown to enable nectin-1-detargeted virus entry into Vero cells (Leoni et al., 2017). In a subsequent study, the same group reported that gD could simultaneously accommodate the HER2 ScFv and the GCN4 peptide for dual virus retargeting by a single recombinant glycoprotein, and described smaller and novel deletions suitable for nectin-1 detargeting and foreign ligand insertion (gD residues 35-39, 214-223 and 219-223) (Leoni et al., 2018a). Moreover, they showed that double retargeting to HER2 and GCN4R could also be accomplished by insertion of the GCN4 peptide at any of four different positions within the $\mathrm{N}$-terminal 100 residues of $\mathrm{gB}$, in combination with either the 6-38 deleted version of HER2-retargeted gD or a novel retargeted $\mathrm{gD}$ design combining a deletion of residue 30 with insertion of the anti-HER2 scFv in place of residue 38 (Petrovic et al., 2018). Although differences in replication and spread efficiencies were noted on either or both Vero-GCN4R and HER2+/nectin-1+ cancer cells between different doubly retargeted viruses, all were detargeted from the natural $\mathrm{gD}$ receptors and cytotoxic for both cell lines (Leoni et al., 2018a; Petrovic et al., 2018).

\section{e. Retargeted virus efficacy in preclinical models}

Ultimately, retargeted viruses are intended to increase tumor cell specificity and decrease off-target cell infection and toxicity, thereby improving vector safety while retaining efficient vector replication in tumor cells in vivo. The EGFR- and HER2-retargeted viruses have both been tested in preclinical mouse models of human tumors. The retargeted virus bearing an scFv against EGFR (KNE, Figure 2) recognizes both wild-type EGFR and its uniquely tumor-associated variant EGFRvIll prevalent on human GBM cells. This virus was effective in an orthotopic human-tumor model of GBM, i.e., a model where the tumor is located at its normal place (brain for GBM), with approximately $75 \%$ of oHSVtreated mice surviving beyond 90 days following a single intratumoral virus injection. No toxicity was observed upon direct injection of the virus into mouse brain, and systemic injection demonstrated preferential homing of the virus in 
nude mice to GBM flank tumors over non-tumor tissues (Uchida et al., 2013). The HER2-retargeted virus R-LM113 (Figure 2) was also found to be safe upon direct brain injection. In murine GBM tumors engineered to express human HER2, a single injection of R-LM113 lengthened median survival time of treated animals by 21 days compared to controls (Gambini et al., 2012). Both of these studies illustrated that retargeted oHSVs abolished neuroinvasiveness in the brain. However, to further ensure tumor specificity, the EGFR-retargeted gD was coupled with insertion of miR-124 binding sites in the 3' UTR of the essential ICP4 gene, abolishing virus (KGE-4:T124) replication in miR-124-expressing neurons while permitting virus replication in miR-124 deficient GBM tumor cells (Mazzacurati et al., 2015). KGE-4:T124 was as efficacious in the treatment of orthotopic human tumors as its retargeted parent virus, lacking the miR-124 binding sites (KGE), while providing increased safety (Mazzacurati et al., 2015).

The HER2-retargeted virus R-LM249, bearing a different insertion site for the anti-HER2 scFv than R-LM113 (Figure 2), readily infected a HER2+ human ovarian carcinoma cell line, SK-OV-3. R-LM249 demonstrated a dosedependent reduction in tumor growth following a single administration of virus directly into subcutaneous SK-OV-3 flank tumors, while repeat administration of the virus (4 doses) led to a significant reduction in tumor burden, with $60 \%$ of mice being tumor-free past 200 days (Menotti et al., 2009). Treatment of intraperitoneal (i.p.) SK-OV-3 tumors with weekly i.p. delivery of R-LM249 (5 doses) also reduced tumor burden and increased median survival from 103 days to 440 days (Nanni et al., 2013). HER2 is also expressed in a subset of human breast cancers, and weekly intratumoral administration of R-LM249 was effective against subcutaneous flank tumors formed by HER2+ human breast cancer cells (Nanni et al., 2013). Moreover, weekly i.p. injection of RLM249 in a multiorgan metastasis model induced by intravenous injection of the same cells significantly reduced ovarian and brain metastatic burden (Nanni et al., 2013). These studies demonstrated that R-LM249 in repeated doses was able to impair the growth of both local and disseminated HER2expressing tumors. 
While the work described above has shown that treatment with retargeted viruses can effectively reduce tumor burden and extend the survival of tumorbearing immune-deficient mice, the current approach to oncolytic virotherapy seeks to expand immune-system engagement by arming vectors with immune modulatory transgenes. Recently, HER2-targeted R-LM113 armed with IL-12 (R-LM115) was tested in immune-competent mice in a flank tumor model induced by implantation of HER2-transduced murine Lewis lung carcinoma (LLC) cells (Leoni et al., 2018b). The results demonstrated that 4 doses of either R-LM113 or R-LM115 extended animal survival compared to controls, particularly when treatment was given at the early time point of 3 days post tumor cell injection. Of note, while the R-LM115 virus expressing IL-12 was significantly more effective than the unarmed virus at extending animal survival and reducing tumor volume, both viruses inhibited formation of tumors after rechallenge of animals that survived the primary tumor. Analysis of an array of immune cell markers and cytokines illustrated key changes in the tumor microenvironment in response to virus treatment and, in particular, to IL-12 expression, suggesting increased immune-stimulatory factors and tumor infiltration by activated immune cells in responder mice. These data highlight the importance of the immune system in tumor treatment, stimulated, in part, by the virus and its lytic activity, and, in part, by the expression of immunestimulatory transgenes as discussed in detail below.

\section{D. oHSVs as the next wave of immuno-oncology therapies}

\section{1. oHSV and immunogenic tumor cell killing}

HSV replication causes tumor cell death resulting in the release of tumorassociated antigens/neoantigens (Bommareddy et al., 2018; Thomas et al., 2019) (Fig 3), viral pathogen-associated molecular patterns (PAMPs), and cellderived damage-associated molecular patterns (DAMPs). Induction of innate immunity, assessed by the production of type I IFN and other proinflammatory cytokines, is triggered by these DAMPs, PAMPs, and various sensing mechanisms that recognize viral proteins, DNA and RNA [also see section B. $2 b$; reviewed in (Paludan et al., 2011)]. For example, viral dsDNA is sensed by 
the cGAS/STING pathway (Ishikawa et al., 2009; Sun et al., 2013; Wu et al., 2013; Zhang et al., 2013) and the PYHIN domain-containing protein IFI16 (Unterholzner et al., 2010; Almine et al., 2017), which induce type I IFN and the expression of proinflammatory cytokines such as CXCL9 and CXCL10. HSV-1 infection also leads to the production of prototypic DAMPs, including the extracellular release of high mobility group protein B1 (HMGB1) and translocation of the ER chaperone calreticulin to the surface of infected cells, which, in conjunction with IFN and cytokines, results in recruitment and activation of NK cells, phagocytic cells and APCs to the site of infection (Obeid et al., 2007; Paolini et al., 2015; Takasu et al., 2016; Muller et al., 2017).

NK cells are innate immune cells recruited to the site of viral infection that are cytotoxic and can produce cytokines without prior antigen stimulation (Orr and Lanier, 2010; Abel et al., 2018). In part, NK cell cytotoxicity is regulated by binding of NK cell activation receptors, such as NKG2D and the natural cytotoxicity receptors (NCRs) NKp30 and NKp46, to various cell surface ligands expressed on target cells (Sauer et al., 2017). Humans express eight NKG2D ligands [ $\mathrm{U}_{\llcorner} 16$ binding proteins (ULBPs) 1 to 6 and MHC class I-related chains $A$ and $B$ (MICA, MICB)] while mice express 5-6 different ligands among the group of RAE-1( $\alpha-\varepsilon), H 60(a-c)$, and MULT1, depending on the mouse strain (Vivier et al., 2002; Abel et al., 2018). Healthy cells express MHC class I and typically do not display NK cell-activating ligands on their surface and are shielded from NK cell-mediated lysis. However, cellular stresses associated with transformation, viral infection or other danger signals to the host cause an up-regulation of NKG2D/NCR ligand expression and NK cell activation. The anti-tumor innate immune response mediated by NK cells can be directly inhibited by tumor-expressed metalloproteinases that cleave NKG2D and NKp30 ligands on the cell surface or by tumor-mediated suppression of the expression of NK cell-activating ligands (Raulet et al., 2013; Schlecker et al., 2014; Pogge von Strandmann et al., 2015). However, these effects may be tempered by oHSV infection, which causes upregulation of NCR ligand expression (Chisholm et al., 2007). In addition, NK cells can eliminate HSVinfected tumor cells by HSV-antibody-dependent cell-mediated cytotoxicity 
(ADCC) involving simultaneous binding of anti-HSV IgG to viral proteins on the tumor cell surface and the Fc receptor CD16a on NK cells (Dai and Caligiuri, 2018). Furthermore, recent evidence suggests that NK cells can recognize and

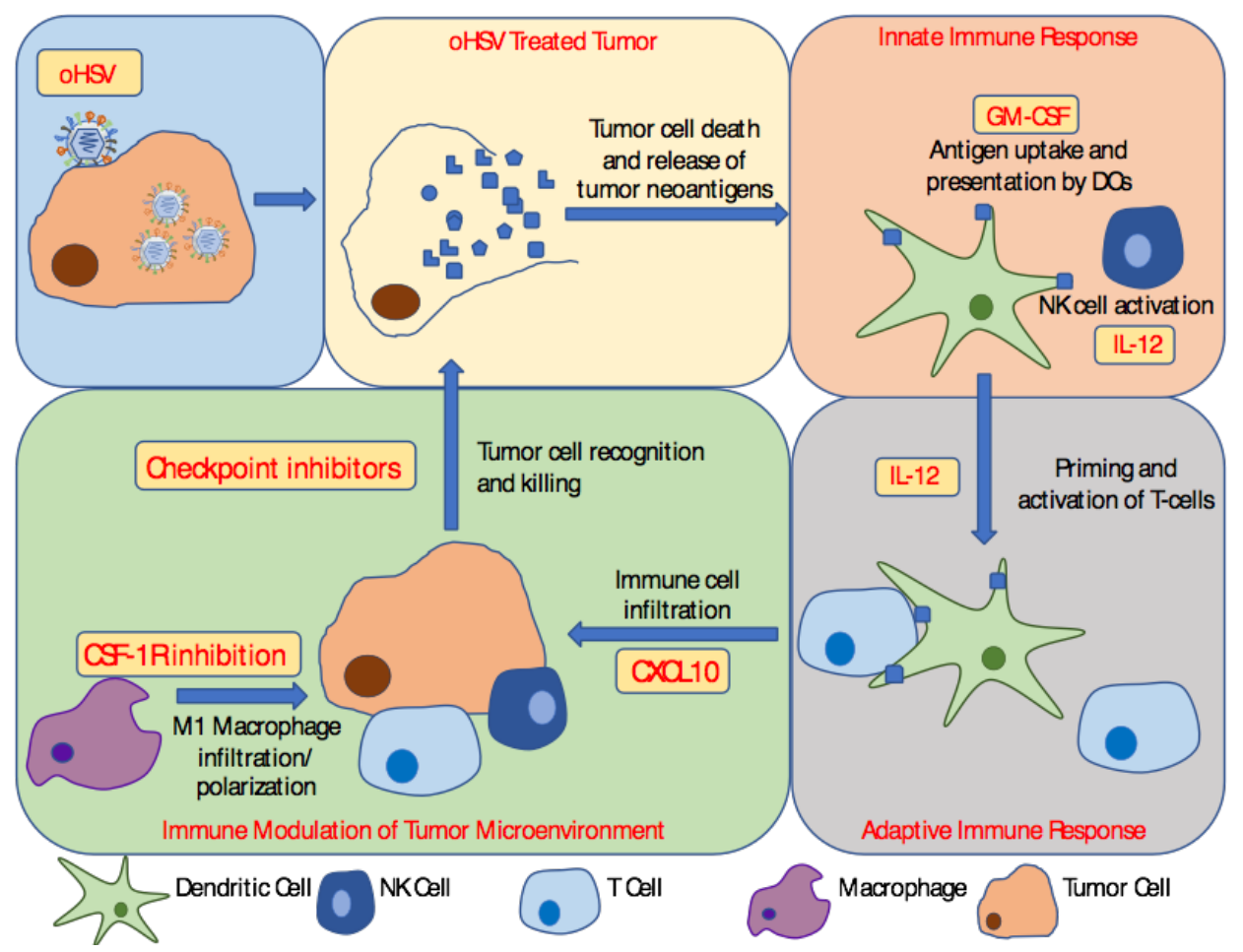

Figure 3. Armed oHSV treatment of GBM. Illustration of the immune response to oHSV infection of GBM tumor cells and examples of arming genes or gene functions (yellow boxes) for oHSV to augment the immune response to tumor antigens. Tumor and immune cell types are depicted at the bottom. Clockwise from the top left, oHSV infection of tumor cells results in virus replication and cell lysis, releasing tumor and viral antigens. Viral infection/cell death elicits an innate immune response, recruiting denditic cells (DCs) and natural killer (NK) cells to the site of infection. The adaptive immune response is stimulated via antigen uptake and presentation by DCs and results in priming and activation of T cells that infiltrate the TME. Tumor infiltration by immune cells results in further tumor cell killing by NK cells, T cells, or macrophages. Arming of oHSV with immune modulatory transgenes can influence different steps of the process: recruitment of DCs (GM-CSF), activation of NK and T cells (IL-12), recruitment of activated immune cells to the tumor (CXCL10), polarization and/or recruitment of pro-inflammatory macrophages (CSF-1R inhibition), and increased tumor cell recognition and killing within the TME (checkpoint inhibitors). 
destroy oHSV-infected GBM in the absence of specific anti-viral antibodies in a process referred to as Fc-bridging cellular cytotoxicity ( $F C B C C$ ) (Dai et al., 2017a; Dai and Caligiuri, 2018). Although NK cells can lead to premature virus clearance in GBM xenograft models (Alvarez-Breckenridge et al., 2012; Alvarez-Breckenridge et al., 2013), the combination of oHSV and NK cells can be exploited to induce tumor cell killing (Chen et al., 2016; Yoo et al., 2016). The outcome of this complex dual role of NK cells in response to virotherapy may be a function of the ratio of effector to target cells in the tumor microenvironment (Kim et al., 2018).

A key feature of oncolytic viral therapies is the capacity to induce both anti-viral and anti-tumor adaptive immune responses (Figure 3). The initial infection of tumor cells by oHSV causes tumor cell virolysis and an innate immune response to virus infection mediated by NK cells and DCs, ultimately creating a pro-inflammatory, antiviral state. Activated NK cells are a primary source of cytokines (e.g., FLT3L) and chemokines (e.g., CCL5) that can recruit and activate cross-presenting cDC1 cells (Barry et al., 2018; Bottcher et al., 2018), which prime an adaptive immune response by activating antigen-specific CD8+ T cells. CDC1 cells, also referred to as conventional type $1 \mathrm{DCs}$, are a subset of migratory DCs that are CD103+ (mice)/CD141+ (human), depend on the basic leucine zipper ATF-like transcription factor 3 (BATF3), and have been identified as key players in the cross presentation of both viral and tumor antigens (Hildner et al., 2008; Schlitzer and Ginhoux, 2014; Schlitzer et al., 2015; Roberts et al., 2016; Dai et al., 2017b). This subset has been associated with enhanced therapeutic responses in animal models (Roberts et al., 2016; Salmon et al., 2016; Spranger et al., 2017; Bottcher et al., 2018), and the prevalence of its gene expression signature in human tumors is positively correlated with T cell infiltration and clinical outcome (Broz et al., 2014; Spranger et al., 2016). Together, these innate and adaptive immune responses to viral infection offer a mechanism to explain how oHSVs can promote the generation of a 'hot' tumor environment and a clinical response in combination with immune checkpoint inhibitors, as observed by Ribas and colleagues (Ribas et al., 2017). 


\section{Immunotherapy and oHSV arming with immune-modulatory genes}

Current immunotherapy approaches fall into two broad categories. In the first, specific antigens are targeted while the second is agnostic in relation to tumor antigens (Kamran et al., 2016). Antigen-targeted therapies such as CAR-T therapy, T-cell receptor (TCR)-transduced T-cell therapy, and peptide/RNA based-vaccine immunotherapy generate $T$ cells recognizing known or predicted tumor antigens or antigens that would not be normally expressed in adult diploid tissue (Coulie et al., 2014). While these strategies may be effective, they require advance knowledge of the tumor antigen, autologous immune cells, complex and individualized manufacturing processes, and are often restricted to a specific MHC haplotype. They also depend on functioning active T cells, and T-cell exhaustion within the TME is an important problem so far limiting the clinical efficacy of these agents to hematological malignancies (Kalos et al., 2011; Grupp et al., 2013; Kamran et al., 2016; Bagley et al., 2018). Conversely, therapies such as checkpoint pathway inhibitors, cytokine gene therapy, and oncolytic viral therapies can counter the immunosuppression created in the TME and enhance T-cell recognition of tumor cells without the knowledge of specific antigens.

Checkpoint inhibition therapies have demonstrated remarkable success in recent years. These therapies block T-cell inhibitory receptors that function to turn off inflammation, in an attempt to maintain CD8+ T-cell anti-tumor activity. The interaction between PD-L1 on tumor cells and PD-1 on T cells results in T cell exhaustion (Zhang et al., 2018), and CTLA-4 binding to B7-1 on antigenpresenting cells (APCs) blocks the expansion of $\mathrm{T}$ cells and interferes with activation of the T-cell co-stimulatory protein CD28 (Chikuma, 2017). Targeting the PD-1/PD-L1 axis and CTLA-4 has received FDA approval in multiple cancer indications (Hargadon et al., 2018). Several factors have been considered in determining whether a patient will be responsive to checkpoint therapy, including expression of PD-L1 on tumor cells and the presence of intra-tumoral CD8+ T cells (Tumeh et al., 2014; Shields et al., 2017; Zhang et al., 2018). In the TME, CD8+ T cells may be tumor-reactive, but exhausted by 
checkpoint ligand-receptor interactions. Blocking of these interactions can lead to CTL reactivation and tumor-cell killing. In addition, increased tumor mutational burden has been linked to response to immunotherapy (Rizvi et al., 2015; Colli et al., 2016; Hellmann et al., 2018). In a first-of-its-kind decision, the FDA approved the anti-PD-1 antibody pembrolizumab (Keytruda) for use in any cancer that is high in microsatellite instability or deficient in mismatch repair, has progressed following prior treatment, and has no suitable alternative treatment options (Prasad et al., 2018). These tumors typically have an extremely high mutation load (Le et al., 2015; Le et al., 2017). While checkpoint inhibitors have mostly failed in brain tumor patients, reported cases of response have included patients with mismatch-repair deficiency (Bouffet et al., 2016). The concepts of immunosuppression, mutational burden, and immune evasion can help explain why a tumor may be immunologically "cold" and refractory to immunotherapy or immunologically "hot", and thereby responsiveness to immunotherapy. Cold tumors typically contain large numbers of immunosuppressive monocytes and few tumor-specific cytotoxic $T$ cells whereas hot tumors are seeded with immunologically active macrophages and lymphocytes.

The promise of OVs turning up the heat in cold tumors and enabling a response to immune checkpoint inhibitors is under evaluation in multiple large clinical studies (Chen et al., 2018; Gujar et al., 2018b). The MASTERKEY-265/ KEYNOTE-034 trial (NCT02263508) is sponsored by Merck Sharp and Dohme Corp. and Amgen, Inc. and will report the outcome of the combination of Keytruda with and without T-VEC/Imlygic in 713 patients with unresected melanoma (Dummer et al., 2017; Ribas et al., 2017; Sun et al., 2018). This combination is also being tested in recurrent metastatic head and neck squamous cell carcinoma (MASTERKEY232/KEYNOTE-137 (NCT02626000), in sarcoma (NCT03069378), and in liver cancer (NCT02509507). T-VEC is also under evaluation in smaller studies in combination with anti-PD-1 antibody nivolumab (Opdivo) in lymphoma and pleural effusion and with anti-PD-L1 antibody atezolizumab (Tecentriq) in triple-negative breast cancer (TNBC) and colorectal cancer (CRC) with liver metastasis. T-VEC in combination with 
ipilimumab (Yervoy) displayed slightly improved efficacy over T-VEC or ipilimumab monotherapies for stage II-IV melanoma (Puzanov et al., 2016). HF10 in combination with nivolumab is being tested in the neoadjuvant setting in resectable melanoma (NCT03259425).

Preclinically, many groups are actively engaged in establishing the potential benefit of adding checkpoint blockade to HSV therapy for GBM because checkpoint inhibition monotherapies have provided convincing evidence of increased survival and immune activation in GBM mouse models (Reardon et al., 2016; Garg et al., 2017; Garzon-Muvdi et al., 2018; Hung et al., 2018). In two different syngeneic models of murine glioma, using G47 $\Delta$ expressing murine IL-12 (G47D-mIL12) in combination with anti-PD-1 and anti-CTLA-4 antibody administration, long term survival was only observed in mice that received the triple combination therapy for CT-2A tumors (50\% long-term survival) or glioblastoma stem cell line-derived tumors (89\% long-term survival) (Saha et al., 2017b). In this model, CD4+ T cells, CD8+ $T$ cells and macrophages were required for the efficacy of the triple combination therapy. Additionally, triple combination therapy resulted in an influx of pro-inflammatory and anti-tumor M1-polarized macrophages (Saha et al., 2017b). While clinically little therapeutic benefit was afforded by anti-PD-1 monotherapy or the combination of PD-1 and CLTLA4 blockade for GBM (Filley et al., 2017; Omuro et al., 2018), these preclinical data suggest that a greater benefit may be provided by a combination of intratumoral injection of oHSV and systemic treatment with anti-checkpoint monoclonal antibody.

Alternative checkpoint pathways exist that can also be targeted for antibodymediated inhibition to help maintain CD8+ T-cell anti-tumor activity (Anderson et al., 2016). These include (i) LAG-3 (lymphocyte activation gene 3 ) on T cells and NK cells that can inhibit T cell expansion (He et al., 2016), (ii) TIGIT (T cell immunoreceptor with Ig and ITIM domains) on T cells and NK cells that can bind CD155 [PVR (poliovirus receptor) or necl-5] and CD112 (nectin-2) to suppress immune activation (Solomon and Garrido-Laguna, 2018), and (iii) TIM-3 (T cell immunoglobulin and mucin domain 3 ) on multiple immune cell 
types that can trigger $\mathrm{T}$ cell and NK cell exhaustion and immune suppression through different pathways involving DCs, MDSCs and Tregs (He et al., 2018). Tim-3, TIGIT and Lag-3 expression have been associated with glioblastoma in mouse tumor models or in human tumor samples (Li et al., 2017; HarrisBookman et al., 2018; Hung et al., 2018), and preclinical studies in a GL261 mouse model of GBM demonstrated that combining PD-1 and TIGIT checkpoint blockade resulted in improved survival over each monotherapy (Hung et al., 2018). Future studies will likely engage antibodies that antagonize these interactions in combination with oHSV therapy. While systemic use of anti-checkpoint antibodies could provoke autoimmunity, vector-mediated local expression of antibodies will likely be effective and minimize potential side effects. Attempts are currently underway to locally deliver an anti-PD1 singlechain variable fragment antibody (scFv) by expression from an oHSV (oHSVscFvPD-1). In early reports, oHSVscFvPD-1 was able to express the scFv in multiple glioma models and delayed tumor growth in mice bearing orthotopic gliomas (Passaro et al., 2018). Other efforts in this direction include the exploitation of PTEN to block oHSV infection-induced upregulation of PDL1 expression on tumor cells to augment anti-tumor immunotherapy in conjunction with oncolysis (Russell et al., 2018). As described above, the effectiveness of checkpoint inhibitors relies on the reactivation of CD8+ T cells that recognize tumor antigens but are exhausted by checkpoint ligand-receptor interactions. In the event that these cells are not available or the number of TAAs is limited, the use of oHSV to stimulate a T-cell response to tumor antigens could potentiate the effect of checkpoint antibodies, whether delivered systemically or as oHSV cargo.

When considering potential targets within the TME for further oHSV vector arming (Figure 3), it is important to recognize that the composition of the TME differs between tumor types such that arming strategies will likely require typespecific optimization. The immune stimulatory cytokine IL-12 plays an important role in activating both adaptive (NK cell) and acquired ( $T$ cell) immune responses and, as already referred to, IL-12-expressing oHSV alone or in combination with other therapies has delivered promising results in 
preclinical studies (Toda et al., 1998; Parker et al., 2000; Chiu et al., 2012; Cody et al., 2012; Markert et al., 2012; Cheema et al., 2013; Roth et al., 2014; Thaci et al., 2014; Bauer et al., 2016; Patel et al., 2016; Ring et al., 2017; Saha et al., 2017a; Friedman et al., 2018; Leoni et al., 2018b), including an increase of pro-inflammatory M1-polarized macrophages. Multiple studies have highlighted the immunosuppressive and tumor-supportive activities of M2-like macrophages as opposed to the anti-tumor activities of M1-like macrophages and their association with poor and improved prognosis, respectively (Lisi et al., 2017; Saha et al., 2017b; van den Bossche et al., 2018). In GBM, tumor associated macrophages, in addition to CNS-resident microglia, are particularly prevalent, representing more than half of the cell content (Darmanis et al., 2017). Macrophages in GBM express transcripts that are associated with both M1 and M2 phenotypes, suggestive of a wound healing and tolerogenic program (Bowman et al., 2016; Takenaka et al., 2019). The chemokine CCL2, through its receptor CCR2, and the growth factor CSF-1 via binding to the macrophage CSF-1 receptor (CSF-1R), are thought to play major roles in macrophage recruitment and maintenance, respectively. Small-molecule inhibitors as well as monoclonal antibodies are under development to block these interactions [reviewed in (Ries et al., 2015)]. In a mouse GBM model, the small molecule CCR2 inhibitor CCX872 reduced myeloid cells recruitment and enhanced the survival benefit of a PD-1 inhibitor antibody (Flores-Toro et al., 2020). CSF-1R inhibition using the receptor tyrosine kinase inhibitor BLZ945 counteracted M2 polarization while increasing phagocytosis, consistent with macrophage/microglia "re-education" (Pyonteck et al., 2013) (Figure 3). Unfortunately, IGF1-driven activation of the PI3K pathway led to resistance to CSF-1R inhibitor and the evaluation of this pathway in the clinic using PLX3397 (NCT01349036) did not yield a significant therapeutic benefit despite reaching pharmacologically active CNS concentration (Butowski et al., 2016; Quail et al., 2016). The investigation of BLZ945 is ongoing in solid tumors in combination with spartalizumab, Novartis' anti-PD-1 antibody (NCT02829723). Expression of indoleamine-2,3-dioxygenase (IDO) in the myeloid cell line THP-1 promotes adoption of the immunosuppressive M2 phenotype (Wang et al., 2014). oHSV infection can downregulate IDO synthesis in IFNy-treated 
glioma cells (Reinhart et al., 2012), raising the possibility that it can promote macrophage M2-to-M1 repolarization. The failure of the IDO1 inhibitor epacadostat to show a benefit in combination with pembrolizumab in the ECHO301/Keynote 252 randomized phase III melanoma trial led to a global demise of the investigation of this axis (Long et al., 2019). Although the CSF-1 and IDO axes may represent viable targets for combining with oHSV to repolarize M2 macrophages to an M1-like tumoricidal phenotype, clearly other therapeutic approaches are warranted in light of the lackluster activity of the drugs targeting these pathways.

Recently, the publication of an armed HSV-1 highlighted the potential for the KLRK1 ligand ULBP3 to modulate tumor associated macrophages and prolong survival in a genetically engineered model of glioblastoma (Wirsching et al., 2019b). oHSV expressing ULBP3, but not the empty oHSV, stimulated abscopal activity in a dual GBM tumor model and its activity was enhanced by the administration of a PD-1 antagonist antibody. Surprisingly, while the cognate receptor for ULBP3 is not expressed in myeloid cells and ULBP3 has no mouse ortholog, oHSV-ULBP3 upregulated pathways linked to antigen processing and presentation in tumor myeloid cells. Although much remains to be understood regarding the mode of action of oHSV-ULBP3, this data suggest a different route for macrophage modulation.

In addition to tumor associated macrophages, the immunosuppressive TME is supported by myeloid-derived suppressor cells (MDSCs) (Ostrand-Rosenberg and Sinha, 2009; Youn and Gabrilovich, 2010), a poorly defined myeloid population in humans, which have been shown to suppress anti-tumor immunity while stimulating tumor growth, angiogenesis and metastasis (Kohanbash and Okada, 2012; Gabrilovich, 2017). In mice, MDSCs are defined as a diverse population of $\mathrm{CD} 11 \mathrm{~b}+/ \mathrm{Gr} 1+$ immature myeloid cells that include precursors of granulocytes, macrophages and dendritic cells (Fujita et al., 2011; Zhu et al., 2011). MDSC-mediated immunosuppression involves the production of IL-10 and IL-4 (Kohanbash et al., 2013), which promotes M2 macrophage polarization and inhibits interferon production. MDSC, through 
high expression of arginase, may lead to the local depletion of arginine, an essential amino acid for T-cell activation and proliferation (Lisi et al., 2017). Additionally, MDSCs can inhibit anti-tumor immunity through production of iNOS, reactive oxygen species, and TGF $\beta$, and can recruit M2 macrophages through the secretion of chemokines that act via CCR2 (Chang et al., 2016; Kamran et al., 2018). Three primary ways can be considered to target human MDSCs: (i) depletion by antibodies targeting MDSC, (ii) maturing the cells to an M1 macrophage phenotype, and (iii) targeting the specific immunosuppressive pathways, such as arginase activity. Antibody-mediated depletion of MDSCs is effective in mice (Fujita et al., 2011), although as yet not fully specific (Kamran et al., 2018). However, so far no antibodies have been described for selective human MDSC depletion as the definition of human MDSC remains unsettled (Elliott et al., 2017). It is unclear which of these strategies may ultimately provide the most therapeutic value but each may potentially be accomplished through the selection of suitable oHSV-arming genes (Kamran et al., 2017; Lowenstein and Castro, 2018).

oHSV infection must recruit APCs to traffic tumor antigens to regional lymph nodes where they may be presented by DCs for T-cell activation (AlvarezBreckenridge et al., 2015; Roberts et al., 2016). Therefore, arming vectors with cytokines/chemokines such as FLT3L, XCL1 or CXCL10 could enhance APC recruitment (Figure 3) while inhibition of CD47, a "don't-eat-me" protein expressed on various tumor cells, may improve antigen presentation (Chao et al., 2011; Willingham et al., 2012; Wang et al., 2013; Cioffi et al., 2015). Toll-like receptor agonists may be useful as direct tumor immune-therapeutics and can act as adjuvants for T-cell activation (Kaczanowska et al., 2013; Sato-Kaneko et al., 2017). The large payload capacity of some oHSVs (Mazzacurati et al., 2015), approximately $25 \mathrm{~kb}$, allows combinations of arming genes to be introduced into a single vector, but the most effective combinations have yet to be determined. Replimune, Inc., a company funded by the T-VEC developers, is leading the way with the progression in clinical trials of a first oHSV expressing the fusogenic protein GALV (Fu et al., 2003; Price et al., 2010; 
Thomas et al., 2019), in addition to GM-CSF, and a second oHSV candidate in addition expressing a CTLA-4 antagonist antibody.

\section{GBM models for armed oHSV evaluation}

The initial studies of oncolytic vectors employed orthotopic implantation of various genetically distinct human tumor cell lines in immune-deficient mice. While appropriate for the evaluation of oncolytic activity, the lack of an adaptive immune response in these mice does not allow for an assessment of the impact of the immune system on both virus replication and tumor cell destruction. Preclinical studies of the ability of armed oHSVs to induce antitumor immunity are essential for success in treatment of highly aggressive GBM and necessitate the use of immunocompetent model systems. To achieve this goal, models have been established using murine cells implanted in syngeneic backgrounds [reviewed by (Oh et al., 2014)]. For example, models of GBM have been created by intracranial injection of murine glioma tumor cell lines grown in vitro and by using genetic systems where tumors arise locally from neuronal precursor cells within the brain parenchyma.

The simplest model systems rely on the injection of well-characterized murine tumor cell lines. The CT-2A cell line was derived by chemical mutagenesis and has been shown to consistently form heterogenous, invasive tumors that demonstrate multiple characteristics of GBM in the C57BL/6 mouse strain background. The GL261 model, widely used in preclinical testing of GBM therapeutics, is another C57BL/6-based, chemically induced model of GBM that is more immunogenic than most human GBM. GL261 lacks MHC class II molecules while displaying low levels of B7-1 and B7-2, and is sensitive to radiotherapy and to immune checkpoint inhibitor treatment (Szatmari et al., 2006; Wu et al., 2016). More recently, a glioma stem cell (GSC)-based model was developed by Inder Verma (Salk Institute, San Diego) and co-authors from GBM tumors induced by Cre-mediated expression of activated $\mathrm{H}$-Ras and Akt into the stem cell niche of GFAP-Cre Tp53+/- immunocompetent C57BL/6 mice (Marumoto et al., 2009). This model possesses such characteristics of GBM as 
invasiveness and genetic heterogeneity as well as an immunosuppressive TME and moderate response to G47A-IL-12 oHSV (Cheema et al., 2013).

One genetic model system, developed by Eric Holland (Fred Hutchinson Cancer Research Center), uses an HSV-permissive transgenic mouse strain with genotype N/t-va;Ink4A/Arf-/-;PTENfl/fl that forms brain tumors on intracranial administration of a pair of engineered avian retroviruses (RCAS) expressing Cre recombinase and PDGF B-chain, respectively. The mice express the RCAS receptor (TVA) from the nestin promoter, which restricts Cre and PDGFB expression to neuronal precursor cells. Cre expression results in deletion of the loxP-flanked ("floxed", fl/fl) PTEN tumor-suppressor gene, and the resulting tumors resemble the proneural variant of glioblastoma with few, if any, $T$ cells. In mice with a N/t-va;Ink4A/Arf-/-;PTENf//fl;LSL-EGFRvIII//vIII background, Cre expression additionally induces EGFRvIll expression by removal of a transcription termination element (lox-stop-lox, LSL) between the promoter and coding sequence. EGFRvIll leads to a more classical or mesenchymal phenotype that includes the presence of a few $T$ cells primarily in the perivascular region. Both models give rise to rapidly developing, predominantly mono-focal murine GBM with a TME that closely resembles that in human patients. Tumors arising in these models mimic many other aspects of human GBM, including tumor invasion of the brain parenchyma. This and similar systems with varying genetic mutations have been used to model GBM for oncolytic-vector and other therapeutic treatments (Huse and Holland, 2009, 2010; Pyonteck et al., 2013; Quail et al., 2016).

Another genetic model system that has been utilized to study gliomas, including GBM, is the Sleeping Beauty (SB) glioma model (Wiesner et al., 2009). In this model, neonatal mice receive intracerebroventricular injections of an SB transposase together with SB-compatible vectors containing gliomarelevant oncogenes of the investigator preference, such as EGFRvIII, NRAS(V12), PDGFB, shP53 and many others. In time following the injection, the animals develop tumors and, depending on the gene combination and site of injection, different glioma types can be generated. Additionally, a SB- 
compatible luciferase vector can be included to allow for non-invasive bioluminescence imaging. The benefits of this model are that it is compatible with any strain or background of mice, and that cell lines can be derived from resulting tumors to create genetically relevant cell-line injection models (Fujita et al., 2010; Fujita et al., 2011; Kohanbash et al., 2013). The pathobiology of the tumors arising in these models is highly reminiscent of human GBM, with a high frequency of Iba- $1^{+}$myeloid cells and a low frequency of TILs (Wirsching et al., 2019a).

These models of GBM have all been used to characterize the efficacy of either armed or unarmed oHSV vectors, and comparisons among these models will hopefully shed light on the ability of oHSV to alter the TME in ways to promote an anti-tumor immune environment that can also contribute to the prevention of secondary tumor formation.

\section{E. Conclusions and future directions}

HSV has several important attributes that make it a desirable oncolytic vector, including broad tumor cell permissivity, the ability to engineer variants that specifically lyse tumors and a large transgene capacity that allows for in situ delivery of multiple payload products by a single vector. With the approval of Imlygic $^{\circledR}$ (T-VEC) in the US for the treatment of malignant melanoma, oHSVs are gaining prominence as an addition to standard-of-care, i.e., current clinical protocols including immune therapy and radiation therapy of cancer (Harrington et al., 2010; Andtbacka et al., 2015; Pol et al., 2016; Blake et al., 2018). Combined with checkpoint inhibitors, further improvement of tumor treatment outcome may be achieved, a result pending the completion of phase 3 randomized clinical trails such as Keynote034/Masterkey265. A current focus in the development of oHSVs for the treatment of solid tumors is to demonstrate that arming genes expressed from a lytic vector can overcome immunosuppression and enhance innate and adaptive anti-tumor immunity. Ultimately, the aim is to identify the most effective genes and combinations that create a potent immunostimulatory OV vector. By combining virus-mediated tumor destruction with the activities of specific arming-gene products, oHSVs 
have considerable potential to create tumor vaccines that rely on the ability of the immune system to reject tumors. Ideally, payloads that are tailored to the TME of specific tumors should be developed. At present, several clinical trials are investigating the TME in biopsy material by RNA or proteomics profiling prior to treatment. This information could be very important for selection of arming genes.

Increasing preclinical evidence suggests that armed oHSVs can not only promote the conversion of a tumor-supportive environment in the injected primary tumor to a tumor-hostile environment, but can also bring about rejection of untreated secondary distal or visceral tumors in what has been termed an abscopal effect, the essence of an effective tumor vaccine. While much remains to be learned about the timing, reach and potency of these effects, they raise hope for the treatment of metastatic disease. As an additional strategy to attack metastatic tumor foci, there is also increasing interest in the development of oncolytic vectors for systemic application. These vectors would be (i) engineered for selective infection and replication in tumor cells and (ii) antigenically "stealthed" and thus resistant to neutralization by pre-existing or acquired virus-neutralizing antibodies. As described above, oHSV vectors have been developed that are uniquely retargeted to tumorassociated cell surface markers for attachment and entry in combination with miRNA-dependent attenuation to block virus replication in off-target tissue. While these "retargeted" oHSVs can home in on tumors bearing the target receptor in immune-compromised mice (Uchida et al., 2013), a large fraction of the human population is HSV-seropositive, and systemic treatment of metastatic cancer with even tumor-targeted oHSV will likely be impaired in these patients. Thus, another important future goal is to create retargeted oHSVs that are concealed from pre-existing immunity. Successful development of this novel class of oHSVs would represent a next-generation OV applicable to the systemic treatment of metastatic cancer. 


\section{F. Acknowledgements}

Studies in laboratories 1-6 were supported in part by NIH grant P01 CA163205 (MAC/EAC, co-PIs). Additional support for the JCG lab and collaborators (GK, NA, ECH) was provided by NIH R01 grants CA222804 and CA175052 to JCG. The JCG lab is also funded by a grant from the Alliance for Cancer Gene Therapy (ACGT).

\section{G. Web resources}

1. http://www.abta.org/about-us/news/brain-tumor-statistics/

2. https://clinicaltrials.gov/

\section{H. References}

Abel, A.M., Yang, C., Thakar, M.S., and Malarkannan, S. (2018). Natural Killer Cells: Development, Maturation, and Clinical Utilization. Front Immunol 9, 1869. http://dx.doi.org/10.3389/fimmu.2018.01869.

Advani, S.J., Sibley, G.S., Song, P.Y., Hallahan, D.E., Kataoka, Y., Roizman, B., and Weichselbaum, R.R. (1998). Enhancement of replication of genetically engineered herpes simplex viruses by ionizing radiation: a new paradigm for destruction of therapeutically intractable tumors. Gene Ther 5, 160-165. https://www.ncbi.nlm.nih.gov/pubmed/9578834

Aghi, M., Visted, T., Depinho, R.A., and Chiocca, E.A. (2008). Oncolytic herpes virus with defective ICP6 specifically replicates in quiescent cells with homozygous genetic mutations in p16. Oncogene 27, 4249-4254. http:// dx.doi.org/10.1038/onc.2008.53.

Alain, T., Lun, X., Martineau, Y., Sean, P., Pulendran, B., Petroulakis, E., Zemp, F.J., Lemay, C.G., Roy, D., Bell, J.C., et al. (2010). Vesicular stomatitis virus oncolysis is potentiated by impairing mTORC1-dependent type I IFN production. Proc Natl Acad Sci U S A 107, 1576-1581. https:// www.ncbi.nlm.nih.gov/pubmed/20080710

Almine, J.F., O'Hare, C.A., Dunphy, G., Haga, I.R., Naik, R.J., Atrih, A., Connolly, D.J., Taylor, J., Kelsall, I.R., Bowie, A.G., et al. (2017). IFI16 and cGAS cooperate in the activation of STING during DNA sensing in human 
keratinocytes. Nat Commun 8, 14392. http://dx.doi.org/10.1038/ ncomms14392.

Alvarez-Breckenridge, C.A., Choi, B.D., Suryadevara, C.M., and Chiocca, E.A. (2015). Potentiating oncolytic viral therapy through an understanding of the initial immune responses to oncolytic viral infection. Curr Opin Virol 13, 25-32. https://www.ncbi.nlm.nih.gov/pubmed/25846988

Alvarez-Breckenridge, C.A., Yu, J., Caligiuri, M.A., and Chiocca, E.A. (2013). Uncovering a novel mechanism whereby NK cells interfere with glioblastoma virotherapy. Oncolmmunology 2, e23658. https://doi.org/10.4161/onci.23658

Alvarez-Breckenridge, C.A., Yu, J., Price, R., Wojton, J., Pradarelli, J., Mao, H., Wei, M., Wang, Y., He, S., Hardcastle, J., et al. (2012). NK cells impede glioblastoma virotherapy through NKp30 and NKp46 natural cytotoxicity receptors. Nat Med 18, 1827-1834. https://www.ncbi.nlm.nih.gov/pubmed/ 23178246

Anderson, A.C., Joller, N., and Kuchroo, V.K. (2016). Lag-3, Tim-3, and TIGIT: Co-inhibitory Receptors with Specialized Functions in Immune Regulation. Immunity 44, 989-1004. http://dx.doi.org/10.1016/j.immuni.2016.05.001.

Andreansky, S., He, B., van Cott, J., McGhee, J., Markert, J.M., Gillespie, G.Y., Roizman, B., and Whitley, R.J. (1998). Treatment of intracranial gliomas in immunocompetent mice using herpes simplex viruses that express murine interleukins. Gene Ther 5, 121-130. https://www.ncbi.nlm.nih.gov/pubmed/ 9536273

Andtbacka, R.H., Kaufman, H.L., Collichio, F., Amatruda, T., Senzer, N., Chesney, J., Delman, K.A., Spitler, L.E., Puzanov, I., Agarwala, S.S., et al. (2015). Talimogene Laherparepvec Improves Durable Response Rate in Patients With Advanced Melanoma. J Clin Oncol 33, 2780-2788. https:// www.ncbi.nIm.nih.gov/pubmed/26014293

Andtbacka, R.H.I., Collichio, F., Harrington, K.J., Middleton, M.R., Downey, G., hrling, K., and Kaufman, H.L. (2019). Final analyses of OPTiM: a randomized phase III trial of talimogene laherparepvec versus granulocyte-macrophage colony-stimulating factor in unresectable stage III-IV melanoma. J Immunother Cancer 7, 145. https://www.ncbi.nlm.nih.gov/pubmed/31171039 
Andtbacka, R.H.I., Ross, M.I., Agarwala, S.S., Taylor, M.H., Vetto, J.T., Neves, R.I., Daud, A., Khong, H.T., Ungerleider, R.S., and Tanaka, M. (2018). Efficacy and genetic analysis for a phase II multicenter trial of HF10, a replication-competent HSV-1 oncolytic immunotherapy, and ipilimumab combination treatment in patients with stage IIlb-IV unresectable or metastatic melanoma. J Clin Oncol 36, 9541-9541. http://ascopubs.org/doi/ abs/10.1200/JCO.2018.36.15_suppl.9541

Argnani, R., Boccafogli, L., Marconi, P.C., and Manservigi, R. (2004). Specific targeted binding of herpes simplex virus type 1 to hepatocytes via the human hepatitis B virus preS1 peptide. Gene Ther 11, 1087-1098. https:// www.ncbi.nlm.nih.gov/pubmed/15057264

Arii, J., Goto, H., Suenaga, T., Oyama, M., Kozuka-Hata, H., Imai, T., Minowa, A., Akashi, H., Arase, H., Kawaoka, Y., et al. (2010). Non-muscle myosin IIA is a functional entry receptor for herpes simplex virus-1. Nature 467, 859-862. https://www.ncbi.nlm.nih.gov/pubmed/20944748

Arii, J., Hirohata, Y., Kato, A., and Kawaguchi, Y. (2015). Nonmuscle myosin heavy chain Ilb mediates herpes simplex virus 1 entry. J Virol 89, 1879-1888. https://www.ncbi.nlm.nih.gov/pubmed/25428876

Atanasiu, D., Saw, W.T., Cohen, G.H., and Eisenberg, R.J. (2010). Cascade of events governing cell-cell fusion induced by herpes simplex virus glycoproteins gD, gH/gL, and gB. J Virol 84, 12292-12299. https:// www.ncbi.nlm.nih.gov/pubmed/20861251

Baek, H., Uchida, H., Jun, K., Kim, J.H., Kuroki, M., Cohen, J.B., Glorioso, J.C., and Kwon, H. (2011). Bispecific adapter-mediated retargeting of a receptor-restricted HSV-1 vector to CEA-bearing tumor cells. Mol Ther 19, 507-514. https://www.ncbi.nlm.nih.gov/pubmed/20924362

Bagley, S.J., Desai, A.S., Linette, G.P., June, C.H., and O'Rourke, D.M. (2018). CAR T-cell therapy for glioblastoma: recent clinical advances and future challenges. Neuro Oncol 20, 1429-1438. http://dx.doi.org/10.1093/neuonc/ noy032.

Barry, K.C., Hsu, J., Broz, M.L., Cueto, F.J., Binnewies, M., Combes, A.J., Nelson, A.E., Loo, K., Kumar, R., Rosenblum, M.D., et al. (2018). A natural killer-dendritic cell axis defines checkpoint therapy-responsive tumor 
microenvironments. Nat Med 24, 1178-1191. https://www.ncbi.nlm.nih.gov/ pubmed/29942093

Bauer, D.F., Pereboeva, L., Gillespie, G.Y., Cloud, G.A., Elzafarany, O., Langford, C., Markert, J.M., and Lamb, L.S., Jr. (2016). Effect of HSV-IL12 Loaded Tumor Cell-Based Vaccination in a Mouse Model of High-Grade Neuroblastoma. J Immunol Res 2016, 2568125. https://www.ncbi.nlm.nih.gov/pubmed/27610392

Blake, Z., Marks, D.K., Gartrell, R.D., Hart, T., Horton, P., Cheng, S.K., Taback, B., Horst, B.A., and Saenger, Y.M. (2018). Complete intracranial response to talimogene laherparepvec (T-Vec), pembrolizumab and whole brain radiotherapy in a patient with melanoma brain metastases refractory to dual checkpointinhibition. J Immunother Cancer 6, 25. https://www.ncbi.nlm.nih.gov/pubmed/ 29622046

Blank, S.V., Rubin, S.C., Coukos, G., Amin, K.M., Albelda, S.M., and MolnarKimber, K.L. (2002). Replication-selective herpes simplex virus type 1 mutant therapy of cervical cancer is enhanced by low-dose radiation. Hum Gene Ther 13, 627-639. https://www.ncbi.nlm.nih.gov/pubmed/11916486

Blumenthal, D.T., Gorlia, T., Gilbert, M.R., Kim, M.M., Burt Nabors, L., Mason, W.P., Hegi, M.E., Zhang, P., Golfinopoulos, V., Perry, J.R., et al. (2017). Is more better? The impact of extended adjuvant temozolomide in newly diagnosed glioblastoma: a secondary analysis of EORTC and NRG Oncology/RTOG. Neuro Oncol 19, 1119-1126. https://www.ncbi.nlm.nih.gov/ pubmed/28371907

Bommareddy, P.K., Shettigar, M., and Kaufman, H.L. (2018). Integrating oncolytic viruses in combination cancer immunotherapy. Nat Rev Immunol 18, 498-513. https://www.ncbi.nlm.nih.gov/pubmed/29743717

Bottcher, J.P., Bonavita, E., Chakravarty, P., Blees, H., Cabeza-Cabrerizo, M., Sammicheli, S., Rogers, N.C., Sahai, E., Zelenay, S., and Reis e Sousa, C. (2018). NK Cells Stimulate Recruitment of cDC1 into the Tumor Microenvironment Promoting Cancer Immune Control. Cell 172, 1022-1037 e1014. https://www.ncbi.nlm.nih.gov/pubmed/29429633

Bouffet, E., Larouche, V., Campbell, B.B., Merico, D., de Borja, R., Aronson, M., Durno, C., Krueger, J., Cabric, V., Ramaswamy, V., et al. (2016). Immune Checkpoint Inhibition for Hypermutant Glioblastoma Multiforme Resulting 
From Germline Biallelic Mismatch Repair Deficiency. J Clin Oncol 34, 2206-2211. https://www.ncbi.nlm.nih.gov/pubmed/27001570

Boviatsis, E.J., Park, J.S., Sena-Esteves, M., Kramm, C.M., Chase, M., Efird, J.T., Wei, M.X., Breakefield, X.O., and Chiocca, E.A. (1994). Long-term survival of rats harboring brain neoplasms treated with ganciclovir and a herpes simplex virus vector that retains an intact thymidine kinase gene. Cancer Res 54, 5745-5751. https://www.ncbi.nlm.nih.gov/pubmed/7954393

Bowman, R.L., Klemm, F., Akkari, L., Pyonteck, S.M., Sevenich, L., Quail, D.F., Dhara, S., Simpson, K., Gardner, E.E., lacobuzio-Donahue, C.A., et al. (2016). Macrophage Ontogeny Underlies Differences in Tumor-Specific Education in Brain Malignancies. Cell Rep 17, 2445-2459. https:// www.ncbi.nlm.nih.gov/pubmed/27840052

Bradley, J.D., Kataoka, Y., Advani, S., Chung, S.M., Arani, R.B., Gillespie, G.Y., Whitley, R.J., Markert, J.M., Roizman, B., and Weichselbaum, R.R. (1999). lonizing radiation improves survival in mice bearing intracranial high-grade gliomas injected with genetically modified herpes simplex virus. Clin Cancer Res 5, 1517-1522. https://www.ncbi.nlm.nih.gov/pubmed/10389941

Broz, M.L., Binnewies, M., Boldajipour, B., Nelson, A.E., Pollack, J.L., Erle, D.J., Barczak, A., Rosenblum, M.D., Daud, A., Barber, D.L., et al. (2014). Dissecting the Tumor Myeloid Compartment Reveals Rare Activating Antigen-Presenting Cells Critical for T Cell Immunity. Cancer Cell 26, 938. http://dx.doi.org/10.1016/j.ccell.2014.11.010.

Butowski, N., Colman, H., De Groot, J.F., Omuro, A.M., Nayak, L., Wen, P.Y., Cloughesy, T.F., Marimuthu, A., Haidar, S., Perry, A., et al. (2016). Orally administered colony stimulating factor 1 receptor inhibitor PLX3397 in recurrent glioblastoma: an Ivy Foundation Early Phase Clinical Trials Consortium phase II study. Neuro Oncol 18, 557-564. https:// www.ncbi.nlm.nih.gov/pubmed/26449250

Cairns, T.M., Huang, Z.Y., Gallagher, J.R., Lin, Y., Lou, H., Whitbeck, J.C., Wald, A., Cohen, G.H., and Eisenberg, R.J. (2015). Patient-Specific Neutralizing Antibody Responses to Herpes Simplex Virus Are Attributed to Epitopes on gD, gB, or Both and Can Be Type Specific. J Virol 89, 9213-9231. http://dx.doi.org/10.1128/jvi.01213-15. 
Campadelli-Fiume, G., Petrovic, B., Leoni, V., Gianni, T., Avitabile, E., Casiraghi, C., and Gatta, V. (2016). Retargeting Strategies for Oncolytic Herpes Simplex Viruses. Viruses 8, 63. https://www.ncbi.nlm.nih.gov/ pubmed/26927159

Cao, H., Zhang, G.R., and Geller, A.I. (2010). Antibody-mediated targeted gene transfer to NMDA NR1-containing neurons in rat neocortex by helper virus-free HSV-1 vector particles containing a chimeric HSV-1 glycoprotein Cstaphylococcus A protein. Brain Res 1351, 1-12. https://www.ncbi.nlm.nih.gov/ pubmed/20599821

Carfi, A., Willis, S.H., Whitbeck, J.C., Krummenacher, C., Cohen, G.H., Eisenberg, R.J., and Wiley, D.C. (2001). Herpes simplex virus glycoprotein D bound to the human receptor HveA. Mol Cell 8, 169-179. https:// www.ncbi.nlm.nih.gov/pubmed/11511370

Cassady, K.A., Bauer, D.F., Roth, J., Chambers, M.R., Shoeb, T., Coleman, J., Prichard, M., Gillespie, G.Y., and Markert, J.M. (2017). Pre-clinical Assessment of C134, a Chimeric Oncolytic Herpes Simplex Virus, in Mice and Non-human Primates. Mol Ther Oncolytics 5, 1-10. https:// www.ncbi.nlm.nih.gov/pubmed/28345027

Cassady, K.A., Gross, M., and Roizman, B. (1998). The herpes simplex virus US11 protein effectively compensates for the gamma1(34.5) gene if present before activation of protein kinase $\mathrm{R}$ by precluding its phosphorylation and that of the alpha subunit of eukaryotic translation initiation factor 2. J Virol 72, 8620-8626. https://www.ncbi.nlm.nih.gov/pubmed/9765401

Chahlavi, A., Todo, T., Martuza, R.L., and Rabkin, S.D. (1999). Replicationcompetent herpes simplex virus vector G207 and cisplatin combination therapy for head and neck squamous cell carcinoma. Neoplasia 1, 162-169. https://www.ncbi.nlm.nih.gov/pubmed/10933051

Chaichana, K.L., Cabrera-Aldana, E.E., Jusue-Torres, I., Wijesekera, O., Olivi, A., Rahman, M., and Quinones-Hinojosa, A. (2014). When gross total resection of a glioblastoma is possible, how much resection should be achieved? World Neurosurg 82, e257-265. http://dx.doi.org/10.1016/j.wneu. 2014.01.019. 
Chang, A.L., Miska, J., Wainwright, D.A., Dey, M., Rivetta, C.V., Yu, D., Kanojia, D., Pituch, K.C., Qiao, J., Pytel, P., et al. (2016). CCL2 Produced by the Glioma Microenvironment Is Essential for the Recruitment of Regulatory T Cells and Myeloid-Derived Suppressor Cells. Cancer Res 76, 5671-5682. https://www.ncbi.nlm.nih.gov/pubmed/27530322

Chao, M.P., Alizadeh, A.A., Tang, C., Jan, M., Weissman-Tsukamoto, R., Zhao, F., Park, C.Y., Weissman, I.L., and Majeti, R. (2011). Therapeutic antibody targeting of CD47 eliminates human acute lymphoblastic leukemia. Cancer Res 71, 1374-1384. https://www.ncbi.nlm.nih.gov/pubmed/21177380

Chase, M., Chung, R.Y., and Chiocca, E.A. (1998). An oncolytic viral mutant that delivers the CYP2B1 transgene and augments cyclophosphamide chemotherapy. Nat Biotechnol 16, 444-448. https://www.ncbi.nlm.nih.gov/ pubmed/9592392

Cheema, T.A., Wakimoto, H., Fecci, P.E., Ning, J., Kuroda, T., Jeyaretna, D.S., Martuza, R.L., and Rabkin, S.D. (2013). Multifaceted oncolytic virus therapy for glioblastoma in an immunocompetent cancer stem cell model. Proc Natl Acad Sci U S A 110, 12006-12011. https://www.ncbi.nlm.nih.gov/pubmed/ 23754388

Chen, C.Y., Hutzen, B., Wedekind, M.F., and Cripe, T.P. (2018). Oncolytic virus and PD-1/PD-L1 blockade combination therapy. Oncolytic Virother 7, 65-77. https://www.ncbi.nlm.nih.gov/pubmed/30105219

Chen, X., Han, J., Chu, J., Zhang, L., Zhang, J., Chen, C., Chen, L., Wang, Y., Wang, H., Yi, L., et al. (2016). A combinational therapy of EGFR-CAR NK cells and oncolytic herpes simplex virus 1 for breast cancer brain metastases. Oncotarget 7, 27764-27777. https://www.ncbi.nlm.nih.gov/ pubmed/27050072

Cheng, G., Yang, K., and He, B. (2003). Dephosphorylation of elF-2alpha mediated by the gamma(1)34.5 protein of herpes simplex virus type 1 is required for viral response to interferon but is not sufficient for efficient viral replication. J Virol 77, 10154-10161. https://www.ncbi.nlm.nih.gov/pubmed/ 12941928

Chikuma, S. (2017). CTLA-4, an Essential Immune-Checkpoint for T-Cell Activation. In Emerging Concepts Targeting Immune Checkpoints in Cancer 
and Autoimmunity, A. Yoshimura, ed. (Cham: Springer International Publishing), pp. 99-126.

Chiocca, E.A., Yu, J.S., Lukas, R.V., Solomon, I.H., Ligon, K.L., Nakashima, H., Triggs, D.A., Reardon, D.A., Wen, P., Stopa, B.M., et al. (2019). Regulatable interleukin-12 gene therapy in patients with recurrent high-grade glioma: Results of a phase 1 trial. Sci Transl Med 11. https://www.ncbi.nlm.nih.gov/ pubmed/31413142

Chisholm, S.E., Howard, K., Gomez, M.V., and Reyburn, H.T. (2007). Expression of ICPO is sufficient to trigger natural killer cell recognition of herpes simplex virus-infected cells by natural cytotoxicity receptors. J Infect Dis 195, 1160-1168. http://dx.doi.org/10.1086/512862.

Chiu, T.L., Wang, M.J., and Su, C.C. (2012). The treatment of glioblastoma multiforme through activation of microglia and TRAIL induced by rAAV2mediated IL-12 in a syngeneic rat model. J Biomed Sci 19, 45.

Cioffi, M., Trabulo, S., Hidalgo, M., Costello, E., Greenhalf, W., Erkan, M., Kleeff, J., Sainz, B., Jr., and Heeschen, C. (2015). Inhibition of CD47 Effectively Targets Pancreatic Cancer Stem Cells via Dual Mechanisms. Clin Cancer Res 21, 2325-2337. https://www.ncbi.nlm.nih.gov/pubmed/25717063

Cocchi, F., Fusco, D., Menotti, L., Gianni, T., Eisenberg, R.J., Cohen, G.H., and Campadelli-Fiume, G. (2004). The soluble ectodomain of herpes simplex virus gD contains a membrane-proximal pro-fusion domain and suffices to mediate virus entry. Proc Natl Acad Sci U S A 101, 7445-7450. https:// www.ncbi.nlm.nih.gov/pubmed/15123804

Cody, J.J., Scaturro, P., Cantor, A.B., Yancey Gillespie, G., Parker, J.N., and Markert, J.M. (2012). Preclinical evaluation of oncolytic deltagamma(1)34.5 herpes simplex virus expressing interleukin-12 for therapy of breast cancer brain metastases. Int J Breast Cancer 2012, 628697. https:// www.ncbi.nlm.nih.gov/pubmed/23346408

Colli, L.M., Machiela, M.J., Myers, T.A., Jessop, L., Yu, K., and Chanock, S.J. (2016). Burden of Nonsynonymous Mutations among TCGA Cancers and Candidate Immune Checkpoint Inhibitor Responses. Cancer Res 76, 3767-3772. http://dx.doi.org/10.1158/0008-5472.Can-16-0170. 
Connolly, S.A., Landsburg, D.J., Carfi, A., Whitbeck, J.C., Zuo, Y., Wiley, D.C., Cohen, G.H., and Eisenberg, R.J. (2005). Potential nectin-1 binding site on herpes simplex virus glycoprotein D. J Virol 79, 1282-1295. https:// www.ncbi.nlm.nih.gov/pubmed/15613355

Connolly, S.A., Landsburg, D.J., Carfi, A., Wiley, D.C., Cohen, G.H., and Eisenberg, R.J. (2003). Structure-based mutagenesis of herpes simplex virus glycoprotein $D$ defines three critical regions at the gD-HveA/HVEM binding interface. J Virol 77, 8127-8140. https://www.ncbi.nlm.nih.gov/pubmed/ 12829851

Coulie, P.G., Van den Eynde, B.J., van der Bruggen, P., and Boon, T. (2014). Tumour antigens recognized by $\mathrm{T}$ lymphocytes: at the core of cancer immunotherapy. Nat Rev Cancer 14, 135-146. https://www.ncbi.nlm.nih.gov/ pubmed/24457417

Cozzi, P.J., Malhotra, S., McAuliffe, P., Kooby, D.A., Federoff, H.J., Huryk, B., Johnson, P., Scardino, P.T., Heston, W.D., and Fong, Y. (2001). Intravesical oncolytic viral therapy using attenuated, replication-competent herpes simplex viruses G207 and Nv1020 is effective in the treatment of bladder cancer in an orthotopic syngeneic model. FASEB J 15, 1306-1308. https:// www.ncbi.nlm.nih.gov/pubmed/11344122

Dai, H.S., and Caligiuri, M.A. (2018). Molecular Basis for the Recognition of Herpes Simplex Virus Type 1 Infection by Human Natural Killer Cells. Front Immunol 9, 183. https://www.ncbi.nlm.nih.gov/pubmed/29483911

Dai, H.S., Griffin, N., Bolyard, C., Mao, H.C., Zhang, J., Cripe, T.P., Suenaga, T., Arase, H., Nakano, I., Chiocca, E.A., et al. (2017a). The Fc Domain of Immunoglobulin Is Sufficient to Bridge NK Cells with Virally Infected Cells. Immunity 47, 159-170 e110. https://www.ncbi.nlm.nih.gov/pubmed/28723548

Dai, P., Wang, W., Yang, N., Serna-Tamayo, C., Ricca, J.M., Zamarin, D., Shuman, S., Merghoub, T., Wolchok, J.D., and Deng, L. (2017b). Intratumoral delivery of inactivated modified vaccinia virus Ankara (iMVA) induces systemic antitumor immunity via STING and Batf3-dependent dendritic cells. Sci Immunol 2, eaal1713. http://dx.doi.org/10.1126/sciimmunol.aal1713.

Darmanis, S., Sloan, S.A., Croote, D., Mignardi, M., Chernikova, S., Samghababi, P., Zhang, Y., Neff, N., Kowarsky, M., Caneda, C., et al. (2017). 
Single-Cell RNA-Seq Analysis of Infiltrating Neoplastic Cells at the Migrating Front of Human Glioblastoma. Cell Rep 21, 1399-1410. https:// www.ncbi.nlm.nih.gov/pubmed/29091775

DeGregori, J., Kowalik, T., and Nevins, J.R. (1995). Cellular targets for activation by the E2F1 transcription factor include DNA synthesis- and G1/Sregulatory genes. Mol Cell Biol 15, 4215-4224. https://www.ncbi.nlm.nih.gov/ pubmed/7623816

Delgado-Lopez, P.D., and Corrales-Garcia, E.M. (2016). Survival in glioblastoma: a review on the impact of treatment modalities. Clin Transl Oncol 18, 1062-1071. https://www.ncbi.nlm.nih.gov/pubmed/26960561

Desjardins, A., Reardon, D.A., and Vredenburgh, J.J. (2009). Current available therapies and future directions in the treatment of malignant gliomas. Biologics 3, 15-25. https://www.ncbi.nlm.nih.gov/pubmed/19707392

Di Giovine, P., Settembre, E.C., Bhargava, A.K., Luftig, M.A., Lou, H., Cohen, G.H., Eisenberg, R.J., Krummenacher, C., and Carfi, A. (2011). Structure of herpes simplex virus glycoprotein $D$ bound to the human receptor nectin-1. PLoS Pathog 7, e1002277. https://www.ncbi.nlm.nih.gov/pubmed/21980294

Dmitrieva, N., Yu, L., Viapiano, M., Cripe, T.P., Chiocca, E.A., Glorioso, J.C., and Kaur, B. (2011). Chondroitinase ABC I-mediated enhancement of oncolytic virus spread and antitumor efficacy. Clin Cancer Res 17, 1362-1372. https://www.ncbi.nlm.nih.gov/pubmed/21177410

Douglas, J.T., Miller, C.R., Kim, M., Dmitriev, I., Mikheeva, G., Krasnykh, V., and Curiel, D.T. (1999). A system for the propagation of adenoviral vectors with genetically modified receptor specificities. Nat Biotechnol 17, 470-475. https://www.ncbi.nlm.nih.gov/pubmed/10331807

Dummer, R., Hoeller, C., Gruter, I.P., and Michielin, O. (2017). Combining talimogene laherparepvec with immunotherapies in melanoma and other solid tumors. Cancer Immunol Immunother 66, 683-695. https:// www.ncbi.nlm.nih.gov/pubmed/28238174

Ebright, M.I., Zager, J.S., Malhotra, S., Delman, K.A., Weigel, T.L., Rusch, V.W., and Fong, Y. (2002). Replication-competent herpes virus NV1020 as direct treatment of pleural cancer in a rat model. J Thorac Cardiovasc Surg 124, 123-129. https://www.ncbi.nlm.nih.gov/pubmed/12091817 
Eisenberg, R.J., Atanasiu, D., Cairns, T.M., Gallagher, J.R., Krummenacher, C., and Cohen, G.H. (2012). Herpes virus fusion and entry: a story with many characters. Viruses 4, 800-832. https://www.ncbi.nlm.nih.gov/pubmed/ 22754650

Elliott, L.A., Doherty, G.A., Sheahan, K., and Ryan, E.J. (2017). Human TumorInfiltrating Myeloid Cells: Phenotypic and Functional Diversity. Front Immunol 8, 86. http://dx.doi.org/10.3389/fimmu.2017.00086.

Fan, Q., Kopp, S., Connolly, S.A., Muller, W.J., and Longnecker, R. (2017). Mapping sites of herpes simplex virus type 1 glycoprotein $D$ that permit insertions and impact gD and gB receptors usage. Sci Rep 7, 43712. https:// www.ncbi.nlm.nih.gov/pubmed/28255168

Feenstra, V., Hodaie, M., and Johnson, D.C. (1990). Deletions in herpes simplex virus glycoprotein $D$ define nonessential and essential domains. J Virol 64, 2096-2102. https://www.ncbi.nlm.nih.gov/pubmed/2157872

Feng, E., Sui, C., Wang, T., and Sun, G. (2017). Temozolomide with or without Radiotherapy in Patients with Newly Diagnosed Glioblastoma Multiforme: A Meta-Analysis. Eur Neurol 77, 201-210. https://www.ncbi.nlm.nih.gov/ pubmed/28192785

Ferris, R.L., Gross, N.D., Nemunaitis, J.J., Andtbacka, R.H., Argiris, A., Ohr, J., Vetto, J.T., Senzer, N., Bedell, C., Ungerleider, R.S., et al. (2014). Phasel trial of intratumoral therapy using HF10, an oncolytic HSV-1, demonstrates safety in HSV+/HSV- patients with refractory and superficial cancers. J Clin Oncol 32, 6082. http://dx.doi.org/10.1200/jco.2014.32.15_suppl.6082.

Filley, A.C., Henriquez, M., and Dey, M. (2017). Recurrent glioma clinical trial, CheckMate-143: the game is not over yet. Oncotarget 8, 91779-91794. https://www.ncbi.nlm.nih.gov/pubmed/29207684

Flores-Toro, J.A., Luo, D., Gopinath, A., Sarkisian, M.R., Campbell, J.J., Charo, I.F., Singh, R., Schall, T.J., Datta, M., Jain, R.K., et al. (2020). CCR2 inhibition reduces tumor myeloid cells and unmasks a checkpoint inhibitor effect to slow progression of resistant murine gliomas. Proc Natl Acad Sci U S A 117, 1129-1138. https://www.ncbi.nlm.nih.gov/pubmed/31879345

Friedman, G.K., Bernstock, J.D., Chen, D., Nan, L., Moore, B.P., Kelly, V.M., Youngblood, S.L., Langford, C.P., Han, X., Ring, E.K., et al. (2018). 
Enhanced Sensitivity of Patient-Derived Pediatric High-Grade Brain Tumor Xenografts to Oncolytic HSV-1 Virotherapy Correlates with Nectin-1 Expression. Sci Rep 8, 13930. https://www.ncbi.nlm.nih.gov/pubmed/ 30224769

Fruh, K., Ahn, K., Djaballah, H., Sempe, P., van Endert, P.M., Tampe, R., Peterson, P.A., and Yang, Y. (1995). A viral inhibitor of peptide transporters for antigen presentation. Nature 375, 415-418. https://www.ncbi.nlm.nih.gov/ pubmed/7760936

Fu, X., Rivera, A., Tao, L., De Geest, B., and Zhang, X. (2012). Construction of an oncolytic herpes simplex virus that precisely targets hepatocellular carcinoma cells. Mol Ther 20, 339-346. https://www.ncbi.nlm.nih.gov/ pubmed/22146341

Fu, X., Tao, L., Jin, A., Vile, R., Brenner, M.K., and Zhang, X. (2003). Expression of a fusogenic membrane glycoprotein by an oncolytic herpes simplex virus potentiates the viral antitumor effect. Mol Ther 7, 748-754. https://www.ncbi.nlm.nih.gov/pubmed/12788648

Fujii, K., Kurozumi, K., Ichikawa, T., Onishi, M., Shimazu, Y., Ishida, J., Chiocca, E.A., Kaur, B., and Date, I. (2013). The integrin inhibitor cilengitide enhances the anti-glioma efficacy of vasculostatin-expressing oncolytic virus. Cancer Gene Ther 20, 437-444. https://www.ncbi.nlm.nih.gov/pubmed/ 23827879

Fujimoto, Y., Mizuno, T., Sugiura, S., Goshima, F., Kohno, S., Nakashima, T., and Nishiyama, Y. (2006). Intratumoral injection of herpes simplex virus HF10 in recurrent head and neck squamous cell carcinoma. Acta Otolaryngol 126, 1115-1117. https://www.ncbi.nlm.nih.gov/pubmed/16923721

Fujita, M., Kohanbash, G., Fellows-Mayle, W., Hamilton, R.L., Komohara, Y., Decker, S.A., Ohlfest, J.R., and Okada, H. (2011). COX-2 blockade suppresses gliomagenesis by inhibiting myeloid-derived suppressor cells. Cancer Res 71, 2664-2674. https://www.ncbi.nlm.nih.gov/pubmed/21324923 Fujita, M., Scheurer, M.E., Decker, S.A., McDonald, H.A., Kohanbash, G., Kastenhuber, E.R., Kato, H., Bondy, M.L., Ohlfest, J.R., and Okada, H. (2010). Role of type 1 IFNs in antiglioma immunosurveillance--using mouse 
studies to guide examination of novel prognostic markers in humans. Clin Cancer Res 16, 3409-3419. https://www.ncbi.nlm.nih.gov/pubmed/20472682

Fukuhara, H., Ino, Y., and Todo, T. (2016). Oncolytic virus therapy: A new era of cancer treatment at dawn. Cancer Sci 107, 1373-1379. https:// www.ncbi.nlm.nih.gov/pubmed/27486853

Fulci, G., and Chiocca, E.A. (2007). The status of gene therapy for brain tumors. Expert Opin Biol Ther 7, 197-208. https://www.ncbi.nlm.nih.gov/ pubmed/17250458

Fulci, G., Dmitrieva, N., Gianni, D., Fontana, E.J., Pan, X., Lu, Y., Kaufman, C.S., Kaur, B., Lawler, S.E., Lee, R.J., et al. (2007). Depletion of peripheral macrophages and brain microglia increases brain tumor titers of oncolytic viruses. Cancer Res 67, 9398-9406. https://www.ncbi.nlm.nih.gov/pubmed/ 17909049

Fuller, A.O., Santos, R.E., and Spear, P.G. (1989). Neutralizing antibodies specific for glycoprotein $\mathrm{H}$ of herpes simplex virus permit viral attachment to cells but prevent penetration. J Virol 63, 3435-3443. https:// www.ncbi.nlm.nih.gov/pubmed/2545914

Fuller, A.O., and Spear, P.G. (1987). Anti-glycoprotein D antibodies that permit adsorption but block infection by herpes simplex virus 1 prevent virion-cell fusion at the cell surface. Proc Natl Acad Sci U S A 84, 5454-5458. https:// www.ncbi.nlm.nih.gov/pubmed/3037552

Fusco, D., Forghieri, C., and Campadelli-Fiume, G. (2005). The pro-fusion domain of herpes simplex virus glycoprotein $D(g D)$ interacts with the $g D N$ terminus and is displaced by soluble forms of viral receptors. Proc Natl Acad Sci U S A 102, 9323-9328. https://www.ncbi.nlm.nih.gov/pubmed/15972328

Gabrilovich, D.I. (2017). Myeloid-Derived Suppressor Cells. Cancer Immunol Res 5, 3-8. http://dx.doi.org/10.1158/2326-6066.Cir-16-0297.

Gambini, E., Reisoli, E., Appolloni, I., Gatta, V., Campadelli-Fiume, G., Menotti, L., and Malatesta, P. (2012). Replication-competent herpes simplex virus retargeted to HER2 as therapy for high-grade glioma. Mol Ther 20, 994-1001. https://www.ncbi.nlm.nih.gov/pubmed/22354378

Garg, A.D., Vandenberk, L., Van Woensel, M., Belmans, J., Schaaf, M., Boon, L., De Vleeschouwer, S., and Agostinis, P. (2017). Preclinical efficacy of 
immune-checkpoint monotherapy does not recapitulate corresponding biomarkers-based clinical predictions in glioblastoma. Oncoimmunology 6 , e1295903. https://www.ncbi.nlm.nih.gov/pubmed/28507806

Garzon-Muvdi, T., Theodros, D., Luksik, A.S., Maxwell, R., Kim, E., Jackson, C.M., Belcaid, Z., Ganguly, S., Tyler, B., Brem, H., et al. (2018). Dendritic cell activation enhances anti-PD-1 mediated immunotherapy against glioblastoma. Oncotarget 9, 20681-20697. https://www.ncbi.nlm.nih.gov/ pubmed/29755681

Gatta, V., Petrovic, B., and Campadelli-Fiume, G. (2015). The Engineering of a Novel Ligand in gH Confers to HSV an Expanded Tropism Independent of gD Activation by Its Receptors. PLoS Pathog 11, e1004907. https:// www.ncbi.nlm.nih.gov/pubmed/25996983

Gaur, A., Jewell, D.A., Liang, Y., Ridzon, D., Moore, J.H., Chen, C., Ambros, V.R., and Israel, M.A. (2007). Characterization of microRNA expression levels and their biological correlates in human cancer cell lines. Cancer Res 67, 2456-2468. https://www.ncbi.nlm.nih.gov/pubmed/17363563

Geevarghese, S.K., Geller, D.A., de Haan, H.A., Horer, M., Knoll, A.E., Mescheder, A., Nemunaitis, J., Reid, T.R., Sze, D.Y., Tanabe, K.K., et al. (2010). Phase I/II study of oncolytic herpes simplex virus NV1020 in patients with extensively pretreated refractory colorectal cancer metastatic to the liver. Hum Gene Ther 21, 1119-1128. https://www.ncbi.nlm.nih.gov/pubmed/20486770

Geraghty, R.J., Krummenacher, C., Cohen, G.H., Eisenberg, R.J., and Spear, P.G. (1998). Entry of alphaherpesviruses mediated by poliovirus receptorrelated protein 1 and poliovirus receptor. Science 280, 1618-1620. https:// www.ncbi.nlm.nih.gov/pubmed/9616127

Gilbert, M.R., Wang, M., Aldape, K.D., Stupp, R., Hegi, M.E., Jaeckle, K.A., Armstrong, T.S., Wefel, J.S., Won, M., Blumenthal, D.T., et al. (2013). Dosedense temozolomide for newly diagnosed glioblastoma: a randomized phase III clinical trial. J Clin Oncol 31, 4085-4091. https://www.ncbi.nlm.nih.gov/ pubmed/24101040

Goldsmith, K., Chen, W., Johnson, D.C., and Hendricks, R.L. (1998). Infected cell protein (ICP)47 enhances herpes simplex virus neurovirulence by 
blocking the CD8+ T cell response. J Exp Med 187, 341-348. https:// www.ncbi.nlm.nih.gov/pubmed/9449714

Goodwin, J.M., Schmitt, A.D., McGinn, C.M., Fuchs, B.C., Kuruppu, D., Tanabe, K.K., and Lanuti, M. (2012). Angiogenesis inhibition using an oncolytic herpes simplex virus expressing endostatin in a murine lung cancer model. Cancer Invest 30, 243-250. https://www.ncbi.nlm.nih.gov/pubmed/ 22360364

Grandi, P., Fernandez, J., Szentirmai, O., Carter, R., Gianni, D., Sena-Esteves, M., and Breakefield, X.O. (2010). Targeting HSV-1 virions for specific binding to epidermal growth factor receptor-vlll-bearing tumor cells. Cancer Gene Ther 17, 655-663. https://www.ncbi.nlm.nih.gov/pubmed/20508670

Grandi, P., Wang, S., Schuback, D., Krasnykh, V., Spear, M., Curiel, D.T., Manservigi, R., and Breakefield, X.O. (2004). HSV-1 virions engineered for specific binding to cell surface receptors. Mol Ther 9, 419-427. https:// www.ncbi.nlm.nih.gov/pubmed/15006609

Grossman, S.A., Ye, X., Piantadosi, S., Desideri, S., Nabors, L.B., Rosenfeld, M., Fisher, J., and Consortium, N.C. (2010). Survival of patients with newly diagnosed glioblastoma treated with radiation and temozolomide in research studies in the United States. Clin Cancer Res 16, 2443-2449. https:// www.ncbi.nlm.nih.gov/pubmed/20371685

Gruenheid, S., Gatzke, L., Meadows, H., and Tufaro, F. (1993). Herpes simplex virus infection and propagation in a mouse $\mathrm{L}$ cell mutant lacking heparan sulfate proteoglycans. J Virol 67, 93-100. https://www.ncbi.nlm.nih.gov/ pubmed/8380101

Grupp, S.A., Kalos, M., Barrett, D., Aplenc, R., Porter, D.L., Rheingold, S.R., Teachey, D.T., Chew, A., Hauck, B., Wright, J.F., et al. (2013). Chimeric antigen receptor-modified T cells for acute lymphoid leukemia. N Engl J Med 368, 1509-1518. http://dx.doi.org/10.1056/NEJMoa1215134.

Gujar, S., Pol, J.G., Kim, Y., Lee, P.W., and Kroemer, G. (2018a). Antitumor Benefits of Antiviral Immunity: An Underappreciated Aspect of Oncolytic Virotherapies. Trends Immunol 39, 209-221. https://www.ncbi.nlm.nih.gov/ pubmed/29275092 
Gujar, S., Pol, J.G., and Kroemer, G. (2018b). Heating it up: Oncolytic viruses make tumors 'hot' and suitable for checkpoint blockade immunotherapies. Oncoimmunology 7, e1442169. https://www.ncbi.nlm.nih.gov/pubmed/ 30221036

Han, J., Chu, J., Keung Chan, W., Zhang, J., Wang, Y., Cohen, J.B., Victor, A., Meisen, W.H., Kim, S.H., Grandi, P., et al. (2015). CAR-Engineered NK Cells Targeting Wild-Type EGFR and EGFRvIll Enhance Killing of Glioblastoma and Patient-Derived Glioblastoma Stem Cells. Sci Rep 5, 11483. https:// www.ncbi.nlm.nih.gov/pubmed/26155832

Hanson, N., Henderson, G., and Jones, C. (1994). The herpes simplex virus type 2 gene which encodes the large subunit of ribonucleotide reductase has unusual regulatory properties. Virus Res 34, 265-280. https:// www.ncbi.nlm.nih.gov/pubmed/7856314

Hargadon, K.M., Johnson, C.E., and Williams, C.J. (2018). Immune checkpoint blockade therapy for cancer: An overview of FDA-approved immune checkpoint inhibitors. Int Immunopharmacol 62, 29-39. https:// www.ncbi.nlm.nih.gov/pubmed/29990692

Harrington, K.J., Andtbacka, R.H., Collichio, F., Downey, G., Chen, L., Szabo, Z., and Kaufman, H.L. (2016). Efficacy and safety of talimogene laherparepvec versus granulocyte-macrophage colony-stimulating factor in patients with stage IIIB/C and IVM1a melanoma: subanalysis of the Phase III OPTiM trial. Onco Targets Ther 9, 7081-7093. https://www.ncbi.nlm.nih.gov/ pubmed/27895500

Harrington, K.J., Hingorani, M., Tanay, M.A., Hickey, J., Bhide, S.A., Clarke, P.M., Renouf, L.C., Thway, K., Sibtain, A., McNeish, I.A., et al. (2010). Phase I/II study of oncolytic HSV GM-CSF in combination with radiotherapy and cisplatin in untreated stage III/IV squamous cell cancer of the head and neck. Clin Cancer Res 16, 4005-4015. https://www.ncbi.nlm.nih.gov/pubmed/ 20670951

Harris-Bookman, S., Mathios, D., Martin, A.M., Xia, Y., Kim, E., Xu, H., Belcaid, Z., Polanczyk, M., Barberi, T., Theodros, D., et al. (2018). Expression of LAG-3 and efficacy of combination treatment with anti-LAG-3 and anti-PD-1 
monoclonal antibodies in glioblastoma. Int J Cancer 143, 3201-3208. http:// dx.doi.org/10.1002/ijc.31661.

Harrow, S., Papanastassiou, V., Harland, J., Mabbs, R., Petty, R., Fraser, M., Hadley, D., Patterson, J., Brown, S.M., and Rampling, R. (2004). HSV1716 injection into the brain adjacent to tumour following surgical resection of highgrade glioma: safety data and long-term survival. Gene Ther 11, 1648-1658. https://www.ncbi.nlm.nih.gov/pubmed/15334111

He, Y., Cao, J., Zhao, C., Li, X., Zhou, C., and Hirsch, F.R. (2018). TIM-3, a promising target for cancer immunotherapy. Onco Targets Ther 11, 7005-7009. http://dx.doi.org/10.2147/ott.S170385.

He, Y., Rivard, C.J., Rozeboom, L., Yu, H., Ellison, K., Kowalewski, A., Zhou, C., and Hirsch, F.R. (2016). Lymphocyte-activation gene-3, an important immune checkpoint in cancer. Cancer Sci 107, 1193-1197. http://dx.doi.org/ 10.1111/cas.12986.

Hellmann, M.D., Callahan, M.K., Awad, M.M., Calvo, E., Ascierto, P.A., Atmaca, A., Rizvi, N.A., Hirsch, F.R., Selvaggi, G., Szustakowski, J.D., et al. (2018). Tumor Mutational Burden and Efficacy of Nivolumab Monotherapy and in Combination with Ipilimumab in Small-Cell Lung Cancer. Cancer Cell 33, 853-861. http://dx.doi.org/10.1016/j.ccell.2018.04.001.

Herold, B.C., Visalli, R.J., Susmarski, N., Brandt, C.R., and Spear, P.G. (1994). Glycoprotein $\mathrm{C}$-independent binding of herpes simplex virus to cells requires cell surface heparan sulphate and glycoprotein B. J Gen Virol 75 1211-1222. https://www.ncbi.nlm.nih.gov/pubmed/8207388

Herold, B.C., WuDunn, D., Soltys, N., and Spear, P.G. (1991). Glycoprotein C of herpes simplex virus type 1 plays a principal role in the adsorption of virus to cells and in infectivity. J Virol 65, 1090-1098. http://dx.doi.org/ 10.1099/0022-1317-75-6-1211.

Hildner, K., Edelson, B.T., Purtha, W.E., Diamond, M., Matsushita, H., Kohyama, M., Calderon, B., Schraml, B.U., Unanue, E.R., Diamond, M.S., et al. (2008). Batf3 deficiency reveals a critical role for CD8alpha+ dendritic cells in cytotoxic T cell immunity. Science 322, 1097-1100. http://dx.doi.org/ 10.1126/science. 1164206 . 
Hirooka, Y., Kasuya, H., Ishikawa, T., Kawashima, H., Ohno, E., Villalobos, I.B., Naoe, Y., Ichinose, T., Koyama, N., Tanaka, M., et al. (2018). A Phase I clinical trial of EUS-guided intratumoral injection of the oncolytic virus, HF10 for unresectable locally advanced pancreatic cancer. BMC Cancer 18, 596. https://www.ncbi.nlm.nih.gov/pubmed/29801474

Hodges, T.R., Ott, M., Xiu, J., Gatalica, Z., Swensen, J., Zhou, S., Huse, J.T., de Groot, J., Li, S., Overwijk, W.W., et al. (2017). Mutational burden, immune checkpoint expression, and mismatch repair in glioma: implications for immune checkpoint immunotherapy. Neuro Oncol 19, 1047-1057. https:// www.ncbi.nlm.nih.gov/pubmed/28371827

Hu, J.C., Coffin, R.S., Davis, C.J., Graham, N.J., Groves, N., Guest, P.J., Harrington, K.J., James, N.D., Love, C.A., McNeish, I., et al. (2006). A phase I study of OncoVEXGM-CSF, a second-generation oncolytic herpes simplex virus expressing granulocyte macrophage colony-stimulating factor. Clin Cancer Res 12, 6737-6747. https://www.ncbi.nlm.nih.gov/pubmed/17121894

Hung, A.L., Maxwell, R., Theodros, D., Belcaid, Z., Mathios, D., Luksik, A.S., Kim, E., Wu, A., Xia, Y., Garzon-Muvdi, T., et al. (2018). TIGIT and PD-1 dual checkpoint blockade enhances antitumor immunity and survival in GBM. Oncoimmunology 7, e1466769. https://www.ncbi.nlm.nih.gov/pubmed/ 30221069

Hunter, W.D., Martuza, R.L., Feigenbaum, F., Todo, T., Mineta, T., Yazaki, T., Toda, M., Newsome, J.T., Platenberg, R.C., Manz, H.J., et al. (1999). Attenuated, replication-competent herpes simplex virus type 1 mutant G207: safety evaluation of intracerebral injection in nonhuman primates. J Virol 73, 6319-6326. https://www.ncbi.nlm.nih.gov/pubmed/10400723

Huse, J.T., and Holland, E.C. (2009). Genetically engineered mouse models of brain cancer and the promise of preclinical testing. Brain Pathol 19, 132-143. https://www.ncbi.nlm.nih.gov/pubmed/19076778

Huse, J.T., and Holland, E.C. (2010). Targeting brain cancer: advances in the molecular pathology of malignant glioma and medulloblastoma. Nat Rev Cancer 10, 319-331. https://www.ncbi.nlm.nih.gov/pubmed/20414201

Huszthy, P.C., Goplen, D., Thorsen, F., Immervoll, H., Wang, J., Gutermann, A., Miletic, H., and Bjerkvig, R. (2008). Oncolytic herpes simplex virus type-1 
therapy in a highly infiltrative animal model of human glioblastoma. Clin Cancer Res 14, 1571-1580. https://www.ncbi.nlm.nih.gov/pubmed/18316582 Ishikawa, H., Ma, Z., and Barber, G.N. (2009). STING regulates intracellular DNA-mediated, type I interferon-dependent innate immunity. Nature 461, 788-792. https://www.ncbi.nlm.nih.gov/pubmed/19776740

Jaime-Ramirez, A.C., Dmitrieva, N., Yoo, J.Y., Banasavadi-Siddegowda, Y., Zhang, J., Relation, T., Bolyard, C., Wojton, J., and Kaur, B. (2017). Humanized chondroitinase $A B C$ sensitizes glioblastoma cells to temozolomide. J Gene Med 19. https://www.ncbi.nlm.nih.gov/pubmed/ 28087981

Jogger, C.R., Montgomery, R.I., and Spear, P.G. (2004). Effects of linkerinsertion mutations in herpes simplex virus $1 \mathrm{gD}$ on glycoprotein-induced fusion with cells expressing HVEM or nectin-1. Virology 318, 318-326. https:// www.ncbi.nlm.nih.gov/pubmed/14972557

Jorgensen, T.J., Katz, S., Wittmack, E.K., Varghese, S., Todo, T., Rabkin, S.D., and Martuza, R.L. (2001). Ionizing radiation does not alter the antitumor activity of herpes simplex virus vector G207 in subcutaneous tumor models of human and murine prostate cancer. Neoplasia 3, 451-456. https:// www.ncbi.nlm.nih.gov/pubmed/11687957

Kaczanowska, S., Joseph Am Fau - Davila, E., and Davila, E. (2013). TLR agonists: our best frenemy in cancer immunotherapy. J Leukoc Biol 93, 847-863. http://dx.doi.org/10.1189/jlb.1012501.

Kalos, M., Levine, B.L., Porter, D.L., Katz, S., Grupp, S.A., Bagg, A., and June, C.H. (2011). T cells with chimeric antigen receptors have potent antitumor effects and can establish memory in patients with advanced leukemia. Sci Transl Med 3, 95ra73. http://dx.doi.org/10.1126/scitrans/med.3002842.

Kambara, H., Okano, H., Chiocca, E.A., and Saeki, Y. (2005). An oncolytic HSV-1 mutant expressing ICP34.5 under control of a nestin promoter increases survival of animals even when symptomatic from a brain tumor. Cancer Res 65, 2832-2839. https://www.ncbi.nlm.nih.gov/pubmed/15805284 Kamiyama, H., Zhou, G., and Roizman, B. (2006). Herpes simplex virus 1 recombinant virions exhibiting the amino terminal fragment of urokinase-type 
plasminogen activator can enter cells via the cognate receptor. Gene Ther 13, 621-629. https://www.ncbi.nlm.nih.gov/pubmed/16292350

Kamran, N., Calinescu, A., Candolfi, M., Chandran, M., Mineharu, Y., Asad, A.S., Koschmann, C., Nunez, F.J., Lowenstein, P.R., and Castro, M.G. (2016). Recent advances and future of immunotherapy for glioblastoma. Expert Opin Biol Ther 16, 1245-1264. https://www.ncbi.nlm.nih.gov/pubmed/ 27411023

Kamran, N., Chandran, M., Lowenstein, P.R., and Castro, M.G. (2018). Immature myeloid cells in the tumor microenvironment: Implications for immunotherapy. Clin Immunol 189, 34-42. https://www.ncbi.nlm.nih.gov/ pubmed/27777083

Kamran, N., Kadiyala, P., Saxena, M., Candolfi, M., Li, Y., Moreno-Ayala, M.A., Raja, N., Shah, D., Lowenstein, P.R., and Castro, M.G. (2017). Immunosuppressive Myeloid Cells' Blockade in the Glioma Microenvironment Enhances the Efficacy of Immune-Stimulatory Gene Therapy. Mol Ther 25, 232-248. https://www.ncbi.nlm.nih.gov/pubmed/28129117

Kasuya, H., Kodera, Y., Nakao, A., Yamamura, K., Gewen, T., Zhiwen, W., Hotta, Y., Yamada, S., Fujii, T., Fukuda, S., et al. (2014). Phase I Doseescalation Clinical Trial of HF10 Oncolytic Herpes Virus in 17 Japanese Patients with Advanced Cancer. Hepatogastroenterology 61, 599-605. https:// www.ncbi.nlm.nih.gov/pubmed/26176043

Kaufman, H.E., Azcuy, A.M., Varnell, E.D., Sloop, G.D., Thompson, H.W., and Hill, J.M. (2005). HSV-1 DNA in tears and saliva of normal adults. Invest Ophthalmol Vis Sci 46, 241-247. https://www.ncbi.nlm.nih.gov/pubmed/ 15623779

Kaufman, H.L., Kim, D.W., DeRaffele, G., Mitcham, J., Coffin, R.S., and KimSchulze, S. (2010). Local and distant immunity induced by intralesional vaccination with an oncolytic herpes virus encoding GM-CSF in patients with stage IIIc and IV melanoma. Ann Surg Oncol 17, 718-730. https:// www.ncbi.nlm.nih.gov/pubmed/19915919

Kemeny, N., Brown, K., Covey, A., Kim, T., Bhargava, A., Brody, L., Guilfoyle, B., Haag, N.P., Karrasch, M., Glasschroeder, B., et al. (2006). Phase I, openlabel, dose-escalating study of a genetically engineered herpes simplex virus, 
NV1020, in subjects with metastatic colorectal carcinoma to the liver. Hum Gene Ther 17, 1214-1224. https://www.ncbi.nlm.nih.gov/pubmed/17107303

Kesari, S., Lasner, T.M., Balsara, K.R., Randazzo, B.P., Lee, V.M., Trojanowski, J.Q., and Fraser, N.W. (1998). A neuroattenuated ICP34.5-deficient herpes simplex virus type 1 replicates in ependymal cells of the murine central nervous system. J Gen Virol 79 ( Pt 3), 525-536. https://www.ncbi.nlm.nih.gov/pubmed/ 9519831

Kesari, S., Randazzo, B.P., Valyi-Nagy, T., Huang, Q.S., Brown, S.M., MacLean, A.R., Lee, V.M., Trojanowski, J.Q., and Fraser, N.W. (1995). Therapy of experimental human brain tumors using a neuroattenuated herpes simplex virus mutant. Lab Invest 73, 636-648. https:// www.ncbi.nlm.nih.gov/pubmed/7474937

Kim, Y., Lee, H.G., Dmitrieva, N., Kim, J., Kaur, B., and Friedman, A. (2014). Choindroitinase $A B C$ I-mediated enhancement of oncolytic virus spread and anti tumor efficacy: a mathematical model. PLoS One 9, e102499. https:// www.ncbi.nlm.nih.gov/pubmed/25047810

Kim, Y., Yoo, J.Y., Lee, T.J., Liu, J., Yu, J., Caligiuri, M.A., Kaur, B., and Friedman, A. (2018). Complex role of NK cells in regulation of oncolytic virusbortezomib therapy. Proc Natl Acad Sci U S A 115, 4927-4932. https:// www.ncbi.nlm.nih.gov/pubmed/29686060

Kimata, H., Imai, T., Kikumori, T., Teshigahara, O., Nagasaka, T., Goshima, F., Nishiyama, Y., and Nakao, A. (2006). Pilot study of oncolytic viral therapy using mutant herpes simplex virus (HF10) against recurrent metastatic breast cancer. Ann Surg Oncol 13, 1078-1084. https://www.ncbi.nlm.nih.gov/ pubmed/16865590

Kohanbash, G., McKaveney, K., Sakaki, M., Ueda, R., Mintz, A.H., Amankulor, N., Fujita, M., Ohlfest, J.R., and Okada, H. (2013). GM-CSF promotes the immunosuppressive activity of glioma-infiltrating myeloid cells through interleukin-4 receptor-alpha. Cancer Res 73, 6413-6423. https:// www.ncbi.nlm.nih.gov/pubmed/24030977

Kohanbash, G., and Okada, H. (2012). Myeloid-derived suppressor cells (MDSCs) in gliomas and glioma-development. Immunol Invest 41, 658-679. https://www.ncbi.nlm.nih.gov/pubmed/23017140 
Koshizuka, T., Kawaguchi, Y., and Nishiyama, Y. (2005). Herpes simplex virus type 2 membrane protein UL56 associates with the kinesin motor protein KIF1A. J Gen Virol 86, 527-533. https://www.ncbi.nlm.nih.gov/pubmed/ 15722511

Kouvatsis, V., Argnani, R., Tsitoura, E., Arsenakis, M., Georgopoulou, U., Mavromara, P., and Manservigi, R. (2007). Characterization of herpes simplex virus type 1 recombinants that express and incorporate high levels of HCV E2-gC chimeric proteins. Virus Res 123, 40-49. https:// www.ncbi.nlm.nih.gov/pubmed/16989918

Kramm, C.M., Chase, M., Herrlinger, U., Jacobs, A., Pechan, P.A., Rainov, N.G., Sena-Esteves, M., Aghi, M., Barnett, F.H., Chiocca, E.A., et al. (1997). Therapeutic efficiency and safety of a second-generation replicationconditional HSV1 vector for brain tumor gene therapy. Hum Gene Ther 8, 2057-2068. https://www.ncbi.nlm.nih.gov/pubmed/9414254

Krummenacher, C., Nicola, A.V., Whitbeck, J.C., Lou, H., Hou, W., Lambris, J.D., Geraghty, R.J., Spear, P.G., Cohen, G.H., and Eisenberg, R.J. (1998). Herpes simplex virus glycoprotein $D$ can bind to poliovirus receptor-related protein 1 or herpesvirus entry mediator, two structurally unrelated mediators of virus entry. J Virol 72, 7064-7074. https://www.ncbi.nlm.nih.gov/pubmed/ 9696799

Krummenacher, C., Supekar, V.M., Whitbeck, J.C., Lazear, E., Connolly, S.A., Eisenberg, R.J., Cohen, G.H., Wiley, D.C., and Carfi, A. (2005). Structure of unliganded HSV $\mathrm{gD}$ reveals a mechanism for receptor-mediated activation of virus entry. EMBO J 24, 4144-4153. https://www.ncbi.nlm.nih.gov/pubmed/ 16292345

Laquerre, S., Anderson, D.B., Stolz, D.B., and Glorioso, J.C. (1998a). Recombinant herpes simplex virus type 1 engineered for targeted binding to erythropoietin receptor-bearing cells. J Virol 72, 9683-9697. https:// www.ncbi.nlm.nih.gov/pubmed/9811702

Laquerre, S., Argnani, R., Anderson, D.B., Zucchini, S., Manservigi, R., and Glorioso, J.C. (1998b). Heparan sulfate proteoglycan binding by herpes simplex virus type 1 glycoproteins $B$ and $C$, which differ in their contributions 
to virus attachment, penetration, and cell-to-cell spread. J Virol 72, 6119-6130. https://www.ncbi.nlm.nih.gov/pubmed/9621076

Le, D.T., Durham, J.N., Smith, K.N., Wang, H., Bartlett, B.R., Aulakh, L.K., Lu, S., Kemberling, H., Wilt, C., Luber, B.S., et al. (2017). Mismatch repair deficiency predicts response of solid tumors to PD-1 blockade. Science 357, 409-413. http://dx.doi.org/10.1126/science.aan6733.

Le, D.T., Uram, J.N., Wang, H., Bartlett, B.R., Kemberling, H., Eyring, A.D., Skora, A.D., Luber, B.S., Azad, N.S., Laheru, D., et al. (2015). PD-1 Blockade in Tumors with Mismatch-Repair Deficiency. N Engl J Med 372, 2509-2520. https://www.ncbi.nlm.nih.gov/pubmed/26028255

Lee, C.Y., Rennie, P.S., and Jia, W.W. (2009). MicroRNA regulation of oncolytic herpes simplex virus-1 for selective killing of prostate cancer cells. Clin Cancer Res 15, 5126-5135. https://www.ncbi.nlm.nih.gov/pubmed/19671871

Leib, D.A., Alexander, D.E., Cox, D., Yin, J., and Ferguson, T.A. (2009). Interaction of ICP34.5 with Beclin 1 modulates herpes simplex virus type 1 pathogenesis through control of CD4+ T-cell responses. J Virol 83, 12164-12171. https://www.ncbi.nlm.nih.gov/pubmed/19759141

Leoni, V., Gatta, V., Casiraghi, C., Nicosia, A., Petrovic, B., and CampadelliFiume, G. (2017). A Strategy for Cultivation of Retargeted Oncolytic Herpes Simplex Viruses in Non-cancer Cells. J Virol 91, e00067-00017. https:// www.ncbi.nlm.nih.gov/pubmed/28250120

Leoni, V., Petrovic, B., Gianni, T., Gatta, V., and Campadelli-Fiume, G. (2018a). Simultaneous Insertion of Two Ligands in gD for Cultivation of Oncolytic Herpes Simplex Viruses in Noncancer Cells and Retargeting to Cancer Receptors. J Virol 92, e02132-02117. https://www.ncbi.nlm.nih.gov/pubmed/ 29263255

Leoni, V., Vannini, A., Gatta, V., Rambaldi, J., Sanapo, M., Barboni, C., Zaghini, A., Nanni, P., Lollini, P.L., Casiraghi, C., et al. (2018b). A fully-virulent retargeted oncolytic HSV armed with IL-12 elicits local immunity and vaccine therapy towards distant tumors. PLoS Pathog 14, e1007209. https:// www.ncbi.nlm.nih.gov/pubmed/30080893

Li, G., Wang, Z., Zhang, C., Liu, X., Cai, J., Wang, Z., Hu, H., Wu, F., Bao, Z., Liu, Y., et al. (2017). Molecular and clinical characterization of TIM-3 in 
glioma through 1,024 samples. Oncoimmunology 6, e1328339. http:// dx.doi.org/10.1080/2162402x.2017.1328339.

Li, J.M., Kao, K.C., Li, L.F., Yang, T.M., Wu, C.P., Horng, Y.M., Jia, W.W., and Yang, C.T. (2013). MicroRNA-145 regulates oncolytic herpes simplex virus-1 for selective killing of human non-small cell lung cancer cells. Virol J 10, 241. https://www.ncbi.nlm.nih.gov/pubmed/23876001

Li, Y., Zhang, C., Chen, X., Yu, J., Wang, Y., Yang, Y., Du, M., Jin, H., Ma, Y., $\mathrm{He}$, B., et al. (2011). ICP34.5 protein of herpes simplex virus facilitates the initiation of protein translation by bridging eukaryotic initiation factor 2alpha (elF2alpha) and protein phosphatase 1. J Biol Chem 286, 24785-24792. https://www.ncbi.nlm.nih.gov/pubmed/21622569

Lisi, L., Ciotti, G.M., Braun, D., Kalinin, S., Curro, D., Dello Russo, C., Coli, A., Mangiola, A., Anile, C., Feinstein, D.L., et al. (2017). Expression of iNOS, CD163 and ARG-1 taken as M1 and M2 markers of microglial polarization in human glioblastoma and the surrounding normal parenchyma. Neurosci Lett 645, 106-112. https://www.ncbi.nlm.nih.gov/pubmed/28259657

Liu, B.L., Robinson, M., Han, Z.Q., Branston, R.H., English, C., Reay, P., McGrath, Y., Thomas, S.K., Thornton, M., Bullock, P., et al. (2003). ICP34.5 deleted herpes simplex virus with enhanced oncolytic, immune stimulating, and anti-tumour properties. Gene Ther 10, 292-303. https:// www.ncbi.nlm.nih.gov/pubmed/12595888

Long, G.V., Dummer, R., Hamid, O., Gajewski, T.F., Caglevic, C., Dalle, S., Arance, A., Carlino, M.S., Grob, J.J., Kim, T.M., et al. (2019). Epacadostat plus pembrolizumab versus placebo plus pembrolizumab in patients with unresectable or metastatic melanoma (ECHO-301/KEYNOTE-252): a phase 3, randomised, double-blind study. Lancet Oncol 20, 1083-1097. https:// www.ncbi.nlm.nih.gov/pubmed/31221619

Lowenstein, P.R., and Castro, M.G. (2018). Evolutionary basis of a new geneand immune-therapeutic approach for the treatment of malignant brain tumors: from mice to clinical trials for glioma patients. Clin Immunol 189, 43-51. https://www.ncbi.nlm.nih.gov/pubmed/28720549

Luo, C., Mori, I., Goshima, F., Ushijima, Y., Nawa, A., Kimura, H., and Nishiyama, Y. (2007). Replication-competent, oncolytic herpes simplex virus 
type 1 mutants induce a bystander effect following ganciclovir treatment. J Gene Med 9, 875-883. https://www.ncbi.nlm.nih.gov/pubmed/17685493

Mace, A.T., Ganly, I., Soutar, D.S., and Brown, S.M. (2008). Potential for efficacy of the oncolytic Herpes simplex virus 1716 in patients with oral squamous cell carcinoma. Head Neck 30, 1045-1051. https:// www.ncbi.nlm.nih.gov/pubmed/18615711

Mace, A.T., Harrow, S.J., Ganly, I., and Brown, S.M. (2007). Cytotoxic effects of the oncolytic herpes simplex virus HSV1716 alone and in combination with cisplatin in head and neck squamous cell carcinoma. Acta Otolaryngol 127, 880-887. https://www.ncbi.nlm.nih.gov/pubmed/17763002

MacKie, R.M., Stewart, B., and Brown, S.M. (2001). Intralesional injection of herpes simplex virus 1716 in metastatic melanoma. Lancet 357, 525-526. https://www.ncbi.nlm.nih.gov/pubmed/11229673

MacLean, A.R., ul-Fareed, M., Robertson, L., Harland, J., and Brown, S.M. (1991). Herpes simplex virus type 1 deletion variants 1714 and 1716 pinpoint neurovirulence-related sequences in Glasgow strain 17+ between immediate early gene 1 and the 'a' sequence. J Gen Virol 72 ( Pt 3), 631-639. https:// www.ncbi.nlm.nih.gov/pubmed/1848598

Manoj, S., Jogger, C.R., Myscofski, D., Yoon, M., and Spear, P.G. (2004). Mutations in herpes simplex virus glycoprotein $D$ that prevent cell entry via nectins and alter cell tropism. Proc Natl Acad Sci U S A 101, 12414-12421. https://www.ncbi.nlm.nih.gov/pubmed/15273289

Markert, J.M., Cody, J.J., Parker, J.N., Coleman, J.M., Price, K.H., Kern, E.R., Quenelle, D.C., Lakeman, A.D., Schoeb, T.R., Palmer, C.A., et al. (2012). Preclinical evaluation of a genetically engineered herpes simplex virus expressing interleukin-12. J Virol 86, 5304-5313. https://www.ncbi.nlm.nih.gov/ pubmed/22379082

Markert, J.M., Liechty, P.G., Wang, W., Gaston, S., Braz, E., Karrasch, M., Nabors, L.B., Markiewicz, M., Lakeman, A.D., Palmer, C.A., et al. (2009). Phase lb trial of mutant herpes simplex virus G207 inoculated pre-and post-tumor resection for recurrent GBM. Mol Ther 17, 199-207. http://www.ncbi.nlm.nih.gov/entrez/ query.fcgi?cmd=Retrieve\&db=PubMed\&dopt=Citation\&list_uids=18957964 
Markert, J.M., Medlock, M.D., Rabkin, S.D., Gillespie, G.Y., Todo, T., Hunter, W.D., Palmer, C.A., Feigenbaum, F., Tornatore, C., Tufaro, F., et al. (2000). Conditionally replicating herpes simplex virus mutant, G207 for the treatment of malignant glioma: results of a phase I trial. Gene Ther 7, 867-874. http://www.ncbi.nlm.nih.gov/entrez/ query.fcgi?cmd=Retrieve\&db=PubMed\&dopt=Citation\&list_uids=10845725

Martuza, R.L., Malick, A., Markert, J.M., Ruffner, K.L., and Coen, D.M. (1991). Experimental therapy of human glioma by means of a genetically engineered virus mutant. Science 252, 854-856. http://www.ncbi.nlm.nih.gov/entrez/ query.fcgi?cmd=Retrieve\&db=PubMed\&dopt=Citation\&list_uids=1851332

Marumoto, T., Tashiro, A., Friedmann-Morvinski, D., Scadeng, M., Soda, Y., Gage, F.H., and Verma, I.M. (2009). Development of a novel mouse glioma model using lentiviral vectors. Nat Med 15, 110-116. https://www.ncbi.nlm.nih.gov/pubmed/ 19122659

Mazzacurati, L., Marzulli, M., Reinhart, B., Miyagawa, Y., Uchida, H., Goins, W.F., Li, A., Kaur, B., Caligiuri, M., Cripe, T., et al. (2015). Use of miRNA response sequences to block off-target replication and increase the safety of an unattenuated, glioblastoma-targeted oncolytic HSV. Mol Ther 23, 99-107. https://www.ncbi.nlm.nih.gov/pubmed/25200130

Meignier, B., Longnecker, R., and Roizman, B. (1988). In vivo behavior of genetically engineered herpes simplex viruses R7017 and R7020: construction and evaluation in rodents. J Infect Dis 158, 602-614. http:// dx.doi.org/10.1093/infdis/158.3.602.

Meisen, W.H., Wohleb, E.S., Jaime-Ramirez, A.C., Bolyard, C., Yoo, J.Y., Russell, L., Hardcastle, J., Dubin, S., Muili, K., Yu, J., et al. (2015). The Impact of Macrophage- and Microglia-Secreted TNFalpha on Oncolytic HSV-1 Therapy in the Glioblastoma Tumor Microenvironment. Clin Cancer Res 21, 3274-3285. https://www.ncbi.nlm.nih.gov/pubmed/25829396

Menotti, L., Avitabile, E., Gatta, V., Malatesta, P., Petrovic, B., and CampadelliFiume, G. (2018). HSV as A Platform for the Generation of Retargeted, Armed, and Reporter-Expressing Oncolytic Viruses. Viruses 10, 352. https:// www.ncbi.nlm.nih.gov/pubmed/29966356

Menotti, L., Cerretani, A., and Campadelli-Fiume, G. (2006). A herpes simplex virus recombinant that exhibits a single-chain antibody to HER2/neu enters 
cells through the mammary tumor receptor, independently of the gD receptors. J Virol 80, 5531-5539. https://www.ncbi.nlm.nih.gov/pubmed/ 16699034

Menotti, L., Cerretani, A., Hengel, H., and Campadelli-Fiume, G. (2008). Construction of a fully retargeted herpes simplex virus 1 recombinant capable of entering cells solely via human epidermal growth factor receptor 2. J Virol 82, 10153-10161. https://www.ncbi.nlm.nih.gov/pubmed/18684832

Menotti, L., Nicoletti, G., Gatta, V., Croci, S., Landuzzi, L., De Giovanni, C., Nanni, P., Lollini, P.L., and Campadelli-Fiume, G. (2009). Inhibition of human tumor growth in mice by an oncolytic herpes simplex virus designed to target solely HER-2-positive cells. Proc Natl Acad Sci U S A 106, 9039-9044. https://www.ncbi.nlm.nih.gov/pubmed/19458262

Milne, R.S., Hanna, S.L., Rux, A.H., Willis, S.H., Cohen, G.H., and Eisenberg, R.J. (2003). Function of herpes simplex virus type $1 \mathrm{gD}$ mutants with different receptor-binding affinities in virus entry and fusion. J Virol 77, 8962-8972. https://www.ncbi.nlm.nih.gov/pubmed/12885913

Mohr, I., Sternberg, D., Ward, S., Leib, D., Mulvey, M., and Gluzman, Y. (2001). A herpes simplex virus type 1 gamma34.5 second-site suppressor mutant that exhibits enhanced growth in cultured glioblastoma cells is severely attenuated in animals. J Virol 75, 5189-5196. https://www.ncbi.nlm.nih.gov/ pubmed/11333900

Montgomery, R.I., Warner, M.S., Lum, B.J., and Spear, P.G. (1996). Herpes simplex virus-1 entry into cells mediated by a novel member of the TNF/NGF receptor family. Cell 87, 427-436. https://www.ncbi.nlm.nih.gov/pubmed/ 8898196

Mossman, K.L., and Smiley, J.R. (2002). Herpes simplex virus ICPO and ICP34.5 counteract distinct interferon-induced barriers to virus replication. J Virol 76, 1995-1998. https://www.ncbi.nlm.nih.gov/pubmed/11799195

Muller, L., Aigner, P., and Stoiber, D. (2017). Type I Interferons and Natural Killer Cell Regulation in Cancer. Front Immunol 8, 304. http://dx.doi.org/ 10.3389/fimmu.2017.00304.

Nakamura, T., Peng, K.W., Harvey, M., Greiner, S., Lorimer, I.A., James, C.D., and Russell, S.J. (2005). Rescue and propagation of fully retargeted 
oncolytic measles viruses. Nat Biotechnol 23, 209-214. https:// www.ncbi.nlm.nih.gov/pubmed/15685166

Nakano, K., Asano, R., Tsumoto, K., Kwon, H., Goins, W.F., Kumagai, I., Cohen, J.B., and Glorioso, J.C. (2005). Herpes simplex virus targeting to the EGF receptor by a gD-specific soluble bridging molecule. Mol Ther 11, 617-626. https://www.ncbi.nlm.nih.gov/pubmed/15771964

Nakao, A., Kasuya, H., Sahin, T.T., Nomura, N., Kanzaki, A., Misawa, M., Shirota, T., Yamada, S., Fujii, T., Sugimoto, H., et al. (2011). A phase I doseescalation clinical trial of intraoperative direct intratumoral injection of HF10 oncolytic virus in non-resectable patients with advanced pancreatic cancer. Cancer Gene Ther 18, 167-175. https://www.ncbi.nlm.nih.gov/pubmed/ 21102422

Nakao, A., Kimata, H., Imai, T., Kikumori, T., Teshigahara, O., Nagasaka, T., Goshima, F., and Nishiyama, Y. (2004). Intratumoral injection of herpes simplex virus HF10 in recurrent breast cancer. Ann Oncol 15, 988-989. https://www.ncbi.nlm.nih.gov/pubmed/15151960

Nakao, A., Takeda, S., Shimoyama, S., Kasuya, H., Kimata, H., Teshigahara, O., Sawaki, M., Kikumori, T., Kodera, Y., Nagasaka, T., et al. (2007). Clinical experiment of mutant herpes simplex virus HF10 therapy for cancer. Curr Cancer Drug Targets 7, 169-174. https://www.ncbi.nlm.nih.gov/pubmed/ 17346108

Nakashima, H., Nguyen, T., Kasai, K., Passaro, C., Ito, H., Goins, W.F., Shaikh, I., Erdelyi, R., Nishihara, R., Nakano, I., et al. (2018). Toxicity and Efficacy of a Novel GADD34-expressing Oncolytic HSV-1 for the Treatment of Experimental Glioblastoma. Clin Cancer Res 24, 2574-2584. https:// www.ncbi.nlm.nih.gov/pubmed/29511029

Nanni, P., Gatta, V., Menotti, L., De Giovanni, C., lanzano, M., Palladini, A., Grosso, V., Dall'ora, M., Croci, S., Nicoletti, G., et al. (2013). Preclinical therapy of disseminated HER-2(+) ovarian and breast carcinomas with a HER-2-retargeted oncolytic herpesvirus. PLoS Pathog 9, e1003155. https:// www.ncbi.nlm.nih.gov/pubmed/23382683 
Nicola, A.V., McEvoy, A.M., and Straus, S.E. (2003). Roles for endocytosis and low $\mathrm{pH}$ in herpes simplex virus entry into HeLa and Chinese hamster ovary cells. J Virol 77, 5324-5332. https://www.ncbi.nlm.nih.gov/pubmed/12692234

Nicola, A.V., and Straus, S.E. (2004). Cellular and viral requirements for rapid endocytic entry of herpes simplex virus. J Virol 78, 7508-7517. https:// www.ncbi.nlm.nih.gov/pubmed/15220424

Norden, A.D., Lesser, G.J., Drappatz, J., Ligon, K.L., Hammond, S.N., Lee, E.Q., Reardon, D.R., Fadul, C.E., Plotkin, S.R., Batchelor, T.T., et al. (2013). Phase 2 study of dose-intense temozolomide in recurrent glioblastoma. Neuro Oncol 15, 930-935. https://www.ncbi.nlm.nih.gov/pubmed/23553268

Obeid, M., Tesniere, A., Ghiringhelli, F., Fimia, G.M., Apetoh, L., Perfettini, J.L., Castedo, M., Mignot, G., Panaretakis, T., Casares, N., et al. (2007). Calreticulin exposure dictates the immunogenicity of cancer cell death. Nat Med 13, 54-61. http://dx.doi.org/10.1038/nm1523.

Oh, T., Fakurnejad, S., Sayegh, E.T., Clark, A.J., Ivan, M.E., Sun, M.Z., Safaee, M., Bloch, O., James, C.D., and Parsa, A.T. (2014). Immunocompetent murine models for the study of glioblastoma immunotherapy. J Transl Med 12, 107. https://www.ncbi.nlm.nih.gov/pubmed/24779345

Omuro, A., Vlahovic, G., Lim, M., Sahebjam, S., Baehring, J., Cloughesy, T., Voloschin, A., Ramkissoon, S.H., Ligon, K.L., Latek, R., et al. (2018). Nivolumab with or without ipilimumab in patients with recurrent glioblastoma: results from exploratory phase I cohorts of CheckMate 143. Neuro Oncol 20, 674-686. https://www.ncbi.nlm.nih.gov/pubmed/29106665

Orr, M.T., and Lanier, L.L. (2010). Natural killer cell education and tolerance. Cell 142, 847-856. https://www.ncbi.nlm.nih.gov/pubmed/20850008

Orvedahl, A., Alexander, D., Talloczy, Z., Sun, Q., Wei, Y., Zhang, W., Burns, D., Leib, D.A., and Levine, B. (2007). HSV-1 ICP34.5 confers neurovirulence by targeting the Beclin 1 autophagy protein. Cell Host Microbe 1, 23-35. https://www.ncbi.nlm.nih.gov/pubmed/18005679

Ostrand-Rosenberg, S., and Sinha, P. (2009). Myeloid-derived suppressor cells: linking inflammation and cancer. J Immunol 182, 4499-4506. https:// www.ncbi.nlm.nih.gov/pubmed/19342621 
Paludan, S.R., Bowie, A.G., Horan, K.A., and Fitzgerald, K.A. (2011). Recognition of herpesviruses by the innate immune system. Nat Rev Immunol 11, 143-154. https://www.ncbi.nlm.nih.gov/pubmed/21267015

Pan, S., Liu, X., Ma, Y., Cao, Y., and He, B. (2018). Herpes Simplex Virus 1 gamma134.5 Protein Inhibits STING Activation That Restricts Viral Replication. J Virol 92, e01015-01018. https://www.ncbi.nlm.nih.gov/pubmed/ 30045990

Paolini, R., Bernardini, G., Molfetta, R., and Santoni, A. (2015). NK cells and interferons. Cytokine Growth Factor Rev 26, 113-120. http://dx.doi.org/ 10.1016/j.cytogfr.2014.11.003.

Papanastassiou, V., Rampling, R., Fraser, M., Petty, R., Hadley, D., Nicoll, J., Harland, J., Mabbs, R., and Brown, M. (2002). The potential for efficacy of the modified (ICP 34.5(-)) herpes simplex virus HSV1716 following intratumoural injection into human malignant glioma: a proof of principle study. Gene Ther 9, 398-406. https://www.ncbi.nlm.nih.gov/pubmed/ 11960316

Parker, J.N., Gillespie, G.Y., Love, C.E., Randall, S., Whitley, R.J., and Markert, J.M. (2000). Engineered herpes simplex virus expressing IL-12 in the treatment of experimental murine brain tumors. Proc Natl Acad Sci U S A 97, 2208-2213. https://www.ncbi.nlm.nih.gov/pubmed/10681459

Parry, C., Bell, S., Minson, T., and Browne, H. (2005). Herpes simplex virus type 1 glycoprotein $\mathrm{H}$ binds to alphavbeta3 integrins. J Gen Virol 86, 7-10. https://www.ncbi.nlm.nih.gov/pubmed/15604426

Passaro, C., Alayo, Q., DeLaura, I., McNulty, J.J., Grauwet, K., Ito, H., Bhaskaran, V., Mineo, M., Lawler, S.E., Shah, K., et al. (2018). Arming an oncolytic herpes simplex virus Type 1 with a single chain fragment variable antibody against PD-1 for experimental glioblastoma therapy. Clin Cancer Res. https://www.ncbi.nlm.nih.gov/pubmed/30279232

Patel, D.M., Foreman, P.M., Nabors, L.B., Riley, K.O., Gillespie, G.Y., and Markert, J.M. (2016). Design of a Phase I Clinical Trial to Evaluate M032, a Genetically Engineered HSV-1 Expressing IL-12, in Patients with Recurrent/ Progressive Glioblastoma Multiforme, Anaplastic Astrocytoma, or Gliosarcoma. 
Hum Gene Ther Clin Dev 27, 69-78. https://www.ncbi.nlm.nih.gov/pubmed/ 27314913

Petrovic, B., Gianni, T., Gatta, V., and Campadelli-Fiume, G. (2017). Insertion of a ligand to HER2 in gB retargets HSV tropism and obviates the need for activation of the other entry glycoproteins. PLoS Pathog 13, e1006352. https://www.ncbi.nlm.nih.gov/pubmed/28423057

Petrovic, B., Leoni, V., Gatta, V., Zaghini, A., Vannini, A., and CampadelliFiume, G. (2018). Dual Ligand Insertion in gB and gD of Oncolytic Herpes Simplex Viruses for Retargeting to a Producer Vero Cell Line and to Cancer Cells. J Virol 92, e02122-02117. https://www.ncbi.nlm.nih.gov/pubmed/ 29263257

Poffenberger, K.L., Tabares, E., and Roizman, B. (1983). Characterization of a viable, noninverting herpes simplex virus 1 genome derived by insertion and deletion of sequences at the junction of components $L$ and $S$. Proc Natl Acad Sci U S A 80, 2690-2694. http://dx.doi.org/10.1073/pnas.80.9.2690.

Pogge von Strandmann, E., Shatnyeva, O., and Hansen, H.P. (2015). NKp30 and its ligands: emerging players in tumor immune evasion from natural killer cells. Ann Transl Med 3, 314. http://dx.doi.org/10.3978/j.issn.2305-5839.2015.09.08.

Pol, J., Kroemer, G., and Galluzzi, L. (2016). First oncolytic virus approved for melanoma immunotherapy. Oncoimmunology 5, e1115641. https:// www.ncbi.nlm.nih.gov/pubmed/26942095

Poppers, J., Mulvey, M., Khoo, D., and Mohr, I. (2000). Inhibition of PKR activation by the proline-rich RNA binding domain of the herpes simplex virus type 1 Us11 protein. J Virol 74, 11215-11221. https://www.ncbi.nlm.nih.gov/ pubmed/11070019

Prasad, V., Kaestner, V., and Mailankody, S. (2018). Cancer Drugs Approved Based on Biomarkers and Not Tumor Type-FDA Approval of Pembrolizumab for Mismatch Repair-Deficient Solid Cancers. JAMA Oncol 4, 157-158. http:// dx.doi.org/10.1001/jamaoncol.2017.4182.

Preusser, M., Lim, M., Hafler, D.A., Reardon, D.A., and Sampson, J.H. (2015). Prospects of immune checkpoint modulators in the treatment of glioblastoma. Nat Rev Neurol 11, 504-514. https://www.ncbi.nlm.nih.gov/pubmed/26260659 
Price, D.L., Lin, S.F., Han, Z., Simpson, G., Coffin, R.S., Wong, J., Li, S., Fong, Y., and Wong, R.J. (2010). Oncolysis using herpes simplex virus type 1 engineered to express cytosine deaminase and a fusogenic glycoprotein for head and neck squamous cell carcinoma. Arch Otolaryngol Head Neck Surg 136, 151-158. https://www.ncbi.nlm.nih.gov/pubmed/20157061

Puzanov, I., Milhem, M.M., Minor, D., Hamid, O., Li, A., Chen, L., Chastain, M., Gorski, K.S., Anderson, A., Chou, J., et al. (2016). Talimogene Laherparepvec in Combination With Ipilimumab in Previously Untreated, Unresectable Stage IIIB-IV Melanoma. J Clin Oncol 34, 2619-2626. https:// www.ncbi.nlm.nih.gov/pubmed/27298410

Pyonteck, S.M., Akkari, L., Schuhmacher, A.J., Bowman, R.L., Sevenich, L., Quail, D.F., Olson, O.C., Quick, M.L., Huse, J.T., Teijeiro, V., et al. (2013). CSF-1R inhibition alters macrophage polarization and blocks glioma progression. Nat Med 19, 1264-1272. https://www.ncbi.nlm.nih.gov/pubmed/ 24056773

Quail, D.F., Bowman, R.L., Akkari, L., Quick, M.L., Schuhmacher, A.J., Huse, J.T., Holland, E.C., Sutton, J.C., and Joyce, J.A. (2016). The tumor microenvironment underlies acquired resistance to CSF-1R inhibition in gliomas. Science 352, aad3018. https://www.ncbi.nlm.nih.gov/pubmed/ 27199435

Rampling, R., Cruickshank, G., Papanastassiou, V., Nicoll, J., Hadley, D., Brennan, D., Petty, R., MacLean, A., Harland, J., McKie, E., et al. (2000). Toxicity evaluation of replication-competent herpes simplex virus (ICP 34.5 null mutant 1716) in patients with recurrent malignant glioma. Gene Ther 7 , 859-866. https://www.ncbi.nlm.nih.gov/pubmed/10845724

Randazzo, B.P., Kesari, S., Gesser, R.M., Alsop, D., Ford, J.C., Brown, S.M., Maclean, A., and Fraser, N.W. (1995). Treatment of experimental intracranial murine melanoma with a neuroattenuated herpes simplex virus 1 mutant. Virology 211, 94-101. https://www.ncbi.nlm.nih.gov/pubmed/7645240

Raulet, D.H., Gasser, S., Gowen, B.G., Deng, W., and Jung, H. (2013). Regulation of ligands for the NKG2D activating receptor. Annu Rev Immunol 31, 413-441. http://dx.doi.org/10.1146/annurev-immunol-032712-095951. 
Reardon, D.A., Gokhale, P.C., Klein, S.R., Ligon, K.L., Rodig, S.J., Ramkissoon, S.H., Jones, K.L., Conway, A.S., Liao, X., Zhou, J., et al. (2016). Glioblastoma Eradication Following Immune Checkpoint Blockade in an Orthotopic, Immunocompetent Model. Cancer Immunol Res 4, 124-135. https://www.ncbi.nlm.nih.gov/pubmed/26546453

Reinhart, B., Mazzacurati, L., Forero, A., Hong, C.S., Eguchi, J., Okada, H., Fellows, W., Niranjan, A., Cohen, J.B., Glorioso, J.C., et al. (2012). Inhibition of Indoleamine-2,3-dioxygenase (IDO) in Glioblastoma Cells by Oncolytic Herpes Simplex Virus. Adv Virol 2012, 815465. https://www.ncbi.nlm.nih.gov/ pubmed/22924042

Ribas, A., Dummer, R., Puzanov, I., VanderWalde, A., Andtbacka, R.H.I., Michielin, O., Olszanski, A.J., Malvehy, J., Cebon, J., Fernandez, E., et al. (2017). Oncolytic Virotherapy Promotes Intratumoral T Cell Infiltration and Improves Anti-PD-1 Immunotherapy. Cell 170, $1109-1119$ e1110. https:// www.ncbi.nlm.nih.gov/pubmed/28886381

Richards, A.L., Sollars, P.J., Pitts, J.D., Stults, A.M., Heldwein, E.E., Pickard, G.E., and Smith, G.A. (2017). The pUL37 tegument protein guides alphaherpesvirus retrograde axonal transport to promote neuroinvasion. PLoS Pathog 13, e1006741. https://www.ncbi.nlm.nih.gov/pubmed/29216315

Ries, C.H., Hoves, S., Cannarile, M.A., and Ruttinger, D. (2015). CSF-1/ CSF-1R targeting agents in clinical development for cancer therapy. Curr Opin Pharmacol 23, 45-51. https://www.ncbi.nlm.nih.gov/pubmed/26051995

Ring, E.K., Li, R., Moore, B.P., Nan, L., Kelly, V.M., Han, X., Beierle, E.A., Markert, J.M., Leavenworth, J.W., Gillespie, G.Y., et al. (2017). Newly Characterized Murine Undifferentiated Sarcoma Models Sensitive to Virotherapy with Oncolytic HSV-1 M002. Mol Ther Oncolytics 7, 27-36. https://www.ncbi.nlm.nih.gov/pubmed/29034313

Rizvi, N.A., Hellmann, M.D., Snyder, A., Kvistborg, P., Makarov, V., Havel, J.J., Lee, W., Yuan, J., Wong, P., Ho, T.S., et al. (2015). Cancer immunology. Mutational landscape determines sensitivity to PD-1 blockade in non-small cell lung cancer. Science 348, 124-128. http://dx.doi.org/10.1126/ science.aaa1348. 
Roberts, E.W., Broz, M.L., Binnewies, M., Headley, M.B., Nelson, A.E., Wolf, D.M., Kaisho, T., Bogunovic, D., Bhardwaj, N., and Krummel, M.F. (2016). Critical Role for CD103(+)/CD141(+) Dendritic Cells Bearing CCR7 for Tumor Antigen Trafficking and Priming of T Cell Immunity in Melanoma. Cancer Cell 30, 324-336. https://www.ncbi.nlm.nih.gov/pubmed/27424807

Roizman, B., and Zhou, G. (2015). The 3 facets of regulation of herpes simplex virus gene expression: A critical inquiry. Virology 479-480, 562-567. https:// www.ncbi.nlm.nih.gov/pubmed/25771487

Roizman, B., and Knipe, D.M. (2001). Herpes simplex viruses and their replication. In Fields Virology, Knipe, D.M. and Howley, P.M., eds. (Philadelphia: Lippincott Williams and Wilkins), pp. 2399-2459.

Roth, J.C., Cassady, K.A., Cody, J.J., Parker, J.N., Price, K.H., Coleman, J.M., Peggins, J.O., Noker, P.E., Powers, N.W., Grimes, S.D., et al. (2014). Evaluation of the safety and biodistribution of M032, an attenuated herpes simplex virus type 1 expressing hIL-12, after intracerebral administration to aotus nonhuman primates. Hum Gene Ther Clin Dev 25, 16-27. https:// www.ncbi.nlm.nih.gov/pubmed/24649838

Saha, D., Martuza, R.L., and Rabkin, S.D. (2017a). Curing glioblastoma: oncolytic HSV-IL12 and checkpoint blockade. Oncoscience 4, 67-69. https:// www.ncbi.nlm.nih.gov/pubmed/28966936

Saha, D., Martuza, R.L., and Rabkin, S.D. (2017b). Macrophage Polarization Contributes to Glioblastoma Eradication by Combination Immunovirotherapy and Immune Checkpoint Blockade. Cancer Cell 32, 253-267 e255. https:// www.ncbi.nlm.nih.gov/pubmed/28810147

Sahin, T.T., Kasuya, H., Nomura, N., Shikano, T., Yamamura, K., Gewen, T., Kanzaki, A., Fujii, T., Sugae, T., Imai, T., et al. (2012). Impact of novel oncolytic virus HF10 on cellular components of the tumor microenviroment in patients with recurrent breast cancer. Cancer Gene Ther 19, 229-237. https:// www.ncbi.nlm.nih.gov/pubmed/22193629

Salmon, H., Idoyaga, J., Rahman, A., Leboeuf, M., Remark, R., Jordan, S., Casanova-Acebes, M., Khudoynazarova, M., Agudo, J., Tung, N., et al. (2016). Expansion and Activation of CD103(+) Dendritic Cell Progenitors at the Tumor Site Enhances Tumor Responses to Therapeutic PD-L1 and BRAF 
Inhibition. Immunity 44, 924-938. https://www.ncbi.nlm.nih.gov/pubmed/ 27096321

Sato-Kaneko, F., Yao, S., Ahmadi, A., Zhang, S.S., Hosoya, T., Kaneda, M.M., Varner, J.A., Pu, M., Messer, K.S., Guiducci, C., et al. (2017). Combination immunotherapy with TLR agonists and checkpoint inhibitors suppresses head and neck cancer. JCl Insight 2, e93397. https://www.ncbi.nlm.nih.gov/ pubmed/28931759

Satoh, T., Arii, J., Suenaga, T., Wang, J., Kogure, A., Uehori, J., Arase, N., Shiratori, I., Tanaka, S., Kawaguchi, Y., et al. (2008). PILRalpha is a herpes simplex virus-1 entry coreceptor that associates with glycoprotein B. Cell 132, 935-944. https://www.ncbi.nlm.nih.gov/pubmed/18358807

Sauer, M., Schuldner, M., Hoffmann, N., Cetintas, A., Reiners, K.S., Shatnyeva, O., Hallek, M., Hansen, H.P., Gasser, S., and von Strandmann, E.P. (2017). CBP/p300 acetyltransferases regulate the expression of NKG2D ligands on tumor cells. Oncogene 36, 933-941. https://www.ncbi.nlm.nih.gov/pubmed/ 27477692

Schlecker, E., Fiegler, N., Arnold, A., Altevogt, P., Rose-John, S., Moldenhauer, G., Sucker, A., Paschen, A., von Strandmann, E.P., Textor, S., et al. (2014). Metalloprotease-mediated tumor cell shedding of B7-H6, the ligand of the natural killer cell-activating receptor NKp30. Cancer Res 74, 3429-3440. http://dx.doi.org/10.1158/0008-5472.Can-13-3017.

Schlitzer, A., and Ginhoux, F. (2014). Organization of the mouse and human DC network. Curr Opin Immunol 26, 90-99. http://dx.doi.org/10.1016/j.coi. 2013.11.002.

Schlitzer, A., McGovern, N., and Ginhoux, F. (2015). Dendritic cells and monocyte-derived cells: Two complementary and integrated functional systems. Semin Cell Dev Biol 41, 9-22. http://dx.doi.org/10.1016/j.semcdb. 2015.03.011.

Sempere, L.F., Freemantle, S., Pitha-Rowe, I., Moss, E., Dmitrovsky, E., and Ambros, V. (2004). Expression profiling of mammalian microRNAs uncovers a subset of brain-expressed microRNAs with possible roles in murine and human neuronal differentiation. Genome Biol 5, R13. https:// www.ncbi.nlm.nih.gov/pubmed/15003116 
Senzer, N.N., Kaufman, H.L., Amatruda, T., Nemunaitis, M., Reid, T., Daniels, G., Gonzalez, R., Glaspy, J., Whitman, E., Harrington, K., et al. (2009). Phase II clinical trial of a granulocyte-macrophage colony-stimulating factorencoding, second-generation oncolytic herpesvirus in patients with unresectable metastatic melanoma. J Clin Oncol 27, 5763-5771. https:// www.ncbi.nlm.nih.gov/pubmed/19884534

Sette, P., Amankulor, N., Li, A., Marzulli, M., Leronni, D., Zhang, M., Goins, W.F., Kaur, B., Bolyard, C., Cripe, T.P., et al. (2019). GBM-Targeted oHSV Armed with Matrix Metalloproteinase 9 Enhances Anti-tumor Activity and Animal Survival. Mol Ther Oncolytics 15, 214-222. https:// www.ncbi.nlm.nih.gov/pubmed/31890868

Shibata, T., Uchida, H., Shiroyama, T., Okubo, Y., Suzuki, T., Ikeda, H., Yamaguchi, M., Miyagawa, Y., Fukuhara, T., Cohen, J.B., et al. (2016). Development of an oncolytic HSV vector fully retargeted specifically to cellular EpCAM for virus entry and cell-to-cell spread. Gene Ther 23, 479-488. https://www.ncbi.nlm.nih.gov/pubmed/26905369

Shieh, M.T., WuDunn, D., Montgomery, R.I., Esko, J.D., and Spear, P.G. (1992). Cell surface receptors for herpes simplex virus are heparan sulfate proteoglycans. J Cell Biol 116, 1273-1281. https://www.ncbi.nlm.nih.gov/ pubmed/1310996

Shields, B.D., Mahmoud, F., Taylor, E.M., Byrum, S.D., Sengupta, D., Koss, B., Baldini, G., Ransom, S., Cline, K., Mackintosh, S.G., et al. (2017). Indicators of responsiveness to immune checkpoint inhibitors. Sci Rep 7, 807. http:// dx.doi.org/10.1038/s41598-017-01000-2.

Shukla, D., Liu, J., Blaiklock, P., Shworak, N.W., Bai, X., Esko, J.D., Cohen, G.H., Eisenberg, R.J., Rosenberg, R.D., and Spear, P.G. (1999). A novel role for 3-O-sulfated heparan sulfate in herpes simplex virus 1 entry. Cell 99, 13-22. https://www.ncbi.nlm.nih.gov/pubmed/10520990

Silber, J., Lim, D.A., Petritsch, C., Persson, A.I., Maunakea, A.K., Yu, M., Vandenberg, S.R., Ginzinger, D.G., James, C.D., Costello, J.F., et al. (2008). miR-124 and miR-137 inhibit proliferation of glioblastoma multiforme cells and induce differentiation of brain tumor stem cells. BMC Med 6, 14. https:// www.ncbi.nlm.nih.gov/pubmed/18577219 
Solomon, B.L., and Garrido-Laguna, I. (2018). TIGIT: a novel immunotherapy target moving from bench to bedside. Cancer Immunol Immunother 67, 1659-1667. http://dx.doi.org/10.1007/s00262-018-2246-5.

Spear, P.G., Shieh, M.T., Herold, B.C., WuDunn, D., and Koshy, T.I. (1992). Heparan sulfate glycosaminoglycans as primary cell surface receptors for herpes simplex virus. Adv Exp Med Biol 313, 341-353. https:// www.ncbi.nlm.nih.gov/pubmed/1332443

Spranger, S., Dai, D., Horton, B., and Gajewski, T.F. (2017). Tumor-Residing Batf3 Dendritic Cells Are Required for Effector T Cell Trafficking and Adoptive T Cell Therapy. Cancer Cell 31, 711-723 e714. https://www.ncbi.nlm.nih.gov/ pubmed/28486109

Spranger, S., Luke, J.J., Bao, R., Zha, Y., Hernandez, K.M., Li, Y., Gajewski, A.P., Andrade, J., and Gajewski, T.F. (2016). Density of immunogenic antigens does not explain the presence or absence of the T-cell-inflamed tumor microenvironment in melanoma. Proc Natl Acad Sci U S A 113, E7759E7768. https://www.ncbi.nlm.nih.gov/pubmed/27837020

St Leger, A.J., and Hendricks, R.L. (2011). CD8+ T cells patrol HSV-1-infected trigeminal ganglia and prevent viral reactivation. J Neurovirol 17, 528-534. https://www.ncbi.nlm.nih.gov/pubmed/22161682

St Leger, A.J., Jeon, S., and Hendricks, R.L. (2013). Broadening the repertoire of functional herpes simplex virus type 1-specific CD8+ $T$ cells reduces viral reactivation from latency in sensory ganglia. J Immunol 191, 2258-2265. https://www.ncbi.nlm.nih.gov/pubmed/23878317

Stanziale, S.F., Petrowsky, H., Joe, J.K., Roberts, G.D., Zager, J.S., Gusani, N.J., Ben-Porat, L., Gonen, M., and Fong, Y. (2002). Ionizing radiation potentiates the antitumor efficacy of oncolytic herpes simplex virus G207 by upregulating ribonucleotide reductase. Surgery 132, 353-359. https:// www.ncbi.nlm.nih.gov/pubmed/12219034

Streby, K.A., Geller, J.I., Currier, M.A., Warren, P.S., Racadio, J.M., Towbin, A.J., Vaughan, M.R., Triplet, M., Ott-Napier, K., Dishman, D.J., et al. (2017). Intratumoral Injection of HSV1716, an Oncolytic Herpes Virus, Is Safe and Shows Evidence of Immune Response and Viral Replication in Young Cancer 
Patients. Clin Cancer Res 23, 3566-3574. https://www.ncbi.nlm.nih.gov/ pubmed/28495911

Stupp, R., Hegi, M.E., Mason, W.P., van den Bent, M.J., Taphoorn, M.J., Janzer, R.C., Ludwin, S.K., Allgeier, A., Fisher, B., Belanger, K., et al. (2009). Effects of radiotherapy with concomitant and adjuvant temozolomide versus radiotherapy alone on survival in glioblastoma in a randomised phase III study: 5-year analysis of the EORTC-NCIC trial. Lancet Oncol 10, 459-466. https://www.ncbi.nlm.nih.gov/pubmed/19269895

Stupp, R., Mason, W.P., van den Bent, M.J., Weller, M., Fisher, B., Taphoorn, M.J., Belanger, K., Brandes, A.A., Marosi, C., Bogdahn, U., et al. (2005). Radiotherapy plus concomitant and adjuvant temozolomide for glioblastoma. N Engl J Med 352, 987-996. https://www.ncbi.nlm.nih.gov/pubmed/15758009 Suenaga, T., Satoh, T., Somboonthum, P., Kawaguchi, Y., Mori, Y., and Arase, H. (2010). Myelin-associated glycoprotein mediates membrane fusion and entry of neurotropic herpesviruses. Proc Natl Acad Sci U S A 107, 866-871. https://www.ncbi.nlm.nih.gov/pubmed/20080767

Sun, L., Funchain, P., Song, J.M., Rayman, P., Tannenbaum, C., Ko, J., McNamara, M., Marcela Diaz-Montero, C., and Gastman, B. (2018). Talimogene Laherparepvec combined with anti-PD-1 based immunotherapy for unresectable stage III-IV melanoma: a case series. J Immunother Cancer 6, 36. https://www.ncbi.nlm.nih.gov/pubmed/29764498

Sun, L., Wu, J., Du, F., Chen, X., and Chen, Z.J. (2013). Cyclic GMP-AMP synthase is a cytosolic DNA sensor that activates the type I interferon pathway. Science 339, 786-791. https://www.ncbi.nlm.nih.gov/pubmed/ 23258413

Szatmari, T., Lumniczky, K., Desaknai, S., Trajcevski, S., Hidvegi, E.J., Hamada, H., and Safrany, G. (2006). Detailed characterization of the mouse glioma 261 tumor model for experimental glioblastoma therapy. Cancer Sci 97, 546-553. https://www.ncbi.nlm.nih.gov/pubmed/16734735

Sze, D.Y., lagaru, A.H., Gambhir, S.S., De Haan, H.A., and Reid, T.R. (2012). Response to intra-arterial oncolytic virotherapy with the herpes virus NV1020 evaluated by [18F]fluorodeoxyglucose positron emission tomography and 
computed tomography. Hum Gene Ther 23, 91-97. https:// www.ncbi.nlm.nih.gov/pubmed/21895536

Takasu, A., Masui, A., Hamada, M., Imai, T., Iwai, S., and Yura, Y. (2016). Immunogenic cell death by oncolytic herpes simplex virus type 1 in squamous cell carcinoma cells. Cancer Gene Ther 23, 107-113. http:// dx.doi.org/10.1038/cgt.2016.8.

Takenaka, M.C., Gabriely, G., Rothhammer, V., Mascanfroni, I.D., Wheeler, M.A., Chao, C.C., Gutierrez-Vazquez, C., Kenison, J., Tjon, E.C., Barroso, A., et al. (2019). Control of tumor-associated macrophages and $T$ cells in glioblastoma via AHR and CD39. Nat Neurosci 22, 729-740. https:// www.ncbi.nlm.nih.gov/pubmed/30962630

Tal-Singer, R., Peng, C., Ponce De Leon, M., Abrams, W.R., Banfield, B.W., Tufaro, F., Cohen, G.H., and Eisenberg, R.J. (1995). Interaction of herpes simplex virus glycoprotein $\mathrm{gC}$ with mammalian cell surface molecules. J Virol 69, 4471-4483. https://www.ncbi.nlm.nih.gov/pubmed/7769707

Tamimi, A.F., and Juweid, M. (2017). Epidemiology and Outcome of Glioblastoma. In Glioblastoma, S. De Vleeschouwer, ed. (Brisbane (AU): Codon Publications).

Thaci, B., Ahmed, A.U., Ulasov, I.V., Wainwright, D.A., Nigam, P., Auffinger, B., Tobias, A.L., Han, Y., Zhang, L., Moon, K.S., et al. (2014). Depletion of myeloid-derived suppressor cells during interleukin-12 immunogene therapy does not confer a survival advantage in experimental malignant glioma. Cancer Gene Ther 21, 38-44. https://www.ncbi.nlm.nih.gov/pubmed/ 24434573

Thaker, N.G., and Pollack, I.F. (2009). Molecularly targeted therapies for malignant glioma: rationale for combinatorial strategies. Expert Rev Neurother 9, 1815-1836. https://www.ncbi.nlm.nih.gov/pubmed/19951140

Thomas, S., Kuncheria, L., Roulstone, V., Kyula, J.N., Mansfield, D., Bommareddy, P.K., Smith, H., Kaufman, H.L., Harrington, K.J., and Coffin, R.S. (2019). Development of a new fusion-enhanced oncolytic immunotherapy platform based on herpes simplex virus type 1. J Immunother Cancer 7, 214. https://www.ncbi.nlm.nih.gov/pubmed/31399043 
Toda, M., Martuza, R.L., Kojima, H., and Rabkin, S.D. (1998). In situ cancer vaccination: an IL-12 defective vector/replication-competent herpes simplex virus combination induces local and systemic antitumor activity. J Immunol 160, 4457-4464. https://www.ncbi.nlm.nih.gov/pubmed/9574551

Todo, T. (2019). ATIM-14. Results of Phase li Clinical Trial of Oncolytic Herpes Virus G47A in Patients with Glioblastoma. Neuro-Oncology 21, vi4-vi4. https://doi.org/10.1093/neuonc/noz175.014

Todo, T., Feigenbaum, F., Rabkin, S.D., Lakeman, F., Newsome, J.T., Johnson, P.A., Mitchell, E., Belliveau, D., Ostrove, J.M., and Martuza, R.L. (2000). Viral shedding and biodistribution of G207, a multimutated, conditionally replicating herpes simplex virus type 1 , after intracerebral inoculation in aotus. Mol Ther 2, 588-595. https://www.ncbi.nlm.nih.gov/pubmed/11124059

Todo, T., Martuza, R.L., Rabkin, S.D., and Johnson, P.A. (2001). Oncolytic herpes simplex virus vector with enhanced MHC class I presentation and tumor cell killing. Proc Natl Acad Sci USA 98, 6396-6401. https://www.ncbi.nlm.nih.gov/ pubmed/11353831

Trybala, E., Roth, A., Johansson, M., Liljeqvist, J.A., Rekabdar, E., Larm, O., and Bergstrom, T. (2002). Glycosaminoglycan-binding ability is a feature of wild-type strains of herpes simplex virus type 1 . Virology 302, 413-419. https://www.ncbi.nlm.nih.gov/pubmed/12441085

Tumeh, P.C., Harview, C.L., Yearley, J.H., Shintaku, I.P., Taylor, E.J., Robert, L., Chmielowski, B., Spasic, M., Henry, G., Ciobanu, V., et al. (2014). PD-1 blockade induces responses by inhibiting adaptive immune resistance. Nature 515, 568-571. http://dx.doi.org/10.1038/nature13954.

Uchida, H., Chan, J., Goins, W.F., Grandi, P., Kumagai, I., Cohen, J.B., and Glorioso, J.C. (2010). A double mutation in glycoprotein gB compensates for ineffective gD-dependent initiation of herpes simplex virus type 1 infection. J Virol 84, 12200-12209. https://www.ncbi.nlm.nih.gov/pubmed/20861246

Uchida, H., Hamada, H., Nakano, K., Kwon, H., Tahara, H., Cohen, J.B., and Glorioso, J.C. (2018). Oncolytic Herpes Simplex Virus Vectors Fully Retargeted to Tumor- Associated Antigens. Curr Cancer Drug Targets 18, 162-170. https://www.ncbi.nlm.nih.gov/pubmed/28176649 
Uchida, H., Marzulli, M., Nakano, K., Goins, W.F., Chan, J., Hong, C.S., Mazzacurati, L., Yoo, J.Y., Haseley, A., Nakashima, H., et al. (2013). Effective treatment of an orthotopic xenograft model of human glioblastoma using an EGFR-retargeted oncolytic herpes simplex virus. Mol Ther 21, 561-569. https://www.ncbi.nlm.nih.gov/pubmed/23070115

Unterholzner, L., Keating, S.E., Baran, M., Horan, K.A., Jensen, S.B., Sharma, S., Sirois, C.M., Jin, T., Latz, E., Xiao, T.S., et al. (2010). IFI16 is an innate immune sensor for intracellular DNA. Nat Immunol 11, 997-1004. https:// www.ncbi.nlm.nih.gov/pubmed/20890285

Ushijima, Y., Luo, C., Goshima, F., Yamauchi, Y., Kimura, H., and Nishiyama, Y. (2007). Determination and analysis of the DNA sequence of highly attenuated herpes simplex virus type 1 mutant HF10, a potential oncolytic virus. Microbes Infect 9, 142-149. https://www.ncbi.nlm.nih.gov/pubmed/17218138

Valyi-Nagy, T., Fareed, M.U., O'Keefe, J.S., Gesser, R.M., MacLean, A.R., Brown, S.M., Spivack, J.G., and Fraser, N.W. (1994). The herpes simplex virus type 1 strain $17+$ gamma 34.5 deletion mutant 1716 is avirulent in SCID mice. J Gen Virol 75 2059-2063. https://www.ncbi.nlm.nih.gov/pubmed/ 8046409

van den Bossche, W.B.L., Kleijn, A., Teunissen, C.E., Voerman, J.S.A., Teodosio, C., Noske, D.P., van Dongen, J.J.M., Dirven, C.M.F., and Lamfers, M.L.M. (2018). Oncolytic virotherapy in glioblastoma patients induces a tumor macrophage phenotypic shift leading to an altered glioblastoma microenvironment. Neuro Oncol 20, 1494-1504. https:// www.ncbi.nlm.nih.gov/pubmed/29796615

Varghese, S., Newsome, J.T., Rabkin, S.D., McGeagh, K., Mahoney, D., Nielsen, P., Todo, T., and Martuza, R.L. (2001). Preclinical safety evaluation of G207, a replication-competent herpes simplex virus type 1, inoculated intraprostatically in mice and nonhuman primates. Hum Gene Ther 12, 999-1010. https://www.ncbi.nlm.nih.gov/pubmed/11387063

Vivier, E., Tomasello, E., and Paul, P. (2002). Lymphocyte activation via NKG2D: towards a new paradigm in immune recognition? Curr Opin Immunol 14, 306-311. https://www.ncbi.nlm.nih.gov/pubmed/11973127 
Wang, R.F., and Wang, H.Y. (2017). Immune targets and neoantigens for cancer immunotherapy and precision medicine. Cell Res 27, 11-37. https:// www.ncbi.nlm.nih.gov/pubmed/28025978

Wang, X., Kong, L., Zhang, G.R., Sun, M., and Geller, A.I. (2005). Targeted gene transfer to nigrostriatal neurons in the rat brain by helper virus-free HSV-1 vector particles that contain either a chimeric HSV-1 glycoprotein CGDNF or a gC-BDNF protein. Brain Res Mol Brain Res 139, 88-102. https:// www.ncbi.nlm.nih.gov/pubmed/15993510

Wang, X.F., Wang, H.S., Wang, H., Zhang, F., Wang, K.F., Guo, Q., Zhang, G., Cai, S.H., and Du, J. (2014). The role of indoleamine 2,3-dioxygenase (IDO) in immune tolerance: focus on macrophage polarization of THP-1 cells. Cell Immunol 289, 42-48. https://www.ncbi.nlm.nih.gov/pubmed/24721110

Wang, Y., Xu, Z., Guo, S., Zhang, L., Sharma, A., Robertson, G.P., and Huang, L. (2013). Intravenous delivery of siRNA targeting CD47 effectively inhibits melanoma tumor growth and lung metastasis. Mol Ther 21, 1919-1929. https://www.ncbi.nlm.nih.gov/pubmed/23774794

Warner, M.S., Geraghty, R.J., Martinez, W.M., Montgomery, R.I., Whitbeck, J.C., Xu, R., Eisenberg, R.J., Cohen, G.H., and Spear, P.G. (1998). A cell surface protein with herpesvirus entry activity (HveB) confers susceptibility to infection by mutants of herpes simplex virus type 1 , herpes simplex virus type 2 , and pseudorabies virus. Virology 246, 179-189. https://www.ncbi.nlm.nih.gov/ pubmed/9657005

Waters, A.M., Johnston, J.M., Reddy, A.T., Fiveash, J., Madan-Swain, A., Kachurak, K., Bag, A.K., Gillespie, G.Y., Markert, J.M., and Friedman, G.K. (2017). Rationale and Design of a Phase 1 Clinical Trial to Evaluate HSV G207 Alone or with a Single Radiation Dose in Children with Progressive or Recurrent Malignant Supratentorial Brain Tumors. Hum Gene Ther Clin Dev 28, 7-16. https://www.ncbi.nlm.nih.gov/pubmed/28319448

Wen, P.Y., and Kesari, S. (2008). Malignant gliomas in adults. N Engl J Med 359, 492-507. https://www.ncbi.nlm.nih.gov/pubmed/18669428

Whitbeck, J.C., Muggeridge, M.I., Rux, A.H., Hou, W., Krummenacher, C., Lou, H., van Geelen, A., Eisenberg, R.J., and Cohen, G.H. (1999). The major neutralizing antigenic site on herpes simplex virus glycoprotein $D$ overlaps a 
receptor-binding domain. J Virol 73, 9879-9890. https://www.ncbi.nlm.nih.gov/ pubmed/10559300

Wiesner, S.M., Decker, S.A., Larson, J.D., Ericson, K., Forster, C., Gallardo, J.L., Long, C., Demorest, Z.L., Zamora, E.A., Low, W.C., et al. (2009). De novo induction of genetically engineered brain tumors in mice using plasmid DNA. Cancer Res 69, 431-439. https://www.ncbi.nlm.nih.gov/pubmed/ 19147555

Willingham, S.B., Volkmer, J.P., Gentles, A.J., Sahoo, D., Dalerba, P., Mitra, S.S., Wang, J., Contreras-Trujillo, H., Martin, R., Cohen, J.D., et al. (2012). The CD47-signal regulatory protein alpha (SIRPa) interaction is a therapeutic target for human solid tumors. Proc Natl Acad Sci U S A 109, 6662-6667. https://www.ncbi.nlm.nih.gov/pubmed/22451913

Wirsching, H.G., Arora, S., Zhang, H., Szulzewsky, F., Cimino, P.J., Queva, C., Houghton, A.M., Glorioso, J.C., Weller, M., and Holland, E.C. (2019a). Cooperation of oncolytic virotherapy with VEGF-neutralizing antibody treatment in IDH wildtype glioblastoma depends on MMP9. Neuro Oncol 21, 1607-1609. https://www.ncbi.nlm.nih.gov/pubmed/31412117

Wirsching, H.G., Zhang, H., Szulzewsky, F., Arora, S., Grandi, P., Cimino, P.J., Amankulor, N., Campbell, J.S., McFerrin, L., Pattwell, S.S., et al. (2019b). Arming oHSV with ULBP3 drives abscopal immunity in lymphocyte-depleted glioblastoma. JCl Insight 4. https://www.ncbi.nlm.nih.gov/pubmed/31292299

Wong, R.J., Kim, S.H., Joe, J.K., Shah, J.P., Johnson, P.A., and Fong, Y. (2001). Effective treatment of head and neck squamous cell carcinoma by an oncolytic herpes simplex virus. J Am Coll Surg 193, 12-21. https:// www.ncbi.nlm.nih.gov/pubmed/11442249

Wu, J., Jordan, M., and Waxman, D.J. (2016). Metronomic cyclophosphamide activation of anti-tumor immunity: tumor model, mouse host, and drug schedule dependence of gene responses and their upstream regulators. BMC Cancer 16, 623. https://www.ncbi.nlm.nih.gov/pubmed/27515027

Wu, J., Sun, L., Chen, X., Du, F., Shi, H., Chen, C., and Chen, Z.J. (2013). Cyclic GMP-AMP is an endogenous second messenger in innate immune signaling by cytosolic DNA. Science 339, 826-830. https:// www.ncbi.nlm.nih.gov/pubmed/23258412 
WuDunn, D., and Spear, P.G. (1989). Initial interaction of herpes simplex virus with cells is binding to heparan sulfate. J Virol 63, 52-58. https:// www.ncbi.nlm.nih.gov/pubmed/2535752

Xing, J., Wang, S., Lin, R., Mossman, K.L., and Zheng, C. (2012). Herpes simplex virus 1 tegument protein US11 downmodulates the RLR signaling pathway via direct interaction with RIG-I and MDA-5. J Virol 86, 3528-3540. https://www.ncbi.nlm.nih.gov/pubmed/22301138

Yarchoan, M., Johnson, B.A., 3rd, Lutz, E.R., Laheru, D.A., and Jaffee, E.M. (2017). Targeting neoantigens to augment antitumour immunity. Nat Rev Cancer 17, 569. https://www.ncbi.nlm.nih.gov/pubmed/28835723

Yoo, J.Y., Haseley, A., Bratasz, A., Chiocca, E.A., Zhang, J., Powell, K., and Kaur, B. (2012). Antitumor efficacy of 34.5ENVE: a transcriptionally retargeted and "Vstat120"-expressing oncolytic virus. Mol Ther 20, 287-297. https://www.ncbi.nlm.nih.gov/pubmed/22031239

Yoo, J.Y., Jaime-Ramirez, A.C., Bolyard, C., Dai, H., Nallanagulagari, T., Wojton, J., Hurwitz, B.S., Relation, T., Lee, T.J., Lotze, M.T., et al. (2016). Bortezomib Treatment Sensitizes Oncolytic HSV-1-Treated Tumors to NK Cell Immunotherapy. Clin Cancer Res 22, 5265-5276. https:// www.ncbi.nlm.nih.gov/pubmed/27390350

Yoon, M., Zago, A., Shukla, D., and Spear, P.G. (2003). Mutations in the N termini of herpes simplex virus type 1 and $2 \mathrm{gDs}$ alter functional interactions with the entry/fusion receptors HVEM, nectin-2, and 3-O-sulfated heparan sulfate but not with nectin-1. J Virol 77, 9221-9231. https:// www.ncbi.nlm.nih.gov/pubmed/12915538

York, I.A., Roop, C., Andrews, D.W., Riddell, S.R., Graham, F.L., and Johnson, D.C. (1994). A cytosolic herpes simplex virus protein inhibits antigen presentation to CD8+ T lymphocytes. Cell 77, 525-535. https:// www.ncbi.nlm.nih.gov/pubmed/8187174

Youn, J.I., and Gabrilovich, D.I. (2010). The biology of myeloid-derived suppressor cells: the blessing and the curse of morphological and functional heterogeneity. Eur J Immunol 40, 2969-2975. https://www.ncbi.nlm.nih.gov/ pubmed/21061430 
Zeng, W., Hu, P., Wu, J., Wang, J., Li, J., Lei, L., and Liu, R. (2013). The oncolytic herpes simplex virus vector G47 effectively targets breast cancer stem cells. Oncol Rep 29, 1108-1114. https://www.ncbi.nlm.nih.gov/pubmed/ 23292314

Zhang, J., Dang, F., Ren, J., and Wei, W. (2018). Biochemical Aspects of PDL1 Regulation in Cancer Immunotherapy. Trends Biochem Sci. 43, 1014-1032. http://dx.doi.org/10.1016/j.tibs.2018.09.004.

Zhang, K.X., Matsui, Y., Lee, C., Osamu, O., Skinner, L., Wang, J., So, A., Rennie, P.S., and Jia, W.W. (2016). Intravesical treatment of advanced urothelial bladder cancers with oncolytic HSV-1 co-regulated by differentially expressed microRNAs. Gene Ther 23, 460-468. https://www.ncbi.nlm.nih.gov/ pubmed/26905370

Zhang, X., Shi, H., Wu, J., Zhang, X., Sun, L., Chen, C., and Chen, Z.J. (2013). Cyclic GMP-AMP containing mixed phosphodiester linkages is an endogenous high-affinity ligand for STING. Mol Cell 51, 226-235. https:// www.ncbi.nlm.nih.gov/pubmed/23747010

Zhou, G., and Roizman, B. (2006). Construction and properties of a herpes simplex virus 1 designed to enter cells solely via the IL-13alpha2 receptor. Proc Natl Acad Sci U S A 103, 5508-5513. https://www.ncbi.nlm.nih.gov/ pubmed/16554374

Zhou, G., and Roizman, B. (2007). Separation of receptor-binding and profusogenic domains of glycoprotein $D$ of herpes simplex virus 1 into distinct interacting proteins. Proc Natl Acad Sci U S A 104, 4142-4146. https:// www.ncbi.nlm.nih.gov/pubmed/17360490

Zhou, G., Ye, G.J., Debinski, W., and Roizman, B. (2002). Engineered herpes simplex virus 1 is dependent on IL13Ralpha 2 receptor for cell entry and independent of glycoprotein D receptor interaction. Proc Natl Acad Sci U S A 99, 15124-15129. https://www.ncbi.nlm.nih.gov/pubmed/12417744

Zhu, X., Fujita, M., Snyder, L.A., and Okada, H. (2011). Systemic delivery of neutralizing antibody targeting CCL2 for glioma therapy. J Neurooncol 104, 83-92. https://www.ncbi.nlm.nih.gov/pubmed/21116835 
